\author{
UNIVERSIDADE DE SÃO PAULO \\ ESCOLA DE ENGENHARIA DE SÃO CARLOS \\ DEPARTAMENTO DE ENGENHARIA MECÂNICA
}

RAFAEL RODRIGUES DE FREITAS

ESTUDO DE UMA ESTRUTURA EM PÓRTICO PARA UTILIZAÇÃO EM UM VEÍCULO AGRÍCOLA AUTÔNOMO

São Carlos

2008 
RAFAEL RODRIGUES DE FREITAS

\section{ESTUDO DE UMA ESTRUTURA EM PÓRTICO PARA UTILIZAÇÃO EM UM VEÍCULO AGRÍCOLA AUTÔNOMO}

Dissertação apresentada à Escola de Engenharia de São Carlos da Universidade de São Paulo, como parte dos requisitos para obtenção do título de Mestre em Engenharia Mecânica.

Área de Concentração: Manufatura Orientador: Prof. Dr. Ricardo Yassushi Inamasu

São Carlos

2008 
Aos meus pais,

Ercílio e Maria José. 


\section{AGRADECIMENTOS}

Ao Professor Ricardo Yassushi Inamasu pelo companheirismo, amizade e pela orientação para o desenvolvimento deste trabalho.

Ao Professor Arthur José Vieira Porto por ter disponibilizado o uso das facilidades do Laboratório de Simulação e Controle da EESC/USP.

Ao Rafael Vieira de Sousa pelas valiosas contribuições na elaboração deste trabalho

A todos os colegas, professores e funcionários do Departamento de Engenharia Mecânica da EESC/USP pela colaboração, em especial aos amigos do Laboratório de Simulação e Controle, pela amizade e apoio. 


\section{RESUMO}

Freitas, R. R. Estudo de uma Estrutura em Pórtico para utilização em um Veículo Autônomo Agrícola. 2008. 93p. Dissertação (Mestrado) - Escola de Engenharia de São Carlos, Universidade de São Paulo, São Carlos, 2008.

Avanços nas pesquisas em Veículos Agrícolas Autônomos (VAA's) e de Robôs Agrícolas Móveis (RAM's) têm sido conquistados nos últimos anos. Entretanto, um número limitado de trabalhos foca o desenvolvimento das estruturas destes veículos.

O presente trabalho apresenta uma revisão de materiais encontrados na literatura e no mercado. Estudou-se modelagem cinemática de veículos autônomos que possuem configurações de suas estruturas projetadas para ter mobilidade melhorada. Estudaram-se estruturas mecânicas de máquinas que atuam em vários estádios de desenvolvimento de lavouras típicas brasileiras. Baseado no levantamento e esse estudo, foi projetado e construído um veículo com conceito modular e de pórtico para ser uma plataforma robótica no qual é utilizado para o sensoriamento em área agrícola. Uma modelagem cinemática simplificada do veículo foi realizada, fundamentada nos conceitos básicos de cinemáticas em robôs móveis. Por fim é apresentado o desenvolvimento da estrutura em pórtico do veículo.

Pretende-se que o resultado auxilie no desenvolvimento de projeto de VAA's.

Palavras-chave: Robô Agrícola Móvel, estruturas em pórtico, cinemática de robôs móveis, máquina agrícola, agricultura de precisão. 


\section{ABSTRACT}

Freitas, R. R. Study of a Portal Frame Structure for use in an Autonomous Agriculture Vehicle. 2008. 93p. Dissertation (Master of Science) - School of Engineering of São Carlos, University of São Paulo, São Carlos, 2008.

Advance on AAV (Autonomous Agriculture Vehicle) and MAR (Mobile Agriculture Robots) research are noticed in the recent years. However, a limited number of works focus in the structure development of such vehicles.

This work introduces a review of the materials found in literature and market. Kinematics models of Autonomous Vehicles that have its structures designed to have mobility improved have been studied. It was studied mechanical structures of machines that act in various stages of typical Brazilians crops. Based on this study and survey, a vehicle has been built with a modular concept and portal frame structure format to be used as a robotic platform in which it performs remote sensing in agricultural areas. A simplified Kinematic model have been done using basics concepts of mobile robots kinematics. At the end of this work is presented the portal frame structure development.

The results obtained may assist in the design development of AAV's

Keywords: Autonomous Agriculture Vehicle, portal frame structures, mobile robots kinematics, agricultural machines, precision agriculture. 


\section{LISTA DE FIGURAS}

Figura 1 - Plataforma Móvel construída pela Embrapa Instrumentação Agropecuária - São CarlosSP.

Figura 2 - (a) sistema de navegação autônoma e (b) veículo autônomo em operação da Universidade

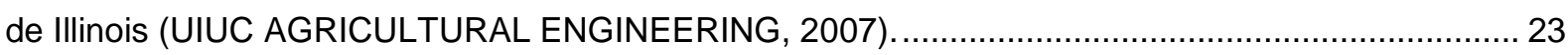

Figura 3 - Transplantador Automático de Arroz (NAGASAKA et al., 2004).

Figura 4 - Robô Agrícola desenvolvido para controle de ervas daninhas (ÅSTRAND E BAERVELDT, 2002)

Figura 5 - Veículo desenvolvido pelo Instituto Silsoe. 26

Figura 6 - VAA desenvolvido por Bak e Jakobsen (2004).

Figura 7 - Veículo Ominidirecional desenvolvido por Moore e Flann (2000). (a) Modelo T2 (1480 lb),

(b) Modelo T1 (95lb) e (c) Detalhe do mecanismo da roda com rotação infinita. 28

Figura 8 - O robô AURORA em uma estufa. (GÓMEZ-DE-GABRIEL et al., 1996). 30

Figura 9 - (a) SOLERO e (b) SHRIMP. 33

Figura 10 - Vista Isométrica do VAA com ilustração dos Principais Módulos. 34

Figura 11 - Módulo de Guiagem e Propulsão (MGP): (a) vista isométrica; e (b) vistas lateral e frontal com detalhamento dos principais componentes. 35

Figura 12 - Conjunto Eletrônico do MGP. 37

Figura 13 - Vistas da estrutura do VAA ilustrando os dispositivos principais interligados pela rede CAN. (Adaptado de Sousa (2007)). 37

Figura 14 - Rede CAN composta por nó controlador de motor e computador embarcável (Adaptdado de Sousa (2002). 38

Figura 15 - Quadro de referência global e quadro de referência local do robô. 44

Figura 16 - Parâmetros da roda padrão esterçável. Adaptado de Siegwart e Nourbakhsh (2004).... 46

Figura 17 - Centro Instantâneo de Rotação - CRI. Adaptado de Siegwart e Nourbakhsh (2004) ...... 50

Figura 18 - Descrição da Geometria do VAA. 57

Figura 19 - Posição do Centro de Massa do VAA. 58

Figura 20 - (a) Quadro de referência do rover da NASA e (b) quadro de referência da Roda (TAROKH e McDERMOTT, 2005). 
Figura 21 - Movimento Incremental por rolagem e escorregamento. (TAROKH e McDERMOTT, 2005).

Figura 22 - Pulverizador com formato da estrutura em pórtico. .71

Figura 23 - Estrutura do SAVAGE (SAVAGE, 2007).... 74

Figura 24 - Vista Frontal do VAA, (a) Abertura Mínima e (b) Abertura Máxima....... 76

Figura 25 - Processo de prototipagem virtual da estrutura mecânica do RAM. .77

Figura 26 - (a) Ambiente simulação de tensão e deformação e (b) resultado da simulação de deformação (deformação visual ampliada). 79

Figura 27 - Resultado da simulação do CHS para torção por forças horizontais. 79 


\section{LISTA DE TABELAS}

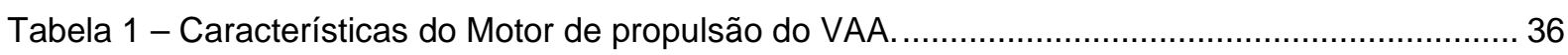

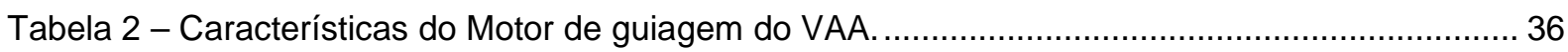

Tabela 3 - Características Geométricas do VAA com abertura máxima e mínima..............................57

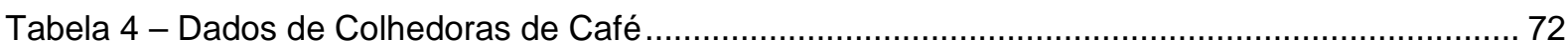

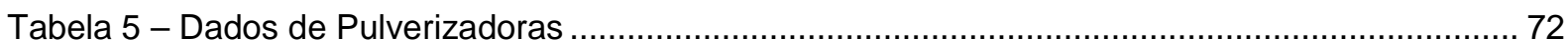

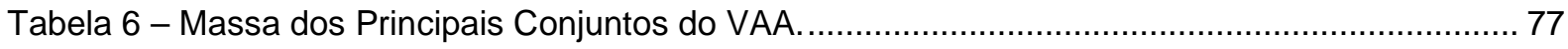

Tabela 7 - Resultados finais da simulação estática das estruturas $\mathrm{CHI}$ e CHS. ................................. 78 


\section{LISTA DE ABREVIATURAS E SIGLAS}

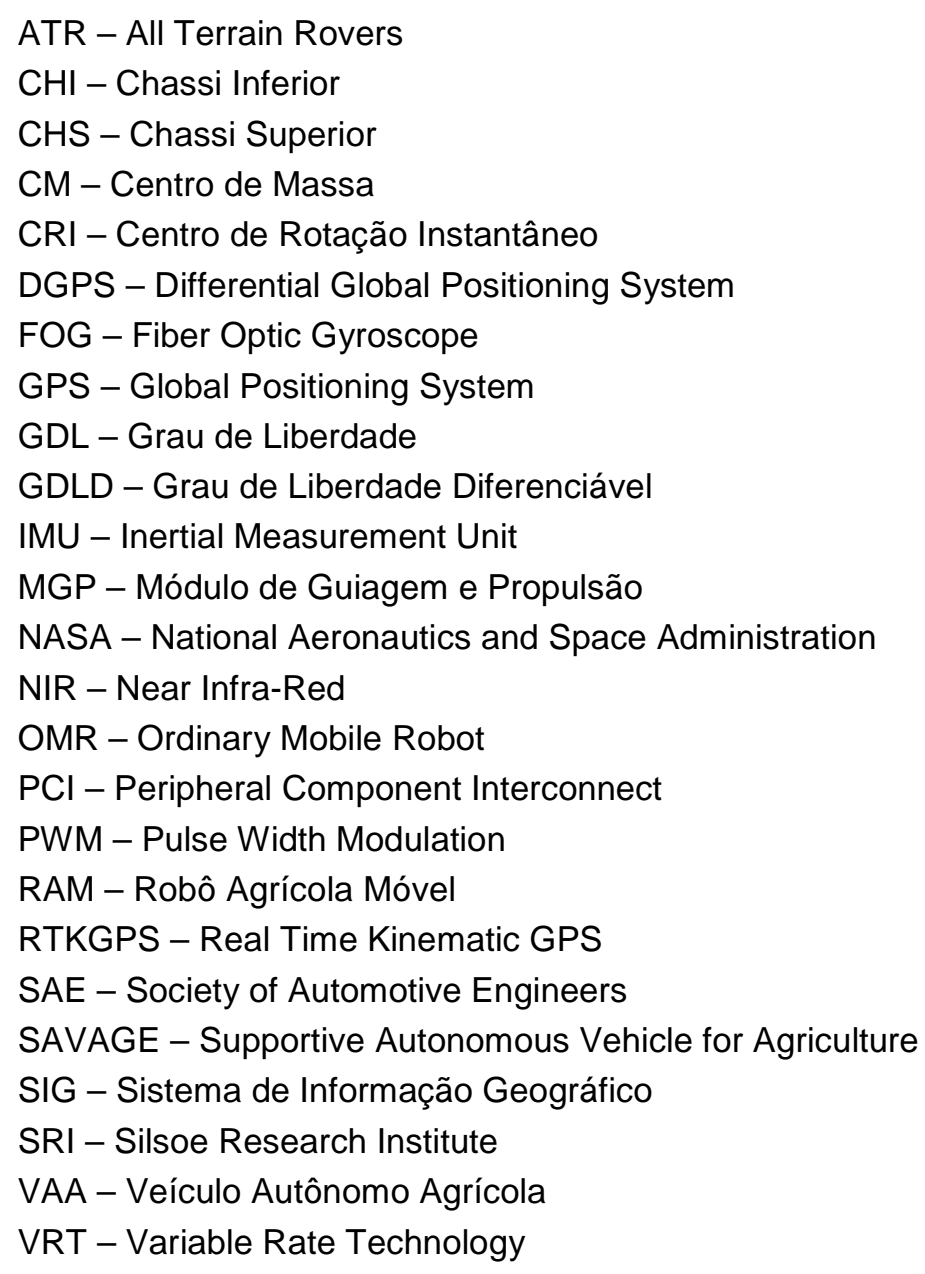




\section{SUMÁRIO}

\section{LISTA DE FIGURAS}

\section{LISTA DE TABELAS}

LISTA DE ABREVIATURA E SIGLAS

1. INTRODUÇÃO

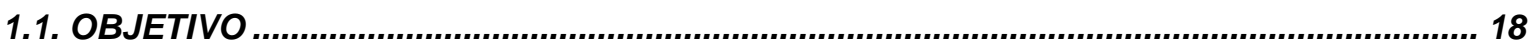

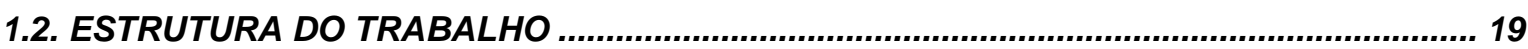

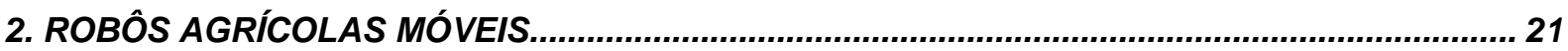

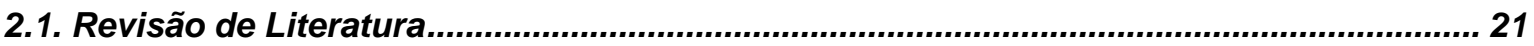

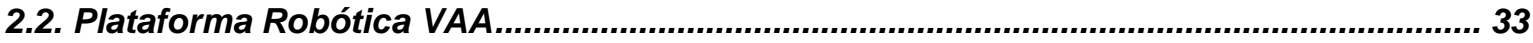

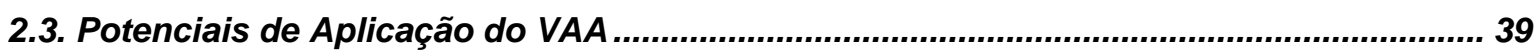

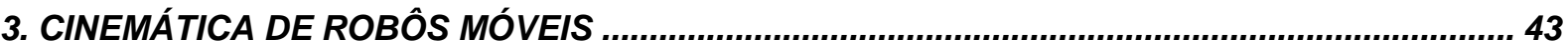

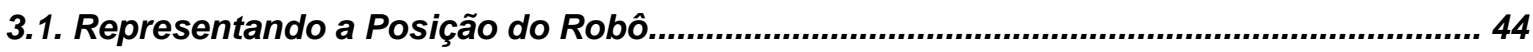

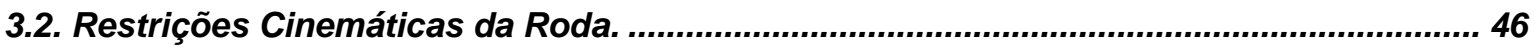

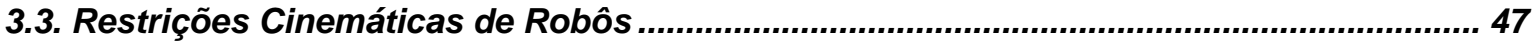

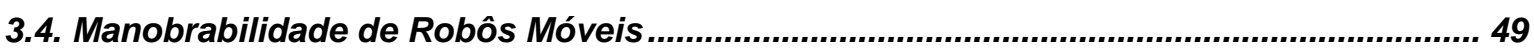

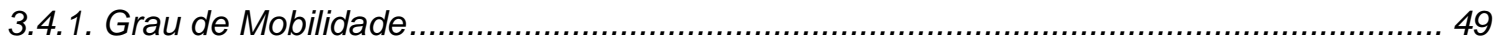

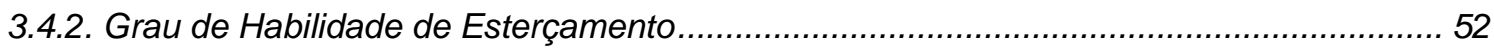

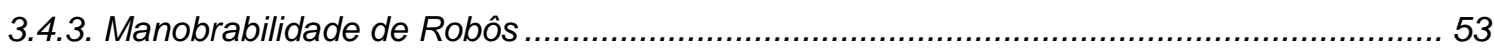

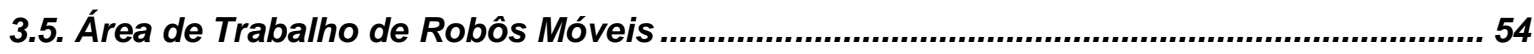

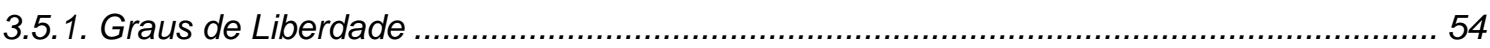

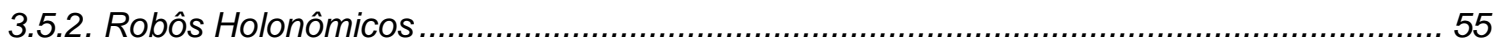

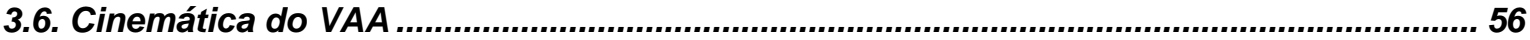

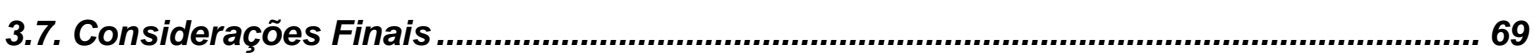

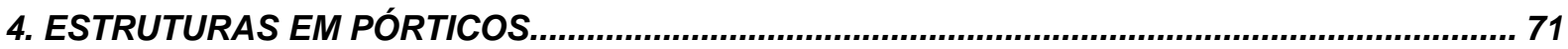

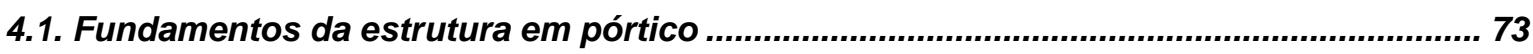

4.2. Desenvolvimento da Estrutura em Pórtico ................................................................... 75

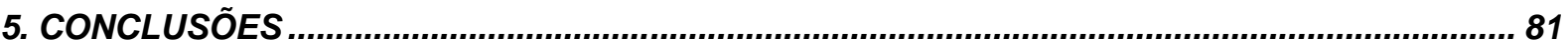

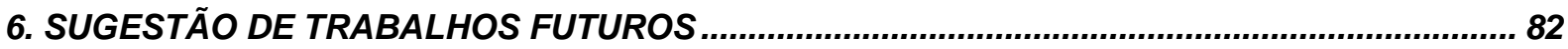

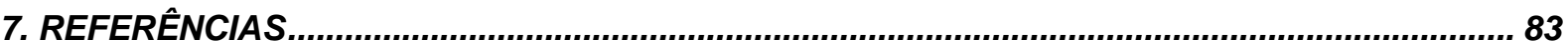

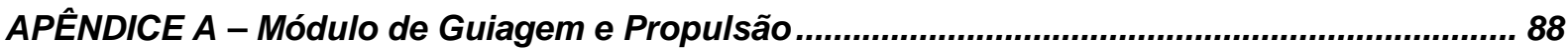

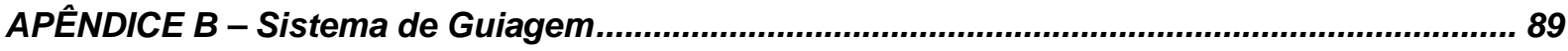

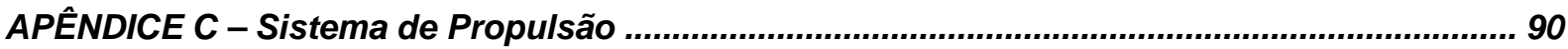

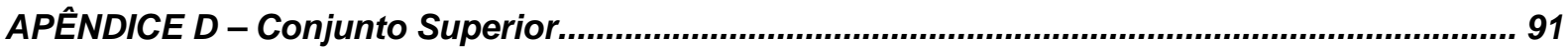




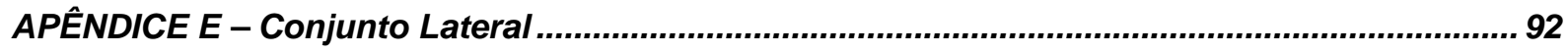

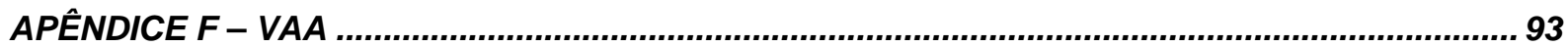




\section{INTRODUÇÃO}

Desenvolvimento e uso de veículos off-road, principalmente tratores agrícolas, fizeram o papel mais importante nas conquistas da mecanização Agrícola no século passado. Atualmente, tecnologias e metodologias em crescente uso e aperfeiçoamento na área agrícola têm demandado o desenvolvimento de sistemas baseado em sensores, atuadores e eletrônica embarcada. Dentre as tecnologias e respectivas metodologias em uso destacam-se:

- VRT (Variable Rate Technology): tecnologias aplicadas a máquinas agrícolas para permitir a aplicação controlada de insumos (fertilização e pulverização) ou permitir o controle de plantio (espaçamento e quantidade de sementes). É requerido um controle de velocidade mais preciso para a máquina agrícola e de um sistema computacional de apoio prévio para estudo e geração de mapa de recomendação por meio de SIG (Sistema de Informação Geográfica);

- Tecnologias On-The-Go: sensoriamento, processamento (tomada de decisão) e atuação durante o movimento da máquina. Freqüentemente demanda redução no tempo de resposta do sistema de processamento, tornado-o mais complexo e soluções mais sofisticadas;

- Piloto Automático: tecnologia aplicada a máquinas agrícolas para permitir a navegação mais precisa através de sistemas semi-autônomos (ex. DGPS ou RTK-GPS + lightbar - barra de luz) ou autônomos (DGPS ou RTK-GPS + sistema inercial - giroscópio e/ou bússola + odometria). Utilizados 
normalmente para viabilização de trabalho noturno, plantio, aplicação precisa de insumos e suporte para as técnicas citadas nos destaques anteriores.

A importância da pesquisa nas áreas referentes aos destaques anteriores pode ser constatada pelo número expressivo de publicações em revistas científicas nacionais e internacionais, e pelo número crescente de produtos para viabilizar tais tecnologias. Nos anais do Congresso Brasileiro de Agricultura de Precisão de 2004 (ConBAP 2004), realizado em Piracicaba-SP na ESALQ-USP, no período de 17 a 19 de maio de 2004, pode-se verificar um considerável número de trabalhos nessas áreas, e, inclusive, uma sessão especifica sobre navegação e guiagem autônoma com palestras e debates entre representantes de empresas e pesquisadores sobre 0 tema. Em 2006, o mesmo evento realizado em São Pedro, no período de 04 a 07 de junho de 2006 (ConBAP 2006), contou com uma sessão temática sobre robôs agrícolas. Além dessas sessões temáticas em eventos, em 2006, foi realizado o Workshop em Tecnologia de Robótica para Agricultura, promovido pelo Laboratório de Simulação e Controle do Departamento de Engenharia Mecânica da Escola de Engenharia de São Carlos da USP (SEM/EESC/USP) e pela Embrapa Instrumentação Agropecuária (Embrapa Cnpdia), com o objetivo de iniciar trabalhos interdisciplinares, bem como iniciar ações que integrem grupos multidisciplinares e multi-institucional, promovendo e fomentando o desenvolvimento das referidas tecnologias no país.

Em países como Japão (TORII, 2000), EUA (REID et al., 2000) e na UE (KEICHER \& SEUFERT, 2000), verifica-se uma forte tendência e um grande avanço em pesquisas e desenvolvimento de Veículos Agrícolas Autônomos (VAA's). Um dos fatores que tem aberto oportunidade para estas pesquisas pode-se atribuir ao surgimento de novas práticas como o Plantio Direto, Agricultura de Precisão, e 
práticas que tomam conta à proteção do meio ambiente. Além disso, outros fatores como o altíssimo custo de mão de obra, o envelhecimento da população rural sem perspectivas de renovação, a necessidade de minimizar a exposição a atividades insalubres e a redução de custo da eletrônica necessária para a construção de tais sistemas.

Estas práticas trouxeram uma série de desafios para a pesquisa, pois a escala de amostragem e a precisão exigida, muitas vezes, são maiores que as praticadas pela agricultura tradicional (AUERNHAMMER, 2001). Tais práticas têm alterado o cenário agrícola, demandando novos conceitos em máquinas, instrumental eletrônico e sensores embarcados.

Segundo Sousa (2007), a realidade brasileira em pesquisa de robôs para sistemas agrícolas é muito diferente e aplicação deste tipo de tecnologia parece estar mais distante. Essa situação coloca o país numa posição cada vez mais de consumidor em tecnologia, o que é inadequada para o tipo de que agricultura necessita.

Em 2001, a Embrapa Instrumentação Agropecuária desenvolveu uma plataforma para auxiliar pesquisa em campo. A plataforma foi construída para levar microcomputador portátil, baterias, coletor de dados e sensores de refletância para medir níveis de nitrogênio em vários estágios da cultura de milho. A Figura 1 ilustra a estrutura da plataforma móvel concebida pela Embrapa. 


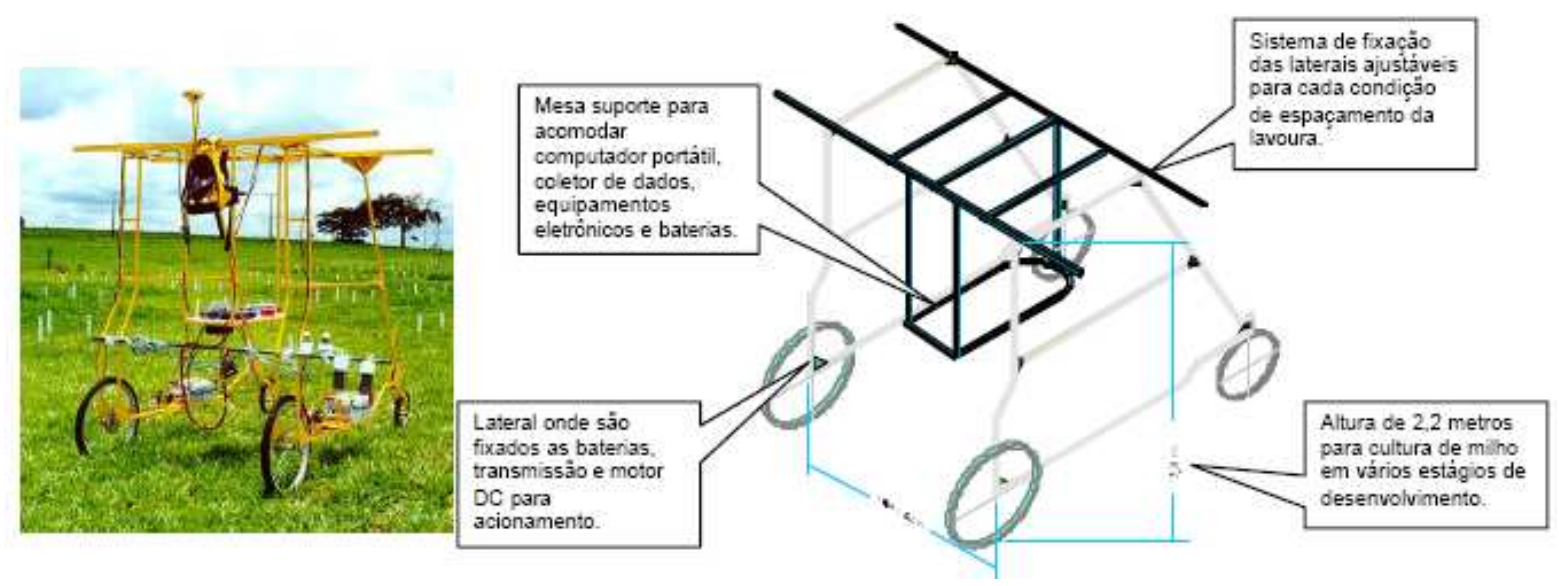

Figura 1 - Plataforma Móvel construída pela Embrapa Instrumentação Agropecuária - São CarlosSP.

Durante o uso da plataforma móvel observou-se a necessidade de um redimensionamento tanto da estrutura como da potência. Apesar de algumas limitações a plataforma móvel desenvolvida mostrou-se possuidora de uma potencialidade de contribuição inédita para aquisição de grandes quantidades de dados para diferentes práticas agrícolas, principalmente para a Agricultura de Precisão.

O presente trabalho ofereceu suporte a um projeto maior de construção de uma plataforma robótica para viabilizar o desenvolvimento de tecnologias de navegação autônoma e para aquisição de dados em um projeto cooperativo entre o Departamento de Engenharia Mecânica da EESC-USP e a Embrapa Instrumentação Agropecuária de São Carlos (Veículo Agrícola Autônomo - VAA: uma plataforma para desenvolvimento de tecnologias de navegação autônoma e para aquisição de dados em Agricultura de Precisão, processo FAPESP 03/06582-0) (PORTO et al., 2003). Este projeto teve como um dos principais objetivos criar competência nacional e interdisciplinar em robótica agrícola por meio da construção de um VAA (SOUSA, 2007). 
Como parte deste projeto maior, este trabalho executou o desenvolvimento e a construção de uma estrutura no qual a plataforma robótica foi montada, sendo esta estrutura dividida em módulos, o qual será detalhado posteriormente. Os principais elementos desta estrutura são: roda, motores elétricos, sensores, e outros dispositivos mecânicos e eletrônicos pertencente a um quadriciclo. Os dispositivos: sensores, atuadores e de processamento são integrados em field-bus (rede de sensores e atuadores inteligentes) utilizando o protocolo de comunicação digital CAN - Controller Area Network. Esse protocolo constitui a base da norma ISO 11783 (ISO 11783, 2007) para integração de dispositivos embarcados em tratores e implementos agrícolas. O uso deste protocolo permite que sistemas desenvolvidos nessa plataforma possam ser rapidamente integrados às máquinas agrícolas. Porém, pode-se dizer que é ainda um desafio tal protocolo ser utilizado em máquinas nacionais e maior ainda em robôs, cujo sistema exige desempenho além da confiabilidade (MOLIN et al., 2005).

O projeto do VAA consiste no desenvolvimento de uma plataforma robótica para mapeamento de variabilidade espacial de parâmetros importantes de culturas como, nível de infestação de pragas e doenças; atributos químicos, físicos e biológicos do solo, sanidade de cultura. Essas informações processadas podem auxiliar no tratamento espacialmente variado. A plataforma de Sousa (2007) foi desenvolvida para demonstrar conceitos inteligentes para veículos autônomos em agricultura no qual pode eventualmente resultar em um novo modelo sustentável para a agricultura desenvolvida. O veículo apresentado aqui é adaptado para operar em linhas de plantio com espaçamento de $0,5 \mathrm{~m}$ a 1,0 m entre as linhas de plantio, é equipado com dispositivos destinados ao controle de guiagem e navegação, assim como dispositivos destinados ao mapeamento de culturas agrícolas. 
Uma abordagem modular é feita com quatro módulos idênticos, permitindo direcionamento e propulsão nas quatro rodas. Controle da plataforma é fornecido pela eletrônica do veículo e o seu sistema de controle é baseado em controladores embarcados que se comunicam por meio do protocolo de comunicação serial padrão CAN. Segundo Sousa (2007) os programas computacionais implementam uma arquitetura de controle de navegação híbrida para permitir a construção de Robôs Agrícolas Móveis - RAM's ou VAA's. A arquitetura desenvolvida sobre esta plataforma flexível busca potencializar características para atuação em culturas brasileiras como soja, café, cana-de-açúcar e citrus e tem como características principais:

- Adaptabilidade para navegação autônoma em diferentes tipos e fases de cultura, permitindo que subsistemas de percepção, controle e atuação sejam inseridos ou removidos em acordo com as necessidades de cada operação;

- Arquitetura flexível para possibilitar o teste de novos dispositivos e metodologias relacionadas com controle de navegação, fornecendo suporte a pesquisa e desenvolvimento de novas tecnologias em robôs agrícolas móveis ou em veículos autônomos.

\subsection{OBJETIVO}

O objetivo maior do trabalho é contribuir com estudos para o desenvolvimento de uma estrutura que sirva de base para a construção de VAA's e RAM's. Foram estudadas estruturas robóticas autônomas e estruturas em pórtico com capacidade para operar em ambiente agrícola das principais culturas brasileiras. Foi projetado um chassi com as seguintes características principais: 
- Leve e flexível no qual possam ser inseridos novos sensores e atuadores.

- Formato em pórtico capaz de operar em culturas com altura de plantas até $2 \mathrm{~m}$ de altura.

- Bitola redimensionável com o objetivo de atuar em diferentes culturas com diferentes espaçamentos entre plantas.

O objetivo imediato foi apoiar o desenvolvimento do projeto processo FAPESP 03/06582-0 como já mencionado anteriormente.

\subsection{ESTRUTURA DO TRABALHO}

No Capítulo 2 são abordados trabalhos relacionados ao estado da arte em relação a robôs móveis destinados à operação em ambiente agrícola ou fora de estrada, também conhecidos como off-road, também é apresentada a proposta desenvolvida no Brasil. No Capítulo 3 é apresentado um modelo Cinemático para o VAA e são abordados trabalhos que estudam as características cinemáticas de veículos móveis não tripulados que possuem alta mobilidade. No Capítulo 4 é apresentado um estudo sobre estruturas de veículos comercias com formato em pórtico, projetados para operar em ambiente agrícola, bem como a motivação e projeto da estrutura desenvolvida para servir de plataforma para o VAA. No Capítulo 5 são apresentadas as principais conclusões do trabalho destacando-se as suas principais contribuições e as possibilidades para trabalhos futuros. 


\section{ROBÔS AGRÍCOLAS MÓVEIS}

Agricultura, horticultura, silvicultura se beneficiaram no passado pela sucessão de desenvolvimentos tecnológicos que trouxeram maiores produtividades e eficiência econômica para sistemas operados em muitas regiões do globo. Historicamente, a ênfase destes desenvolvimentos foi a mecanização de operações do campo para aumentar as taxas de trabalho alcançadas por operadores individuais. Hoje, entretanto, a tendência geral do aumento da eficiência por meio do uso de máquinas maiores e mais pesadas pode ser substituída pela adoção de novas tecnologias baseadas nas informações que podem finalmente proporcionar operações autônomas viáveis e confiáveis em campo (EARL et al., 2000).

\subsection{Revisão de Literatura}

Dentre as áreas de pesquisas de sistemas autônomos uma que se destaca é a área de veículos não tripulados. Robôs móveis foram desenvolvidos e podem operar autonomamente em diferentes ambientes, tais como no ar, água e no espaço externo. Mais recentemente tem acontecido um aumento no interesse de pesquisas sobre veículos terrestres não tripulados, especialmente para uso nas áreas: militar, agrícola e transporte terrestre. Avanços nas áreas de tecnologias de sensoriamento tais como: Sistema de Posicionamento Global (Global Positioning System - GPS); capacidade computacional; miniaturização de eletrônica; algoritmos inteligentes para planejamento e controle, e também avanços nos projetos mecânicos, têm levado 
para a possibilidade de realizar operações autônomas reais para aplicações usando veículos terrestres não tripulados (MOORE e FLANN, 2000).

Destaca-se que em projetos de veículos não tripulados não existem limitações no que se refere ao espaço destinado ao operador do veículo, no caso em que este fosse tripulado. A eliminação do espaço destinado ao operador do veículo pode promover a atribuição de novas características que podem ser incorporadas ao projeto de estrutura destas máquinas, como, por exemplo, configuração de rodas, formato, tamanho, peso, potência, entre outros.

Apesar do potencial de maior liberdade de projeto, na literatura podem-se encontrar trabalhos que buscam adaptar máquinas agrícolas comerciais para tornálas plataformas agrícolas autônomas (veículos autônomos ou robôs móveis autônomos) e, também, trabalhos em que plataformas são construídas especificamente para serem veículos autônomos ou robôs agrícolas. No segundo caso, identificam-se dois desafios: desenvolver uma estrutura física adequada ao ambiente agrícola e para atender as necessidades da aplicação às quais se destinam; e desenvolver uma arquitetura eletrônica para integrar os diversos dispositivos presentes em sistemas como esses, assim como, permitir sua expansão através da inserção de novos dispositivos.

O grupo de pesquisa em veículos autônomos agrícolas do Departamento de Engenharia Agrícola da Universidade de Illinois (EUA) (UIUC AGRICULTURAL ENGINEERING, 2007) utiliza máquinas agrícolas comerciais (tratores) adaptadas em veículos autônomos. Para tal foi necessária a introdução de diversos dispositivos eletrônicos. A Figura 2 (a) mostra a arquitetura eletrônica do sistema. Pode-se notar que um computador central está acoplado a diversos dispositivos (GPS, sistema de visão (machine vision), atuadores das rodas (actuator), válvula de controle de 
esterçamento (steering valve)), que serão responsáveis pela percepção e atuação do sistema. Já a Figura 2 (b) mostra o veículo em operação.

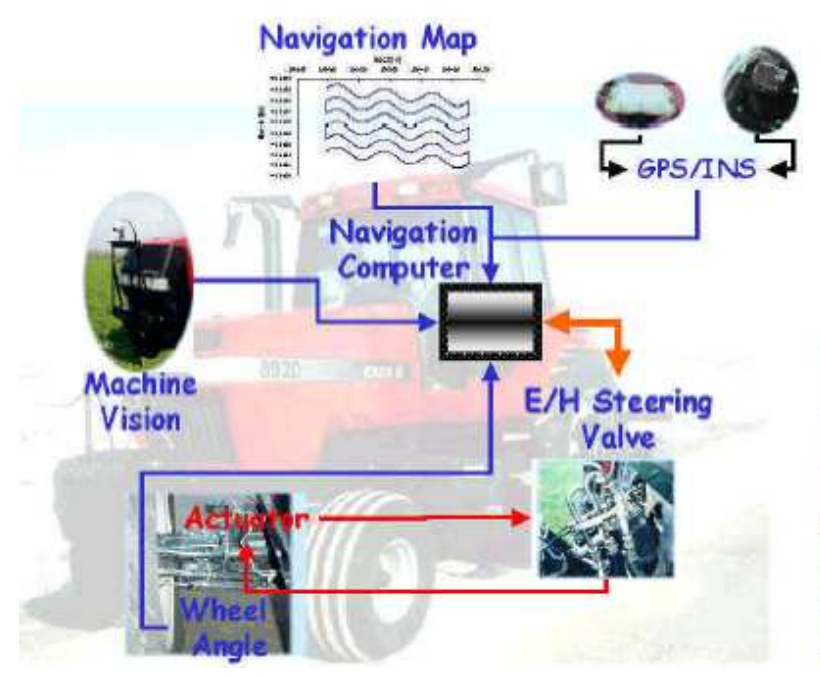

(a)

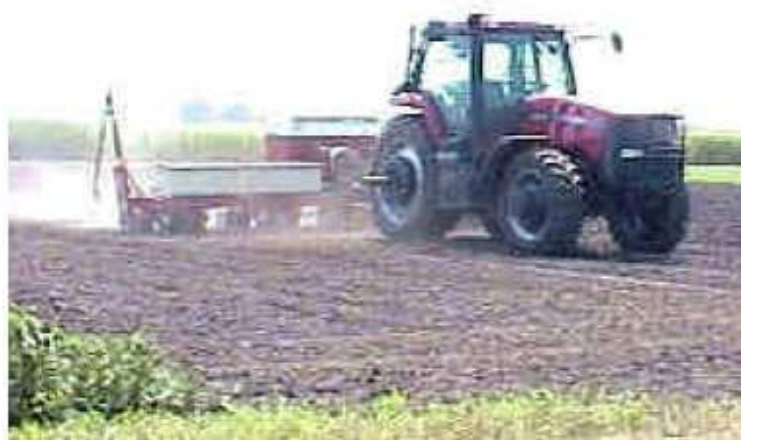

(b)

Figura 2 - (a) sistema de navegação autônoma e (b) veículo autônomo em operação da Universidade de Illinois (UIUC AGRICULTURAL ENGINEERING, 2007).

Nagasaka et al. (2004) apresentam o desenvolvimento de um transplantador de arroz automático (Figura 3), O veículo também é adaptado e atuadores foram inseridos para controlar direcionamento, acelerador, embreagem e freio. Além disso, ele emprega Sistema de Posicionamento Global Cinemático em tempo real - Real Time Kinematic GPS (RTKGPS) e giroscópio de fibra óptica - Fiber Optic Gyroscope (FOG) para medir a direção. O objetivo principal foi o desenvolvimento de um sistema de navegação autônomo que se mostrou eficiente neste tipo operação.

A Figura 3 mostra alguns componentes eletrônicos do transplantador de arroz. O computador central está acoplado com o receptor de GPS (GPS receiver), antena do GPS (GPS Antenna), Giroscópio de Fibra Óptica (Fiber Optic Gyroscope). 


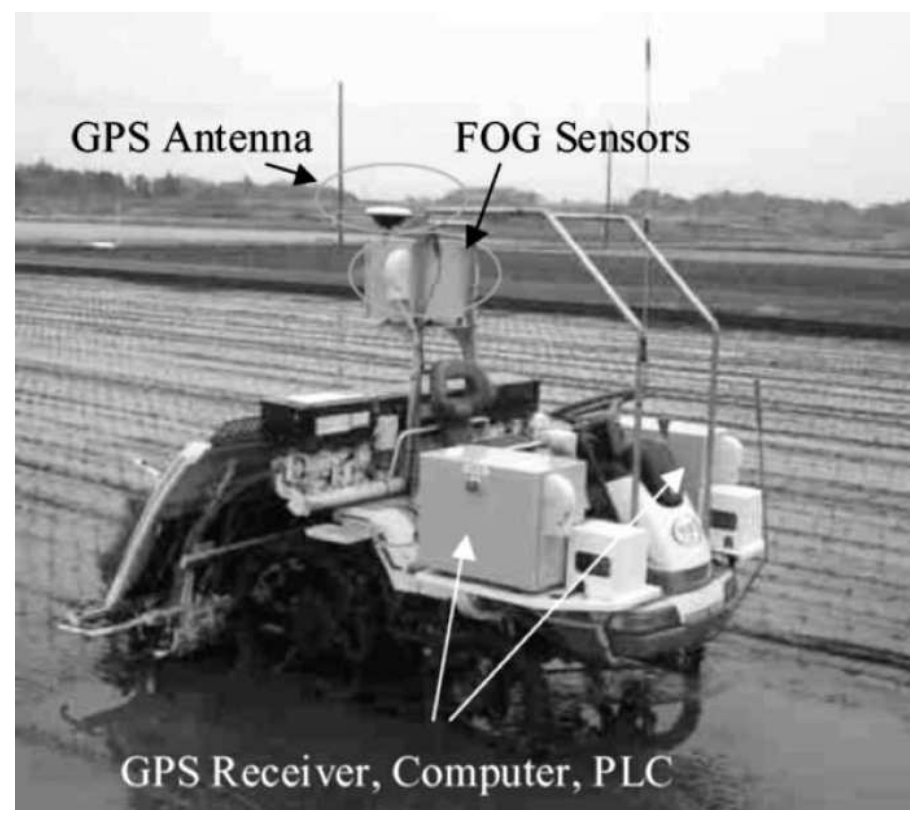

Figura 3 - Transplantador Automático de Arroz (NAGASAKA et al., 2004).

Este tipo de adaptação de veículos agrícolas comuns (tratores) possui a vantagem de apenas incluir os elementos para automação, como por exemplo: computadores, sensores e atuadores. Mas como o veículo aproveita a estrutura da máquina já preparada e dimensionada para operações agrícolas este possui a desvantagem de não poder ser utilizado em tipos diversificados de culturas ou em estágios avançados de crescimento.

Åstrand e Baerveldt (2002) apresentam um robô agrícola móvel para controle de ervas daninhas. O veículo foi projetado para operar em culturas de beterraba e outras culturas cultivadas com distância de linhas de plantio em torno de $50 \mathrm{~cm}$. Possui largura de $70 \mathrm{~cm}$ e comprimento de $120 \mathrm{~cm}$ com uma configuração de roda tipo Ackerman (Configuração de rodas igual a de um automóvel). A ferramenta de controle de ervas daninhas é uma roda girante que gira perpendicularmente em relação à linha de plantio no qual atua, ele atua somente entre as linhas de plantio. O robô emprega dois sistemas de visão: um sistema que é capaz de identificar a estrutura formada pelas plantas e guiar o robô ao longo das linhas e um segundo 
sistema de visão que é capaz de identificar uma única planta no meio de ervas daninhas.

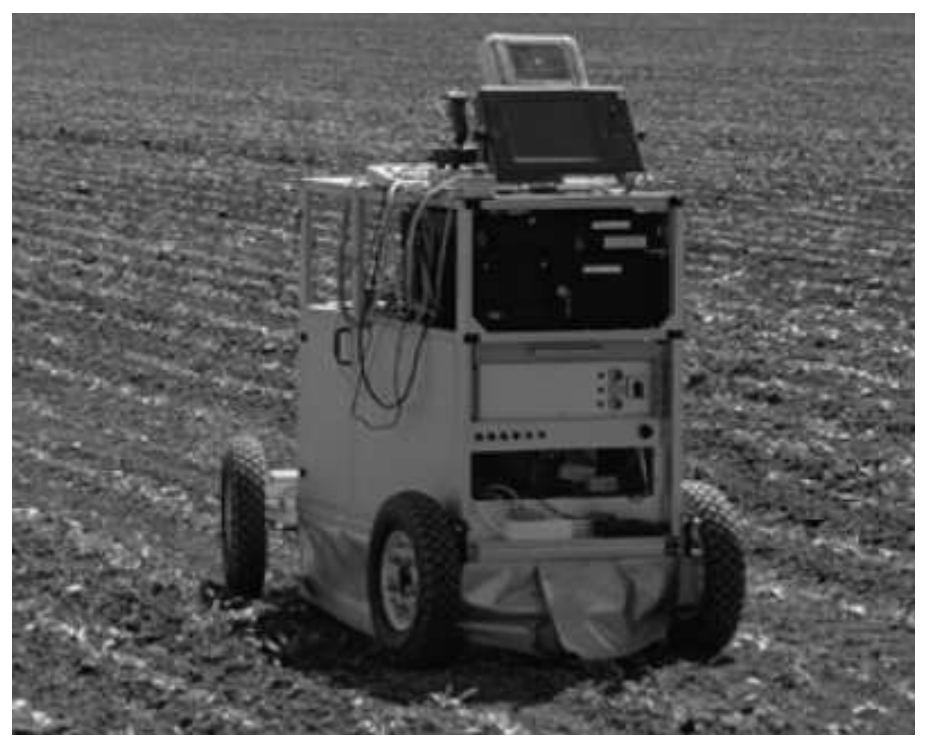

Figura 4 - Robô Agrícola desenvolvido para controle de ervas daninhas (ÅSTRAND E BAERVELDT, 2002).

Já o Grupo de Robótica e Automação do Instituto de Pesquisa de Silsoe Reino Unido (Silsoe Research Institute - SRI) desenvolveu uma plataforma robótica para ser utilizada especificamente em horticultura, como descrito por Hague, Marchant e Tillet (2000) e em SRI (2005). O projeto desta plataforma explora métodos de sensoriamento do chão para correção de posição do veículo. Sensores são estudados em várias categorias, medição de movimento (odometria e inercial), pontos de referências artificiais, (posicionamento utilizando laser, onda de radar milimétrica), e detecção de características locais (sonar, visão de máquina). Ênfase particular é realizada para tecnologias que tem provado sucesso além do campo da agricultura, e de visão de máquina por causa de suas importância atual. Neste robô foi utilizada fusão de sensores, o filtro de Kalman é delineado e pontos práticos são discutidos. Destaca-se que este veículo não usa sistema de posicionamento absoluto, em vez disso ele navega usando características locais, neste caso as plantas. Este veículo usa um pacote de sensores que incluem visão de máquina, 
odômetros, acelerômetros, e uma bússola, onde a fusão de sensor é realizada usando filtro de Kalmam estendido. A configuração do veículo lembra se assemelha a de um trator. Possui quatro rodas e é movido por motor a combustão interna. A Figura 5 mostra o veículo no campo.

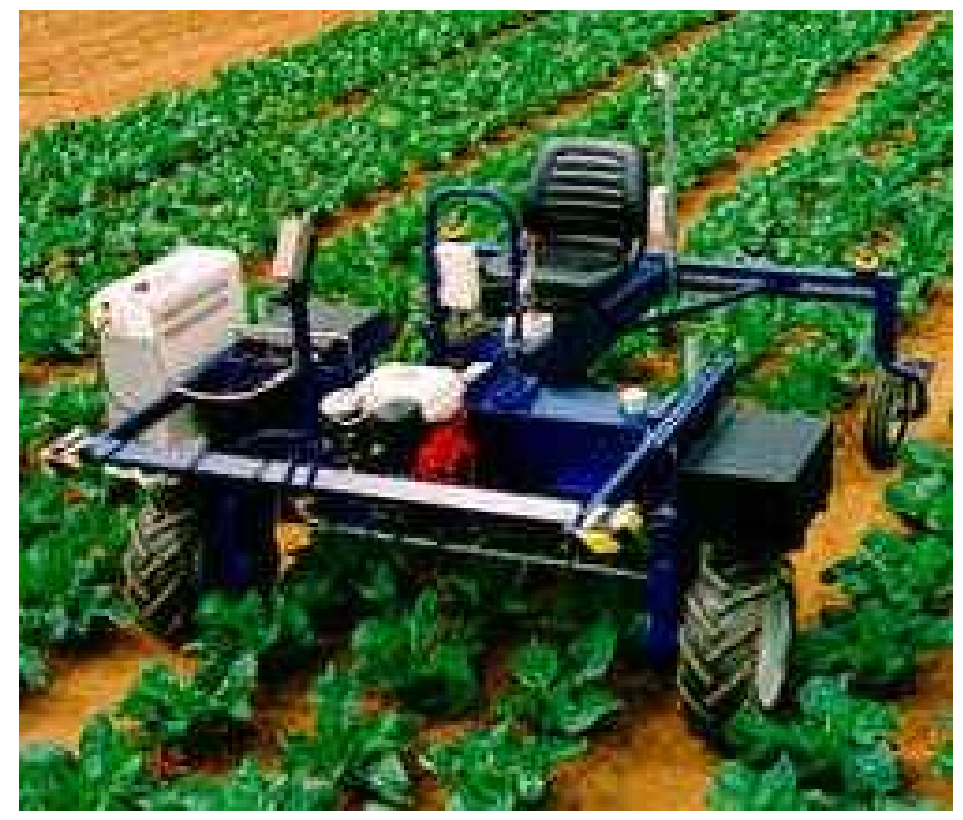

Figura 5 - Veículo desenvolvido pelo Instituto Silsoe.

Bak e Jakobsen (2004) apresentam um robô agrícola móvel, cuja estrutura é formada basicamente por um chassi e quatro conjuntos, formados cada um deles por uma roda e sistema eletromecânico de controle para movimentação. O chassi da plataforma robótica possui dimensão de $1,2 \mathrm{~m}$ por $1 \mathrm{~m}$, e foi projetado especificamente para uso agrícola em linhas de plantio baixas e em terreno limpo. Cada um de seus quatro conjuntos inclui um motor elétrico de propulsão que fornece movimentação, sendo que a eletrônica de controle de cada módulo também faz parte do conjunto. Para a realização de manobras é utilizado um motor de direção montado no topo do conjunto, criando um mecanismo de dois graus de liberdade. A arquitetura eletrônica de controle do robô é baseada em um computador comercial embarcável que controla o posicionamento do servo (motor de direção) e fornece 
controle do torque para o motor de movimentação. A eletrônica do motor de movimentação permite $\mathrm{o}$ controle de velocidade e torque com realimentação enquanto que o sistema de direcionamento que utiliza servo fornece realimentação do ângulo de direção que é obtido através de um encoder ( contador de pulsos para medida de posição e velocidade) montado em seu eixo.

O robô apresentado por Bak e Jakobsen (2004), como mostrado na Figura 6 , possui uma arquitetura eletrônica baseada em um computador embarcado PC/104 (PC/104, 2007) que é responsável pelo papel central do controle do veículo. A eletrônica do conjunto eletromecânico da roda integrada ao computador embarcado através de uma rede digital de dados baseada no protocolo CAN. Alternativamente, outros dispositivos podem ser conectados através de uma segunda rede CAN que está disponível em outra porta do computador. Outros sensores como GPS, giroscópio, bússola magnética, são conectadas ao computador embarcado através interfaces seriais ponto-a-ponto padrão RS232.

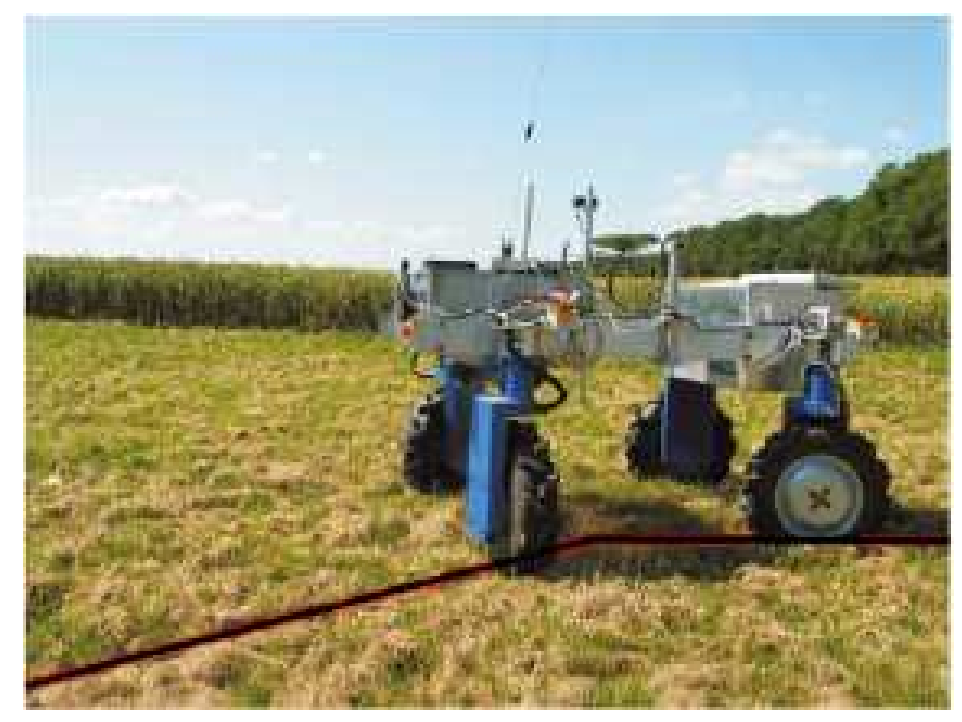

Figura 6 - VAA desenvolvido por Bak e Jakobsen (2004).

Moore e Flann (2000) apresentam um veículo autônomo com seis rodas (Figura 7), em que cada roda possui controle de velocidade e de direção obtidos independentemente através de processadores dedicados. Cada roda possui motor 
de direção e de movimentação. A plataforma robótica obtida pela conexão das seis rodas com um chassi é chamada de ominidirecional porque o veículo resultante pode seguir um caminho com orientação e movimento independentes em $X-Y$. Ele difere de veículo tradicional Ackerman no qual sua orientação é restrita pela direção de viagem. Entretanto deve ser notado que o veículo robótico utilizado não é verdadeiramente ominidirecional. O veículo é de fato, não holonômico porque leva um tempo finito para virar a roda para um novo ângulo de direção. Certamente este tempo apresenta um acoplamento no movimento de $X-Y$ do veículo. No entanto, é usado o termo ominidirecional porque os motores de direção possuem uma taxa de virada ou esterçamento muito rápida em relação à dinâmica do próprio veículo, resultando no que é efetivamente capacidade ominidirecional.

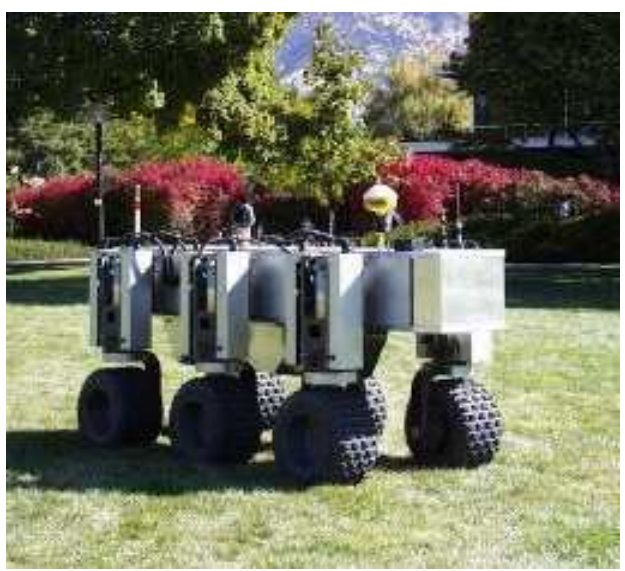

(a)

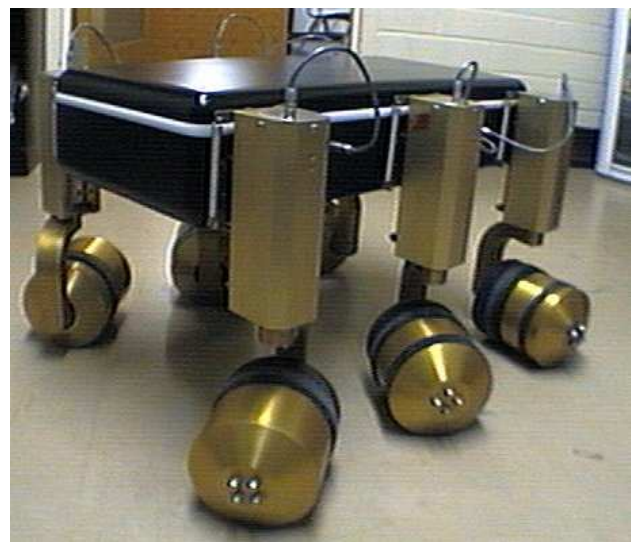

(b)

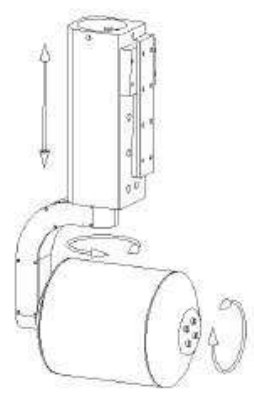

(c)

Figura 7 - Veículo Ominidirecional desenvolvido por Moore e Flann (2000). (a) Modelo T2 (1480 lb), (b) Modelo T1 (95lb) e (c) Detalhe do mecanismo da roda com rotação infinita. 
Destaca-se que neste projeto de robô (Figura 7) foi utilizado um projeto particular de cada uma de suas seis rodas chamadas de smart wheels ou rodas inteligentes (Figura 7c), elas possuem anel de deslizamento que permite rotação infinita de cada roda em relação ao eixo vertical. Este mecanismo permite que dados e alimentação passem pela roda para o chassi sem conexão por fio, mas sim pelo anel de contato deslizante.

A plataforma autônoma apresentada em Moore e Flann (2000) possui uma arquitetura eletrônica baseada em três computadores Pentium com sistema operacional Linux e interligados por uma rede local (LAN) padrão TCP/IP embarcada no veículo. Os computadores se comunicam com vários sensores tais como GPS e giroscópio, e com outros dispositivos de diversas formas: rede CAN, interface RS 232 e barramento $\mathrm{PCl}$ (Peripheral Component Interconnect - Interconector de Componentes Periféricos). Cada nó de roda inclui um microcontrolador com interface para vários sensores, realimentação de malha com os encoders absolutos e incrementais, e uma controladora de motor baseada em PWM (Pulse Width Modulation - Modulação por largura de Impulsos) que está ligada em um barramento de $48 \mathrm{~V}$.

Outro veículo agrícola autônomo apresentado em Gómez-de-Gabriel et al. (1996), denominado AURORA (Figura 8), consiste em uma plataforma cuja estrutura é formada por oito lados e é composta por quatro rodas. Sua estrutura acomoda um dispositivo de pulverização, sistema de energia, componentes eletrônicos e computador além de todos os sensores. Suas dimensões são $80 \mathrm{~cm}$ em largura e $140 \mathrm{~cm}$ em comprimento. Este veículo tem com objetivo executar operações automáticas em estufas, principalmente pulverização. Sendo assim, ele foi projetado para ter a habilidade de navegar em corredores estreitos. Ele possui uma arquitetura 
eletrônica concentrada, ou seja, todos os dispositivos (monitor, joystick, teclado, modem) estão conectados diretamente em um computador. A plataforma foi desenvolvida para navegação autônoma e teleoperada em ambiente agrícola.

AURORA é um robô autônomo móvel com rodas projetado para operações automáticas em estufas sem a presença física de um operador humano ou sua supervisão. Seu foco é realizar operações determinadas em seu ambiente de trabalho, ou seja, ele deve integrar uma variedade de componentes para navegação e operação autônoma e suportar supervisão remota humana e teleoperação. Embora as operações típicas para este sistema seja pulverização química, sua flexibilidade permite sua adaptação para outras operações e aplicações tais como monitoramento de estufas transporte ou inspeção da produção.

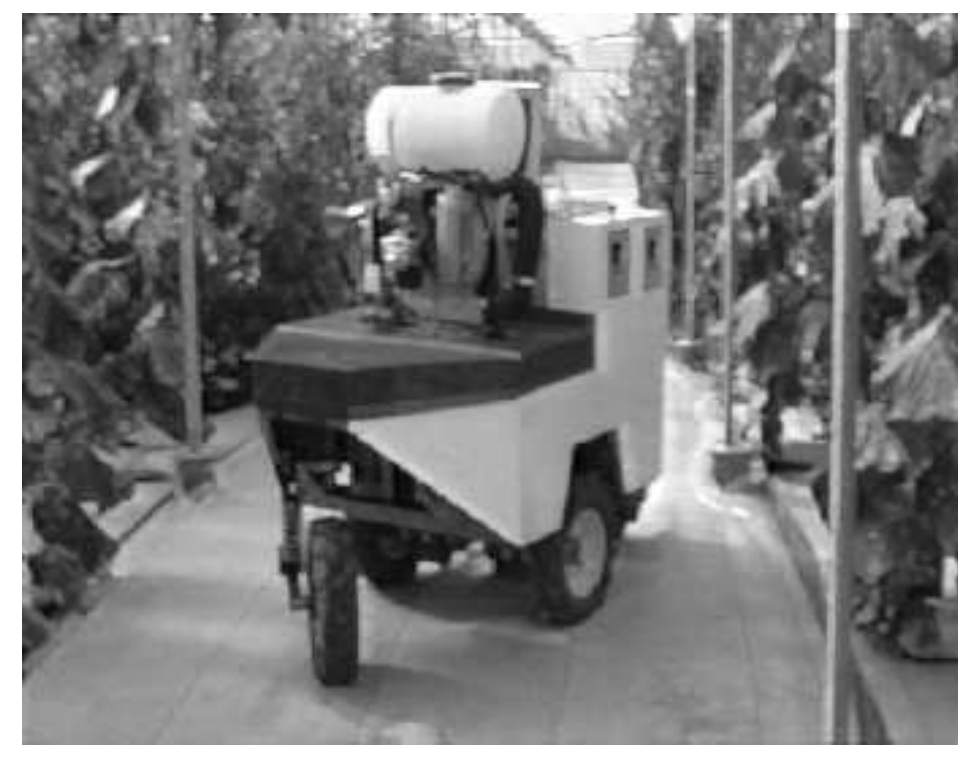

Figura 8 - O robô AURORA em uma estufa. (GÓMEZ-DE-GABRIEL et al., 1996).

A arquitetura de controle no projeto do robô AURORA foi projetada e implementada em uma base de refinamento progressiva, atendendo de forma otimizada situações práticas reais. A principal característica da implementação deste sistema de controle é a necessidade de baixa capacidade computacional de software e hardware, que faz possível um produto confiável e de baixo custo. A 
arquitetura integra sensores, controladores e atuadores assim como componentes de software e comunicação.

Mais recentemente é apresentado o veículo denominado SAVAGE Supportive Autonomous Vehicle for Agriculture ou Veículo Autônomo de Apoio para a Agricultura (SAVAGE, 2007) que está sendo desenvolvido na Universidade de Thessaly, Grécia, conforme descrito pela Figura 23. Corresponde ao desenvolvimento de um veículo de baixo custo e autônomo projetado para desempenhar tarefas especificas dentro dos limites de um campo.

A construção mecânica de SAVAGE é baseada em um projeto modular, formada de tal modo que permite a sua implementação com o uso de tecnologias e fabricação convencionais. A estrutura possui baixo peso, o corpo do robô é formado por uma base de aço suportado por quatro módulos de locomoção. Cada módulo de locomoção possui dois motores, que fornecem esterçamento e rotação independente da roda. Adicionalmente, cada módulo de locomoção possui seus módulos eletromecânicos e eletrônicos que são necessários para o controle da unidade do módulo de locomoção. Toda inteligência de alto nível e unidades de suprimento de energia são hospedados na parte principal da construção.

O objetivo deste projeto é o desenvolvimento de uma plataforma robusta para uso geral (3 graus de liberdade) baseado em arquitetura aberta, capaz de hospedar subsistemas diferentes a fim de desempenhar diversas tarefas em campo durante 0 período correspondente a $60 \%$ do crescimento de planta. O sistema é projetado para ser capaz de carregar um adicional máximo de $40 \mathrm{~kg}$ de carga paga sem queda brusca de desempenho. Isto garante que ele será capaz de equipamento adicionais necessários para as diversas tarefas agrícolas. 
Lamon e Siegwart (2007) apresentam o desenvolvimento de uma plataforma, com seis rodas, chamada SOLERO, como pode ser visto pela Figura 9 (a). Esta plataforma foi equipada com sensores e maior poder computacional em relação à outra plataforma desenvolvida no Autonomous System Lab (Laboratório de Sistemas Autônomos) (SIEGWART et al., 2000). A primeira plataforma denominada SHRIMP (Figura 9b), que é basicamente uma versão em escala reduzida da SOLERO, incorporou capacidade excelente de subida ao possuir capacidade melhorada de sua suspensão mecânica passiva. O rover (veículo de exploração) possui uma roda em um garfo na frente, uma roda acoplada na parte traseira do corpo principal e dois bogies (estrutura que contém as rodas) em cada lado. A arquitetura paralela dos bogies e do garfo suspenso por molas fornece ampla área de vão livre enquanto coloca todas as rodas em contato com o chão em qualquer momento. Segundo Lamon e Siegwart (2007) isto assegura excelente capacidade de escalada sobre obstáculos até duas vezes o diâmetro de sua roda e excelente adaptação para todos os tipos de terrenos. O direcionamento do rover é realizado pela sincronização da rotação das rodas da frente e de trás e pela diferença de velocidades das rodas dos bogies promovendo escorregamento lateral. A habilidade do SOLERO de se mover suavemente em meio a obstáculos agudos em terrenos acidentados possui muitas vantagens. Em particular, ele permite escorregamento limitado das rodas e redução de vibração.

Deste modo a taxa de ruído no sinal dos sensores a bordo do veículo e a precisão da odometria são significantemente melhorados em comparação com as estruturas rígidas tais como os rovers de quatro rodas de direção. Imagens menos borradas podem ser adquiridas e as técnicas de integração da Unidade de Medida 
Inercial (Inertial Measurement Unit - IMU) podem ser aplicadas para melhorar o rastreamento da posição em terrenos acidentados.

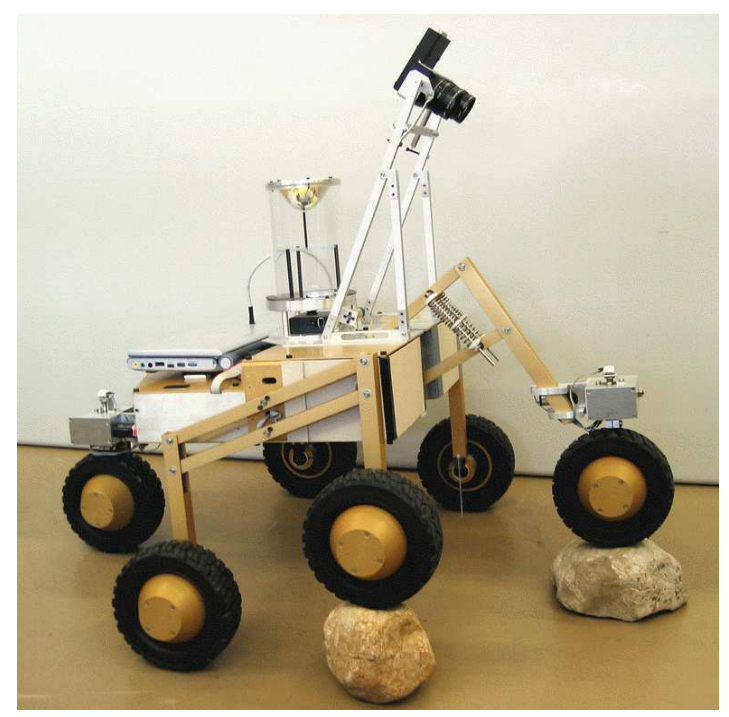

(a)

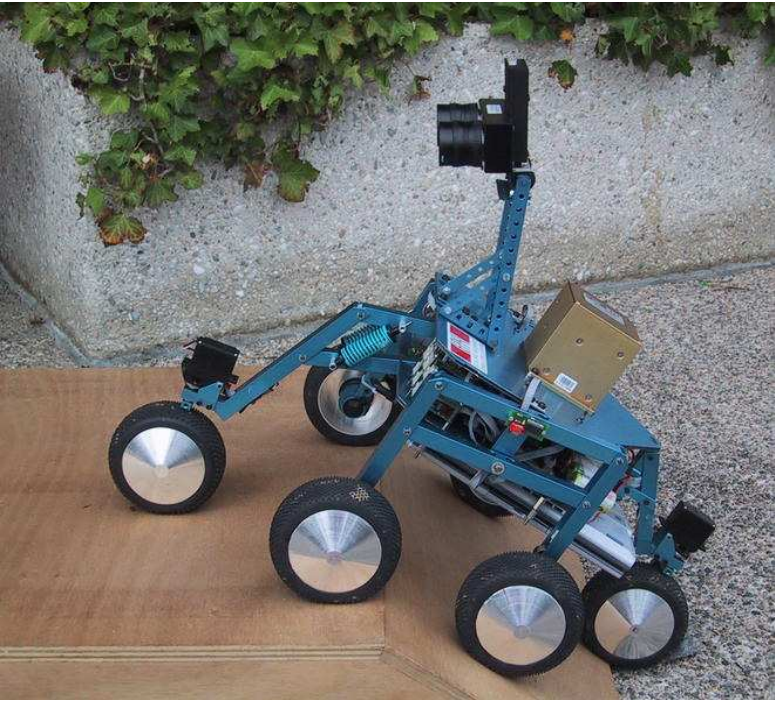

(b)

Figura 9 - (a) SOLERO e (b) SHRIMP.

\subsection{Plataforma Robótica VAA}

O presente projeto de VAA é destinado a monitorar parâmetros de importância agronômica em culturas brasileiras tais como: milho, soja, cana-deaçúcar, café e outras. Este VAA não tem como propósito realizar operações agrícolas como preparo de solo, plantio e colheita e é destinado a sensoriamento de grandes áreas. Diferentemente dos projetos de veículos autônomos para uso em ambientes agrícolas, não é exigido do VAA ações de alta potência (torque e velocidade), porém deve-se locomover de maneira eficiente nestes ambientes. A estrutura do VAA foi desenvolvida em quatro módulos principais apresentados na Figura 10 e descritas a seguir. 
- Chassis inferiores (CHI1 e CHI2): são duas estruturas laterais que conectam e suportam os MGP's, além de transportar baterias e dispositivos diversos;

- Chassi superior (CHS): estrutura responsável pela conexão dos dois chassis inferiores e pelo travamento superior da estrutura;

○ Módulos de guiagem e propulsão: (MGPn: MGP1, MGP2, MGP3, MGP4): são quatro sistemas eletromecânicos responsáveis pelo controle direcional e pela propulsão do VAA.

- Gabinete: estrutura fixada ao CHS que acomoda os computadores principais do VAA, além de dispositivos relacionados com o controle de energia, alarmes e bloqueadores para segurança.

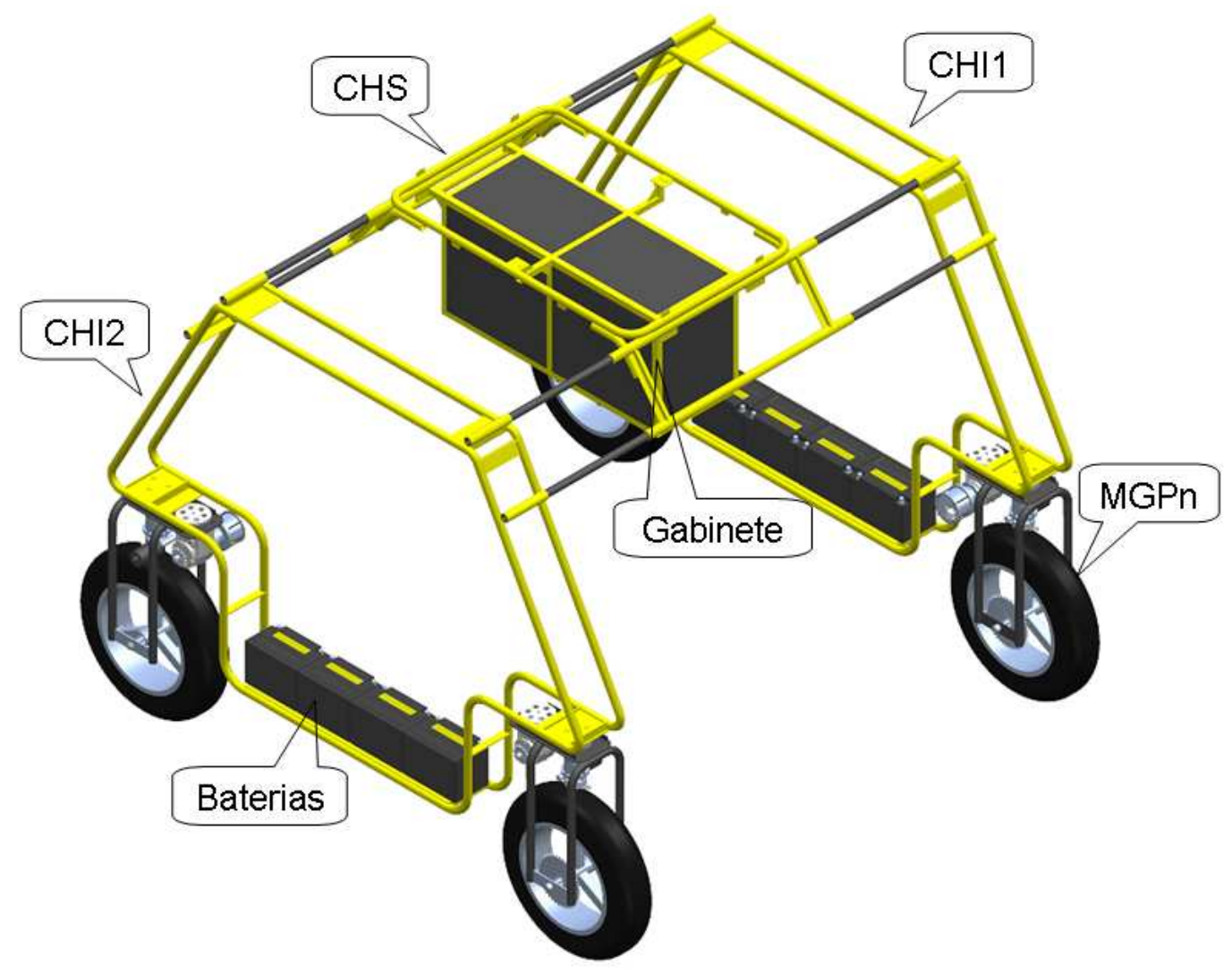

Figura 10 - Vista Isométrica do VAA com ilustração dos Principais Módulos. 
O MGP é o módulo no qual concentram os dispositivos mecânicos, eletromecânicos e eletrônicos responsáveis pela movimentação, direcionamento e controle primário das rodas do veículo, conforme pode ser visto na Figura 11. O MGP é um mecanismo criado para ser flexível e que possa ser eventualmente incorporado em outras estruturas. Tais estruturas poderão ser projetadas especificamente para atuar em culturas diferentes utilizando o mesmo MGP. Tal justificativa pode incluir características de solo, distância entre linhas de plantio, topografia do terreno ou mesmo manobrabilidade melhorada da estrutura.

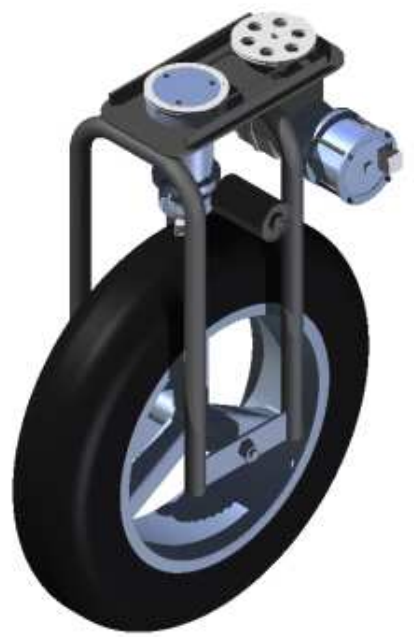

(a)

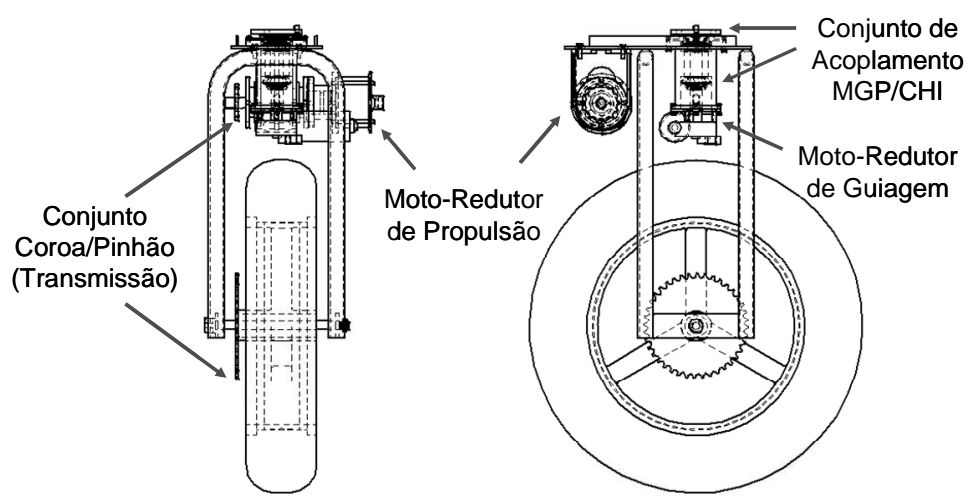

(b)

Figura 11 - Módulo de Guiagem e Propulsão (MGP): (a) vista isométrica; e (b) vistas lateral e frontal com detalhamento dos principais componentes.

Como pode ser visto na Figura 11, o MGP possui um conjunto de acoplamento que permite a rotação do MGP em relação ao $\mathrm{CHI}$. Além disso, a Figura 11 mostra que o sistema de propulsão possui ainda um sistema de transmissão baseado em corrente com coroa e pinhão para a transmissão do torque entre o eixo da roda e a saída do conjunto moto-redutor de propulsão.

O MGP desenvolvido possui motores Bosch (BOSCH, 2004) modelo GPC para a propulsão e Motorredutor modelo CDP para a guiagem. Características dos motores Bosch de propulsão e guiagem estão descritas na Tabela 1 e Tabela 2, 
respectivamente. Possui redutor de velocidade acoplado ao motor de propulsão por meio de correntes. Além disso, cada MGP contém um seu próprio conjunto contendo todos seus dispositivos eletrônicos: controladores de guiagem e propulsão e sensores de posição (potenciômetro) para o motor de direção, conforme a Figura 12.

O sistema de transmissão (coroa, pinhão, corrente, eixo e rolamentos) como as rodas e pneus são componentes de motocicletas comerciais. Optou-se por adequar o projeto para utilização de componentes mecânicos comerciais para reduzir custos de projeto e fabricação de peças especiais.

Tabela 1 - Características do Motor de propulsão do VAA.

\begin{tabular}{lr}
\hline \multicolumn{2}{c}{ Motor Tipo GPC } \\
\hline Tensão dos Motores & 24 VCC \\
\hline Potência Nominal $\left(P_{\mathrm{N}}\right)$ & $210 \mathrm{~W}$ \\
\hline Velocidade & 1 \\
\hline Rotação & 2500 a 3500rpm \\
\hline Consumo Nominal & $10 \mathrm{~A}$ \\
\hline Sentido de Giro & Horário e Anti-horário \\
\hline Torque Nominal $\left(\mathrm{M}_{\mathrm{N}}\right)$ & $75 \mathrm{Ncm}$ \\
\hline Peso & $1500 \mathrm{~kg}$ \\
\hline IP (índice de proteção) & 03 \\
\hline
\end{tabular}

Tabela 2 - Características do Motor de guiagem do VAA.

\begin{tabular}{lr}
\hline \multicolumn{2}{c}{ Motorredutor Tipo CDP } \\
\hline Tensão dos Motores & $24 \mathrm{VCC}$ \\
\hline Consumo Nominal & $5 \mathrm{~A}$ \\
\hline Torque Máximo & $50 \mathrm{Nm}$ \\
\hline Sentido de Giro & Anti-horário \\
\hline Velocidades & 2 \\
\hline Rotações & $22 / 38 \mathrm{rpm}$ \\
\hline Potência Máxima & $65 \mathrm{~W}$ \\
\hline Potência Nominal $\left(\mathrm{P}_{\mathrm{N}}\right)$ & $50 \mathrm{~W}$ \\
\hline Peso & $1300 \mathrm{~kg}$ \\
\hline IP (índice de proteção) & 44 \\
\hline Torque Nominal $\left(\mathrm{M}_{\mathrm{N}}\right)$ & $3 \mathrm{Nm}$ \\
\hline Redução & $\mathrm{I}=77: 1$ \\
\hline
\end{tabular}


Todos esses dispositivos estão conectados a um circuito de condicionamento que por sua vez está conectado ao nó CAN.
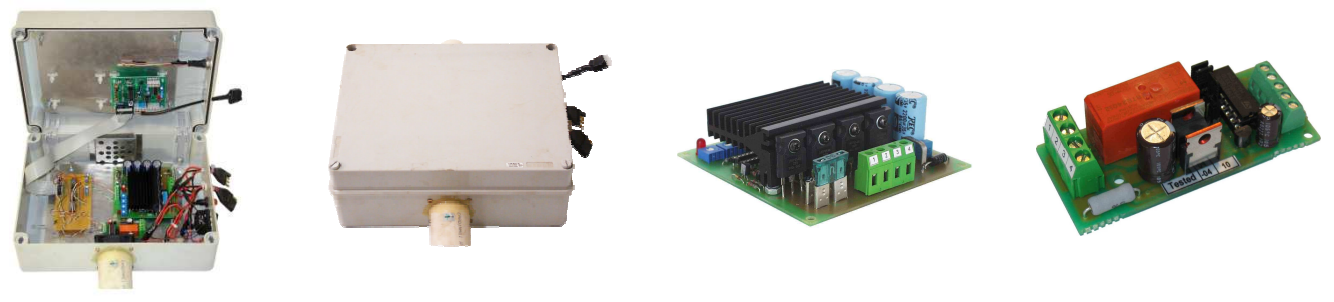

Figura 12 - Conjunto Eletrônico do MGP.

Os principais dispositivos de percepção, computação e atuação possuem posicionamento definido e ilustrado pela Figura 13. Todos os dispositivos serão integrados pela rede CAN embarcada no RAM, sendo que os conjuntos controladores e os computadores fazem parte da rede CAN atualmente.

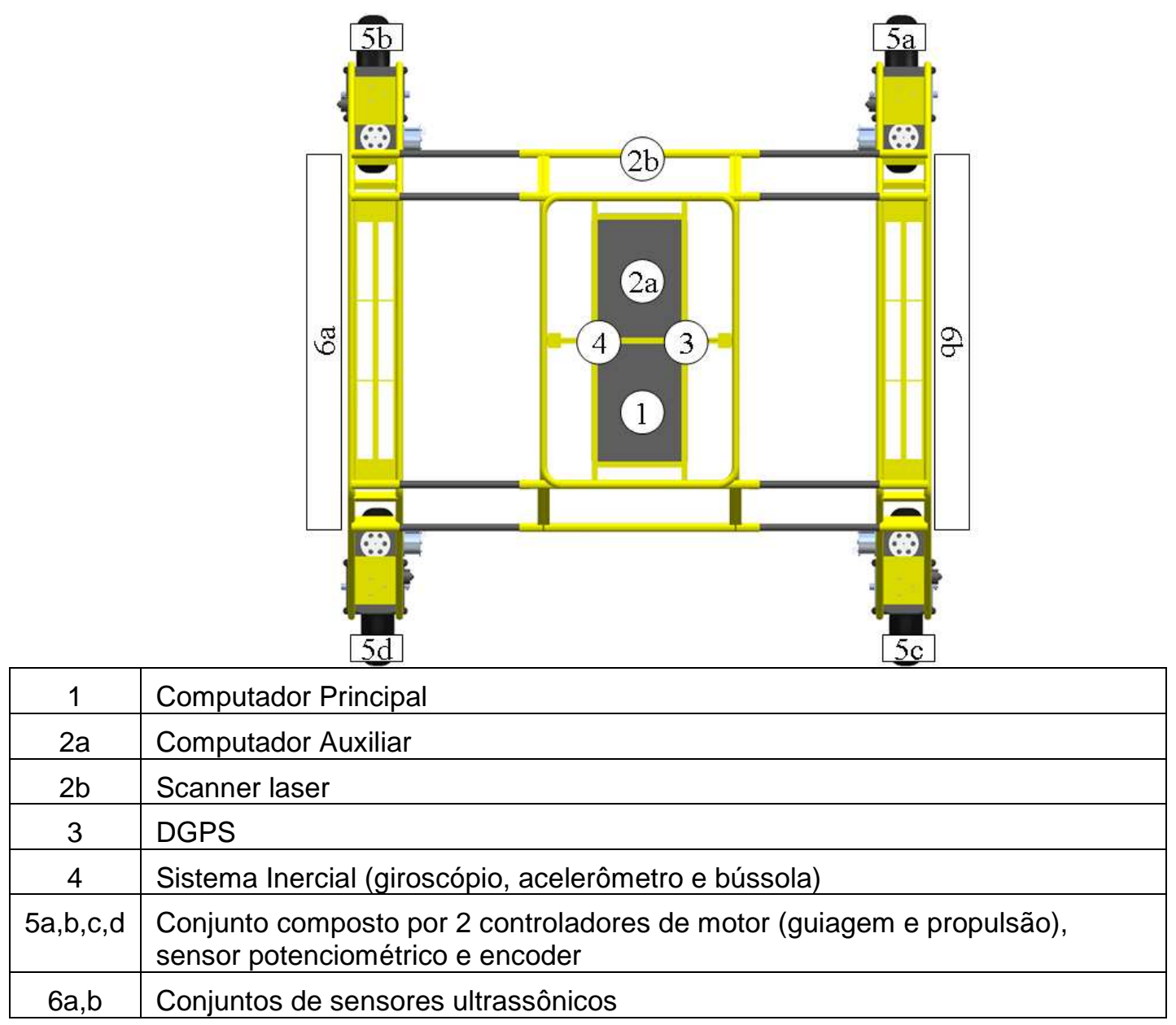

Figura 13 - Vistas da estrutura do VAA ilustrando os dispositivos principais interligados pela rede CAN. (Adaptado de Sousa (2007)). 
Cada dispositivo do módulo de perceptivo listado na Figura 13 está relacionado com uma ou mais funções na arquitetura híbrida para guiagem e navegação como descrito por Sousa (2007).

Os conjuntos $5 a, 5 b, 5 c$ e $5 d$ da Figura 13 contêm os moto-redutores especificados para compor o MGP: motor Bosch modelo GPC (210 W) associado a um redutor Macopema (MACOPEMA, 2004) modelo MC50 (1:25) para propulsão; e um motor-redutor Bosch modelo CPD $(50 \mathrm{~W})$ para guiagem. Esses conjuntos contêm também os controladores dos motores e os sensores de velocidade (encoder) e direção (potenciômetros). Em cada conjunto, os controladores e sensores foram integrados a interface CAN padrão como ilustrado no diagrama na Figura 14.

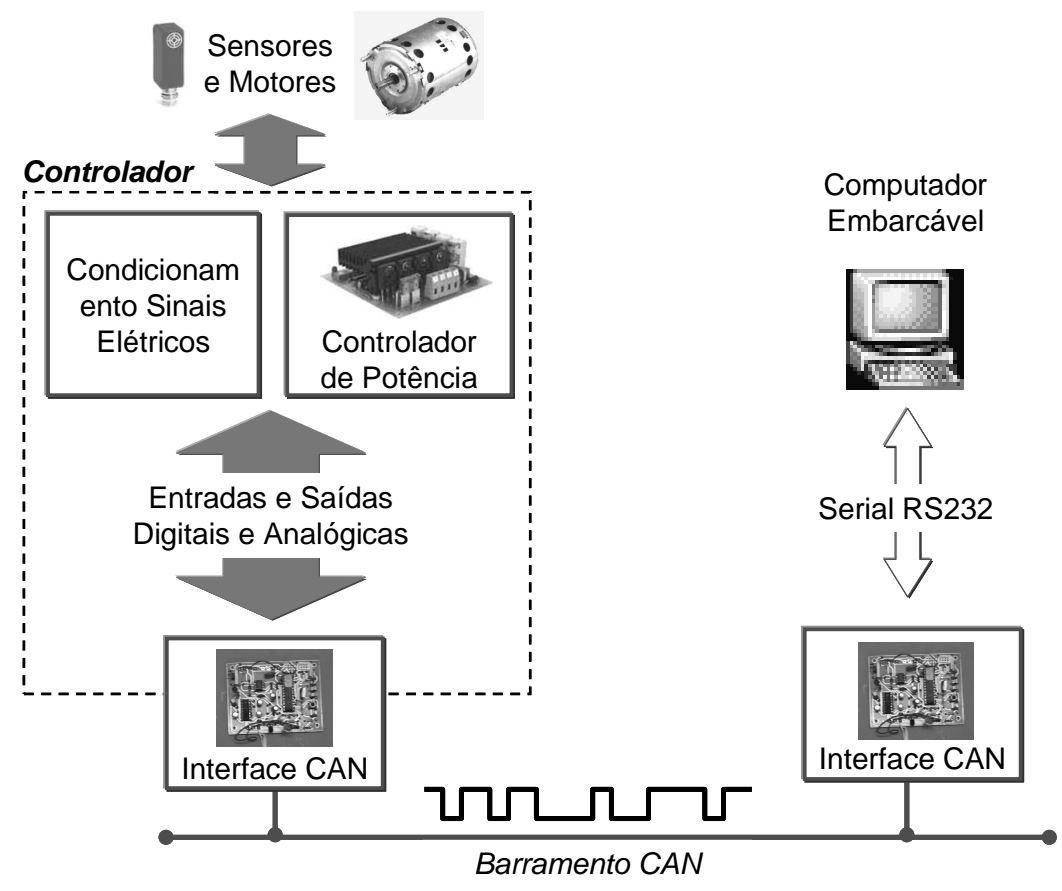

Figura 14 - Rede CAN composta por nó controlador de motor e computador embarcável (Adaptdado de Sousa (2002).

O computador principal, ilustrado na Figura 13 (dispositivo 1) e na Figura 14, será utilizado para processamento dos comportamentos da arquitetura híbrida proposta para controle autônomo de navegação e guiagem, conforme descrito por 
Sousa (2007). Esse computador central utiliza as informações de todos os sensores do módulo de perceptivo e gera comandos para os motores de guiagem e propulsão. A rede CAN permite que além dos dispositivos relacionados com a navegação, os dispositivos para aquisição de dados compartilhem o mesmo barramento. Desta forma, é possível inserção e remoção de forma simples de sensores e de sistemas computacionais que permitem a coleta e armazenamento de dados, assim como o gerenciamento destas atividades.

A interface CAN padrão utilizada para integrar os dispositivos à rede CAN do VAA foi projetada e construída baseando-se na proposta de Sousa (2002).

\subsection{Potenciais de Aplicação do VAA}

O VAA utiliza sensores relativamente sofisticados que exigem treinamento e equipamentos de medida de custo relativamente alto, são equipamentos delicados que exigem cuidados no seu manuseio. Além disso, tais sensores necessitam de fonte externa de energia para o seu funcionamento, conferindo dificuldades para uma pessoa operá-la em campo. Alguns dos sensores que irão compor o VAA podem ser listados: sensores ópticos (medem os espectros visíveis e não visíveis da luz), sensores de ultra-som, sensores a laser, câmeras, sensores de umidade, e eletrodos.

O sensor mais importante previsto para compor ao sistema de monitoramento de parâmetros de interesse agrícola do VAA é o Crop Circle, modelo ACS-210 fabricado por Holland Scientific (2007). Trata-se de um sensor óptico ativo, ele gera sua própria onda modulada a $40.000 \mathrm{~Hz}$ em duas bandas de espectro. Visível (590nm +/-5,5nm) e NIR (Near Infra-Red - Infravermelho Próximo) (880nm +/- 
10nm). Ele mede a porcentagem de luz refletida pelo dossel da plantação, como descrito por Inamasu et al. (2006). Este sensor pode ser empregado para estimar a quantidade clorofila cujo valor é proporcional à disponibilidade de fertilizante nitrogenado no solo para a planta. O sensor trabalha por meio de transdução óptica. A leitura dos dois comprimentos de ondas são convertidos em NDVI=(NIRVis)/(NIR+Vis). O valor de NDVI obtido, por sua vez, é relacionado com a quantidade de clorofila e biomassa da planta.

O VAA foi projetado e equipado para ser um laboratório móvel, pois trata-se de uma aplicação onde seus sensores colhem parâmetros de solo e do dossel de plantas de interesse para a economia brasileira tais como citrus, cana-de-açúcar, café, milho, soja, pastagens e outras. Atualmente, com o estímulo aos programas de desenvolvimento de biocombustíveis, intensifica a necessidade de técnicas para melhorar o desempenho dos processos agrícolas com maior cuidado ao meio ambiente.

Uma possível aplicação de VAA's em citrus é justificável, pois é necessário alcançar lugares de difícil acesso no qual podem ser introduzidos braços e manipuladores mecânicos. Assim, VAA's podem ser usados para levantamento de níveis de infestações de pragas, contagem de ácaros e detecção de fungos como a ferrugem. Destaca-se que neste caso tais sensores podem ser mais sensíveis que os olhos humanos.

Já a cultura de café é caracterizada por estar localizada normalmente em terrenos com alta declividade e difícil acesso. Normalmente o porte de planta exige altura de $2 \mathrm{~m}$ de altura. A cultura de cana-de-açúcar é caracterizada pelo espaçamento de 1,5 m entre suas linhas de plantio, a utilização de VAA neste caso é justificável para detecção de níveis de infestações de plantas e trato cultural que 
pode ser auxiliado com sensores de luz. A soja é uma cultura que pode ser auxiliado para detecção de nematóide e outros e também para o mapeamento de nutrientes absorvidos.

Em todas as possíveis aplicações, após a coleta dos dados obtidos pelo monitoramento do veículo, é necessário o gerenciamento de suas informações e sua correlação com o tempo e sua localização, este processo é conhecido como Georeferenciamento. Todo valor coletado por qualquer tipo de sensor é relacionado ao tempo e à sua respectiva coordenada geográfica no qual são fornecidos por GPS normalmente. Segundo Earl et al. (2000), SIG - Sistema de Informação Geográfica é o termo usado para descrever qualquer sistema baseado em computador que possui capacidade para entrada, armazenamento, manipulação e apresentação de dados que são referenciados geograficamente. A visualização dos dados é normalmente apresentada na forma de mapas.

Este sistema é capaz de manipular e gerenciar grande quantidade de dados coletados de solo e plantações. Isto é de grande importância em sistemas de monitoramento em Agricultura de Precisão, porque exige necessariamente coleção de dados espaciais extensivos com conseqüente aumento no volume de dados que são necessários para ser armazenados se comparados aos dados coletados em escala individual. Ao final de cada atividade de monitoramento é esperada grande quantidade de dados obtidos pelos sensores. SIG também pode ser utilizado em sistemas automáticos de guiagem, porém neste trabalho não iremos abordar este tema.

A primeira tarefa quando se constrói um SIG para operações integradas em campo é realizar o levantamento de dados permanentes, que são os atributos espaciais que não variam em relação ao tempo, nos quais podemos citar: bordas do 
campo, topografia, árvores, valas, morros, lagos, riachos, entre outros. Além disso, atributos semi-permanentes que se mantém estático durante a estação de crescimento tais como bordas da plantação, as ruas de tráfegos e a localização de plantas invasoras.

A viabilidade de ambas as abordagens tem aumentado pelos avanços tecnológicos recentes em posicionamento, sensoriamento e sistemas de controle. Estas tecnologias separadas parecem fornecer as ferramentas necessárias para a adoção das estratégias de gerenciamento de variabilidade espacial em plantações, assumidos por guiagem autônoma (EARL et al.,2000). 


\section{CINEMÁTICA DE ROBÔS MÓVEIS}

Cinemática é o estudo mais básico do comportamento de sistemas mecânicos. Em robôs móveis precisamos entender o comportamento mecânico do robô para projetar robôs móveis apropriados para tarefas e para entender como criar os programas computacionais para aplicação em robôs móveis.

O processo de entendimento do movimento de robôs começa com o processo de descrição da contribuição que cada roda fornece para o movimento. Cada roda tem o papel de permitir o movimento de todo o robô e também impõe restrições ao movimento do robô como, por exemplo, impossibilidade de derrapagem lateral, movimento ao longo do plano da roda entre outros. Deste modo é importante uma notação que possibilita expressar o movimento do robô em um quadro de referência global do robô assim como um sistema de referência local.

A partir da descrição das restrições Cinemáticas individuais das rodas, são combinadas para expressar as restrições Cinemáticas totais do robô. Isto descreve como o robô como um todo move em função de sua geometria e em relação ao comportamento individual da roda. Essas ferramentas podem ser utilizadas para validar os caminhos e trajetórias que definem a manobrabilidade do robô.

A fundamentação teórica apresentada neste capítulo é baseada em Siegwart e Nourbakhsh (2004); Nwokah e Hurmuzlu (2002) e Ge e Lewis (2006). 


\subsection{Representando a Posição do Robô}

Neste processo de análise, o robô é modelado como um corpo rígido sobre rodas, operando num plano horizontal, plano $X-Y$. A quantidade de graus de liberdade do chassi do robô no plano é três, duas para posição no plano e uma para orientação ao longo do eixo vertical, no qual é ortogonal ao plano. Obviamente, existem graus de liberdade adicionais e elasticidade devido aos eixos das rodas, juntas de direcionamento das rodas, e juntas de esterçamento, e juntas de rodas castor (castor wheels). As rodas castor podem esterçar em relação a um eixo vertical, mas diferente das rodas padrões fixas o eixo vertical de rotação não passa pelo ponto de contato com o chão Entretanto, considerando o chassi do robô referese somente ao corpo rígido do robô, ignorando as juntas e graus de liberdade internos para o robô e suas juntas.

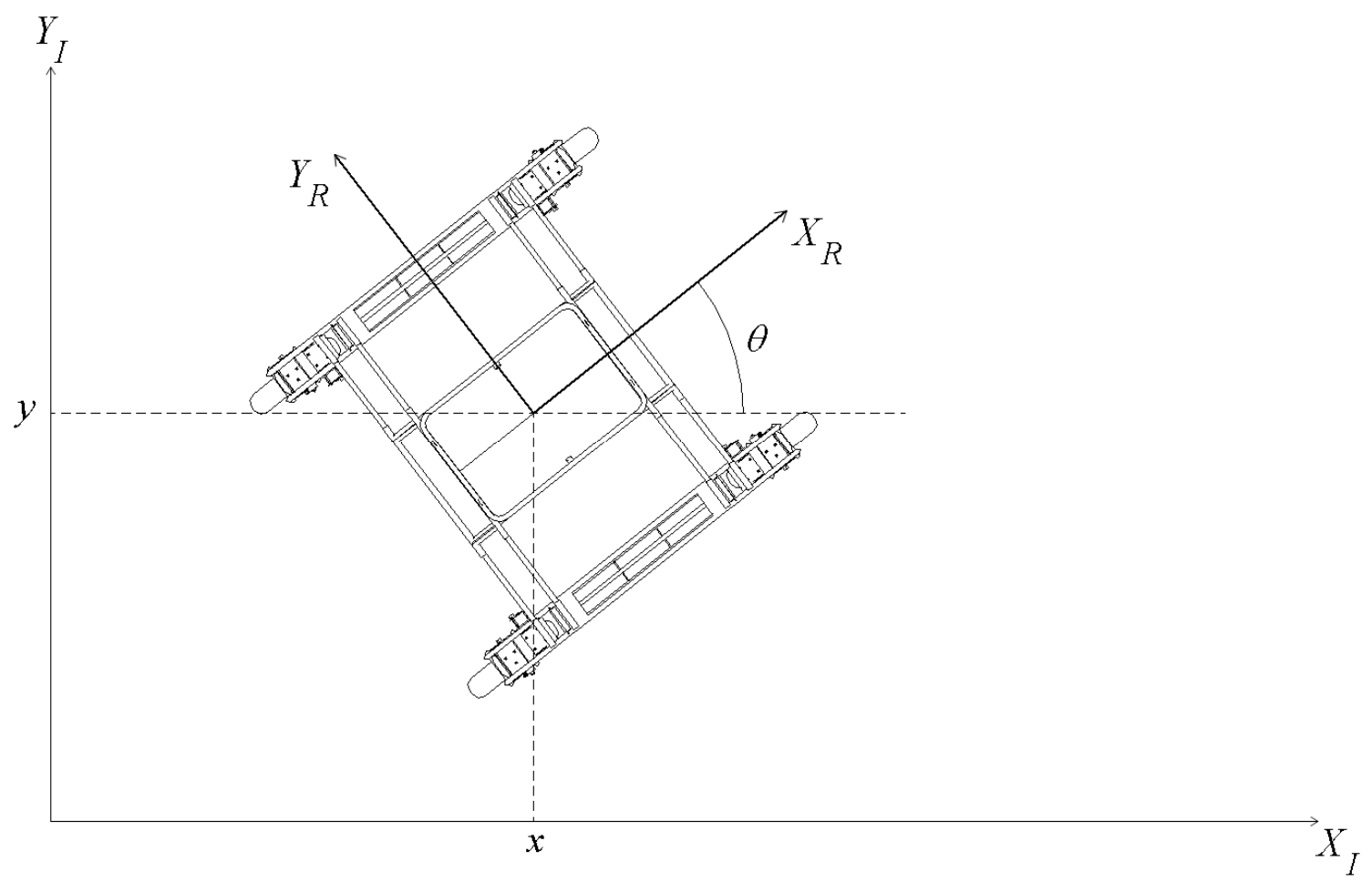

Figura 15 - Quadro de referência global e quadro de referência local do robô. 
A fim de especificar a posição do robô no plano é estabelecida uma relação entre o quadro de referência global do plano e o quadro de referência local do robô, como na Figura 15. Os eixos $X_{1}$ e $Y_{1}$ definem uma base inercial arbitrária no plano como no quadro de referência global de uma origem $\mathrm{O}:\left\{X_{1}, Y_{1}\right\}$. Para especificar a posição do robô, é escolhido um ponto $\mathrm{P}$ no chassi do robô e seu ponto de posição de referência. $A$ base $\left\{X_{R}, X_{R}\right\}$ define dois eixos relativos à $P$ no chassi do robô e consequentemente o quadro de referência local. A posição de $P$ no quadro de referência global é especificada pelas coordenadas $\mathrm{x}$ e y e a diferença angular entre o quadro de referência global e o local é dado por $\theta$. A posição do robô é descrita como um vetor com três elementos. $O$ uso do subscrito $I$ é para identificar a base da posição como quadro de referência global.

$$
\xi_{I}=\left[\begin{array}{l}
x \\
y \\
\theta
\end{array}\right]
$$

O mapeamento do movimento ao longo do quadro de referência global para o quadro de referência local no plano $X-Y$ é alcançado usando a matriz rotacional ortogonal:

$$
R(\theta)=\left[\begin{array}{ccc}
\cos \theta & \operatorname{sen} \theta & 0 \\
-\operatorname{sen} \theta & \cos \theta & 0 \\
0 & 0 & 1
\end{array}\right]
$$

Esta matriz pode ser usada para mapear o movimento no quadro de referência global $\left\{X_{I}, Y_{I}\right\}$ para o movimento em relação ao quadro de referência local $\left\{\mathrm{X}_{\mathrm{R}}, \mathrm{Y}_{\mathrm{R}}\right\}$. Esta operação é denotada por $R(\theta) \dot{\xi}_{I}$ porque o cálculo dessa operação depende do valor de $\theta$ :

$$
\xi_{R}^{\&}=R(\theta) \xi_{I}^{\&}
$$




\subsection{Restrições Cinemáticas da Roda.}

Representar as restrições de movimento de cada roda de um robô é o primeiro passo para representar o modelo Cinemático do robô. Os movimentos individuais das rodas podem ser mais tarde combinados para formar o movimento do robô como um todo.

São apresentadas as equações que descrevem as restrições no plano da roda e as equações que descrevem restrições no plano ortogonal da roda. Assumese que o plano da roda sempre permanece vertical e que em todos os casos há um único ponto de contato entre a roda e o chão. Além disso, assume-se que não existe escorregamento neste único ponto de contato, ou seja, a roda move sob condições de puro rolamento e rotação em torno de seu eixo vertical por meio do ponto de contato.

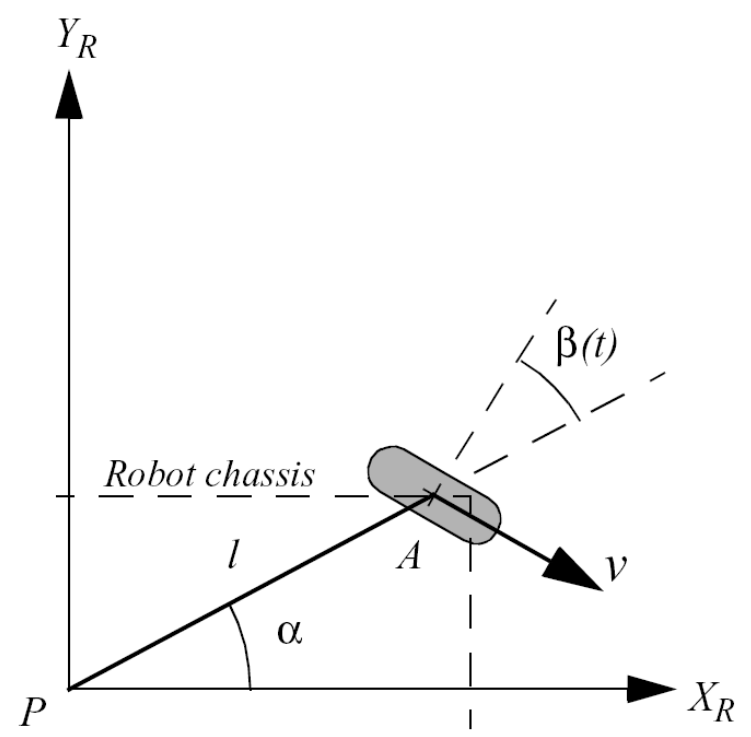

Figura 16 - Parâmetros da roda padrão esterçável. Adaptado de Siegwart e Nourbakhsh (2004). As equações (3.4) e (3.5) se referem às rodas padrões fixas e esterçáveis. Rodas padrões são aquelas que seu eixo de rotação vertical passa pelo ponto de contato da roda com o chão. A diferença da roda padrão esterçável para roda 
padrão fixa é que ela possui um grau de liberdade adicional, a roda pode girar em torno do eixo vertical z. As equações das rodas padrões fixas e esterçáveis são idênticas mas com uma exceção. No caso da roda padrão esterçável, a orientação da roda em relação ao chassi do robô não é um ângulo com valor fixo $\beta$, mas um valor que varia em função do tempo $\beta(t)$. A Figura 16 mostra os parâmetros das rodas padrões esterçáveis, no caso da roda padrão fixa $\beta(t)$ é substituído por $\beta$.

A equação (3.4) descreve o movimento no plano da roda:

$$
[\operatorname{sen}(\alpha+\beta)-\cos (\alpha+\beta) \quad(-l) \cos \beta] R(\theta) \xi_{I}-r \phi k=0
$$

A equação (3.5) descreve a restrição perpendicular ao plano da roda:

$$
[\cos (\alpha+\beta) \quad \operatorname{sen}(\alpha+\beta) \quad l \operatorname{sen} \beta] R(\theta)=0
$$

\subsection{Restrições Cinemáticas de Robôs}

As rodas podem impor nenhuma ou mais restrições no movimento do robô, o processo é então o de combinar apropriadamente todas as restrições vindas de todas as rodas baseado no arranjo destas rodas no chassi do robô. Adota-se que $N$ seja o número total de rodas padrões, compreendendo $N_{f}$ o número de rodas padrões fixas, e $N_{s}$ o número de rodas padrões esterçáveis. $\beta_{s}(t)$ é usado para denotar os ângulos variáveis de esterçamento das $N_{s}$ rodas padrões esterçáveis. Em contraste, $\beta(f)$ se refere à orientação das $N_{f}$ rodas fixas padrões. No caso do giro de ambas as rodas fixas e esterçáveis possuem posições rotacionais em torno de seus eixos horizontais que varia em função do tempo. Denotam-se os casos de 
rodas fixas e esterçáveis separadamente com $\varphi_{f}(t)$ e $\varphi_{s}(t)$, e $\varphi(t)$ é uma matriz agregada que combinam ambos os valores:

$$
\phi(t)=\left[\begin{array}{l}
\phi_{f}(t) \\
\phi_{s}^{\&}(t)
\end{array}\right]
$$

As restrições de rolamento de todas as rodas podem ser coletadas a partir de uma única expressão:

$$
J_{1}\left(\beta_{s}\right) R(\theta) \xi_{I}^{\&}-J_{2} \phi=0
$$

Onde $J_{2}$ é uma matriz $N \times N$ composta pelos raios das rodas padrões. $J_{1}\left(\beta_{s}\right)$ denota a matriz de projeção de todas as rodas em seus movimentos ao longo de seus planos individuais de roda:

$$
J_{1}\left(\beta_{s}\right)=\left[\begin{array}{c}
J_{1 f} \\
J_{1 s}\left(\beta_{s}\right)
\end{array}\right]
$$

Em resumo a equação (3.7) representa a restrição que todas as rodas padrões devem girar em torno de seu eixo horizontal com a quantidade apropriada baseado em seus movimentos ao longo do plano da roda de modo que o rolamento aconteça no ponto de contato do chão.

A mesma técnica é adotada para coletar as restrições de escorregamento de todas as rodas padrões em uma única expressão com a mesma estrutura que a equação (3.5).

$$
C_{1}\left(\beta_{s}\right) R(\theta) \xi \xi_{I}^{\&}=0
$$

Onde, 


$$
C_{1}\left(\beta_{s}\right)=\left[\begin{array}{c}
C_{1 f} \\
C_{1 s}\left(\beta_{s}\right)
\end{array}\right]
$$

\subsection{Manobrabilidade de Robôs Móveis}

A mobilidade Cinemática do chassi de um robô é a habilidade de se mover diretamente no ambiente. A restrição básica que limita mobilidade é a lei que cada roda deve satisfazer suas restrições de escorregamento. Portanto, é possível formalmente derivar a mobilidade do robô começando pela equação (3.9).

Em relação ao movimento Cinemático instantâneo, um robô móvel é capaz de manipular sua posição em relação ao tempo, pelo esterçamento de suas rodas. A manobrabilidade total de um robô é então a combinação da mobilidade disponível baseado nas restrições Cinemáticas de escorregamento das rodas padrões mais a liberdade adicional contribuída pelo esterçamento e rotação das rodas esterçáveis padrões.

\subsubsection{Grau de Mobilidade}

Equação (3.9) impõe a restrição que cada roda deve evitar qualquer escorregamento lateral. É possível especificar esta restrição separadamente para rodas padrões fixas e esterçáveis.

$$
\begin{gathered}
C_{1 f} R(\theta) \xi_{I}^{\&}=0 \\
C_{1 s}\left(\beta_{S}\right) R(\theta) \xi_{I}^{\&}=0
\end{gathered}
$$


Para que ambas estas restrições sejam satisfeitas, o vetor de movimento $R(\theta) \xi_{I}^{\&}$ deve pertencer ao espaço nulo da matriz de projeção, que é simplesmente uma combinação de $C_{1 f}$ e $C_{1 s}$. Matematicamente, o espaço nulo é o espaço $\mathrm{N}$ tal que qualquer vetor $\mathrm{n}$ no $\mathrm{N}, C_{1}\left(\beta_{S}\right) n=0$. Se as restrições Cinemáticas precisam ser satisfeitas, então o movimento do robô deve sempre estar dentro deste espaço N. As restrições Cinemáticas podem também ser demonstradas geometricamente usando o conceito de centro de rotação instantâneo (CRI).

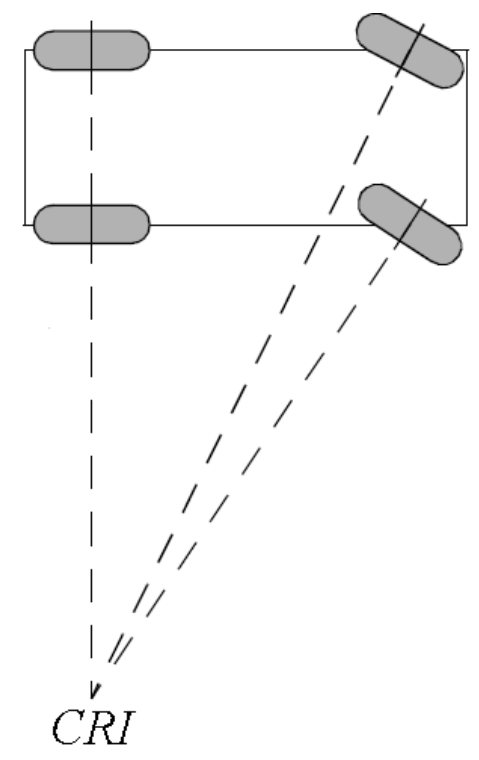

Figura 17 - Centro Instantâneo de Rotação - CRI. Adaptado de Siegwart e Nourbakhsh (2004).

Considere uma única roda padrão. Ela é forçada pela restrição de escorregamento em não ter movimento lateral. Isto pode ser mostrado geometricamente desenhando uma linha de movimento zero através do seu eixo horizontal, perpendicular ao plano da roda conforme mostrado na Figura 17. A qualquer dado instante, o movimento da roda ao longo da linha de movimento zero deve ser zero. Em outras palavras, a roda deve estar se movendo instantaneamente ao longo de alguns círculos de raio $\mathrm{R}$ de tal maneira que o centro deste círculo esteja localizado na linha de movimento zero. Este ponto central, chamado de centro 
de rotação instantâneo, pode permanecer em qualquer lugar ao longo da linha de movimento zero. Quando R está no infinito, a roda move-se em linha reta.

No caso de um robô como o Ackerman, (Figura 17) pode ter várias rodas, mas deve sempre ter um único CRI. Por causa de todas as linhas de movimento zero encontram um único ponto, existe somente uma solução para o movimento do robô, colocando o $\mathrm{CRI}$ neste ponto de encontro.

A construção geométrica deste $\mathrm{CRI}$ demonstra como a mobilidade do robô é função do número de restrições no movimento do robô, não no número de rodas. O veículo Ackerman da Figura 17 demonstra outra maneira no qual uma roda pode ser incapaz de contribuir com uma restrição independente para a Cinemática do robô. Este veículo possui duas rodas padrões esterçáveis. Dado a posição instantânea de somente uma destas rodas esterçáveis e a posição das rodas fixas traseiras há somente uma única solução para o CRI. A posição da segunda roda esterçável é absolutamente restrita pelo $\mathrm{CRI}$. Portanto, ela oferece nenhuma restrição para o movimento do robô.

A Cinemática do chassi do robô é, portanto uma função do conjunto de restrições independentes resultantes de todas as rodas padrões. A interpretação matemática de independência está relacionada ao posto da matriz. O posto da matriz é o menor número de colunas ou linhas independentes. Equação (3.9) representa todas as restrições de escorregamento impostas pelas rodas dos robôs móveis. Portanto posto $\left[C_{1}\left(\beta_{S}\right)\right]$ é o menor número de restrições independentes.

Quanto maior o número de restrições independentes e, portanto maior o número de posto de $C_{1}\left(\beta_{S}\right)$, mais restrito está à mobilidade do robô.

É possível, portanto identificar a variação possível dos valores de posto para qualquer robô: $0 \leq \operatorname{posto}\left[C_{1}\left(\beta_{S}\right)\right] \leq 3$. No caso em que posto $\left[C_{1}\left(\beta_{S}\right)\right]=0$, este somente 
é possível se não existem restrições Cinemáticas independentes em $C_{1}\left(\beta_{S}\right)$. Neste caso não existem nem rodas padrões fixas ou esterçáveis. No outro extremo, quando posto $\left[C_{1}\left(\beta_{S}\right)\right]=3$, que o máximo posto possível desde que as restrições Cinemáticas são especificadas para o caso de 3 graus de liberdade (a matriz de restrição possui 3 colunas). Portanto, não pode ter mais que três restrições independentes. Quando posto $\left[C_{1}\left(\beta_{S}\right)\right]=3$, o robô está completamente restrito em todas as direções.

O grau de mobilidade é definido como $\delta_{m}$ :

$$
\delta_{m}=\operatorname{dim} N\left[C_{1}\left(\beta_{S}\right)\right]=3-\operatorname{posto}\left[C_{1}\left(\beta_{S}\right)\right]
$$

A dimensão do espaço nulo $(\operatorname{dim} N)$ da matriz $C_{1}\left(\beta_{S}\right)$ é uma medição do número de graus de liberdade do chassi do robô que pode ser imediatamente manipulado através de mudanças na velocidade da roda. Portanto $\delta_{m}$ deve variar entre 0 e 3.

\subsubsection{Grau de Habilidade de Esterçamento}

O grau de mobilidade quantifica os graus de liberdade controláveis baseado nas mudanças de velocidade da roda. Esterçamento pode também ter impacto eventual na posição do chassi $\xi$, embora o impacto seja indireto porque depois de mudar o ângulo de uma roda esterçável padrão, o robô deve mover para que a mudança no ângulo de esterçamento possa ter impacto na posição.

Como em mobilidade, é importante o número de parâmetros de esterçamento controláveis independentemente quando definindo o grau de habilidade de esterçamento $\delta_{s}$. 


$$
\delta_{S}=p o s t o\left[C_{1 S}\left(\beta_{S}\right)\right]
$$

No caso de mobilidade, um aumento no posto de $C_{1}\left(\beta_{S}\right)$ implica em mais restrições Cinemáticas e então, menor será a mobilidade do sistema. No caso de habilidade de esterçamento, um aumento no posto de $C_{1 S}\left(\beta_{S}\right)$ implica em mais graus de liberdade de esterçamento e então maior manobrabilidade eventual. Desde que $C_{1}\left(\beta_{S}\right)$ inclua $C_{1 S}\left(\beta_{S}\right)$, isto quer dizer que uma roda direcional padrão pode diminuir a mobilidade e aumentar a habilidade de esterçamento: sua orientação a qualquer instante impõe uma restrição Cinemática, mas sua habilidade de mudar esta direção pode levar em trajetórias adicionais.

A variação de $\delta_{S}$ pode ser especificada: $0 \leq \delta_{S} \leq 2$. O caso em que $\delta_{S}=0$ implica que o robô não possui rodas padrões esterçáveis, $N_{S}=0$. O caso que $\delta_{S}=1$ é mais comum quando a configuração do robô inclui uma ou mais rodas esterçáveis padrões.

\subsubsection{Manobrabilidade de Robôs}

O total de graus de liberdade que um robô pode manipular, chamado grau de manobrabilidade $\delta_{M}$, pode ser definido em termo de mobilidade e habilidade de esterçamento:

$$
\delta_{M}=\delta_{m}+\delta_{S}
$$

Portanto, manobrabilidade inclui os graus de liberdade que o robô manipula diretamente por meio da velocidade da roda e os graus de liberdade que ele manipula indiretamente mudando a configuração de esterçamento e movendo. 
Baseado nas investigações das seções anteriores pode projetar tipos básicos de configurações de roda.

Pode ocorrer que dois robôs com o mesmo $\delta_{M}$ não sejam necessariamente equivalentes.

\section{5. Área de Trabalho de Robôs Móveis}

Para um determinado robô, manobrabilidade é equivalente aos seus graus de liberdade de controle. Mas a questão é situar a análise em sua área de trabalho. É importante focar nos caminhos no qual o robô pode usar seus graus de liberdade de controle a fim de se posicionar no ambiente. No caso do veículo Ackerman, ou automóvel. O número total de graus de liberdade de controle para tal veículo é $\delta_{M}=2$, um para esterçamento e o segundo para atuação nas rodas de tração. Mas na verdade o número de graus de liberdade do veículo neste ambiente é três: o carro pode se posicionar por si próprio no plano em qualquer ponto $\mathrm{x}$, y e com qualquer ângulo $\theta$.

Então a identificação dos espaços possíveis de configurações do robô é importante por que ele pode ultrapassar $\delta_{M}$. Além disso, em área de trabalho, levase em conta como o robô é capaz de se mover entre várias configurações nos quais são os tipos de caminhos que ele pode seguir e, além disso, quais são as trajetórias possíveis através de seu espaço de configurações.

\subsubsection{Graus de Liberdade}


No processo de definição da área de trabalho de um robô, é útil primeiro examinar seu espaço de velocidades admissíveis. Dado as restrições cinemáticas do robô, seu espaço de velocidade descreve as componentes independentes do movimento do robô que o robô pode controlar.

O número de dimensões no espaço de velocidade de um robô é o número de velocidades alcançáveis independentemente. Também chamado de grau de liberdade diferenciável (GDLD). O GDLD de um robô sempre é igual ao seu grau de mobilidade $\delta_{m}$.

Em linhas gerais o grau de liberdade (GDL) governa a habilidade do robô em alcançar várias posições e o GDLD governa a habilidade do robô em alcançar vários caminhos na área de trabalho.

\subsubsection{Robôs Holonômicos}

O termo holonômico possui ampla aplicação em diversas áreas na matemática, incluindo equações diferenciais, funções e expressões de restrições. Em robótica móvel, o termo se refere especificamente a restrições cinemáticas do chassi do robô. Um robô holonômico é um robô que não possui restrições Cinemáticas não-holonômicas. Por sua vez uma restrição cinemática nãoholonômica pode ser expressa como uma função explícita somente das variáveis de posição. Um exemplo clássico de restrição não-holonômica é aquela apresentada pelos automóveis que não podem ser deslocar instantaneamente na direção perpendicular de suas rodas. As rodas padrões fixas e esterçáveis impõe restrições não-holômicas. 


\subsection{Cinemática do VAA}

Neste projeto deste VAA foi proposta inicialmente uma modelagem cinemática simplificada para um veículo com esterçamento somente nas rodas dianteiras. Ressalta-se que ele foi projetado esterçar as quatro rodas independentemente, sendo necessária a inclusão dos sistemas de guiagem e do conjunto eletrônico responsável pelo acionamento de tais motores. Foi feito uma modelagem em plano $X-Y$ para este robô, pelos seguintes motivos: o veículo foi desenvolvido para operar em velocidades baixas, até $3 \mathrm{~m} / \mathrm{s}$; e o veículo não possui sistema de suspensão. A partir desta condição de baixa velocidade de operação é assumido que acelerações deste veículo não irá influenciar de modo significativo seu comportamento.

Canale (1989) descreve o comportamento de rodas rígidas e elásticas em autoveículos. Além disso, descreve o comportamento de solos ou pavimentos como sendo rígidos, elásticos e plásticos. Balastreire (1990) descreve o comportamento mecânico de solos e sua interação com pneus em máquinas agrícolas. Entretanto neste projeto, as rodas foram consideradas como corpos rígidos, não ocorrem desgastes dos pneus e a sua rolagem acontece somente em um único ponto de contato com o solo. Forças de resistências ao rolamento foram desconsideradas. Além disso, as propriedades dinâmicas do solo foram simplificadas e o solo foi idealizado como rígido. Porém ressalta-se que estas simplificações foram feitas por que o desenvolvimento da plataforma está ainda em estágio primário de desenvolvimento e o veículo opera em baixa velocidade. 


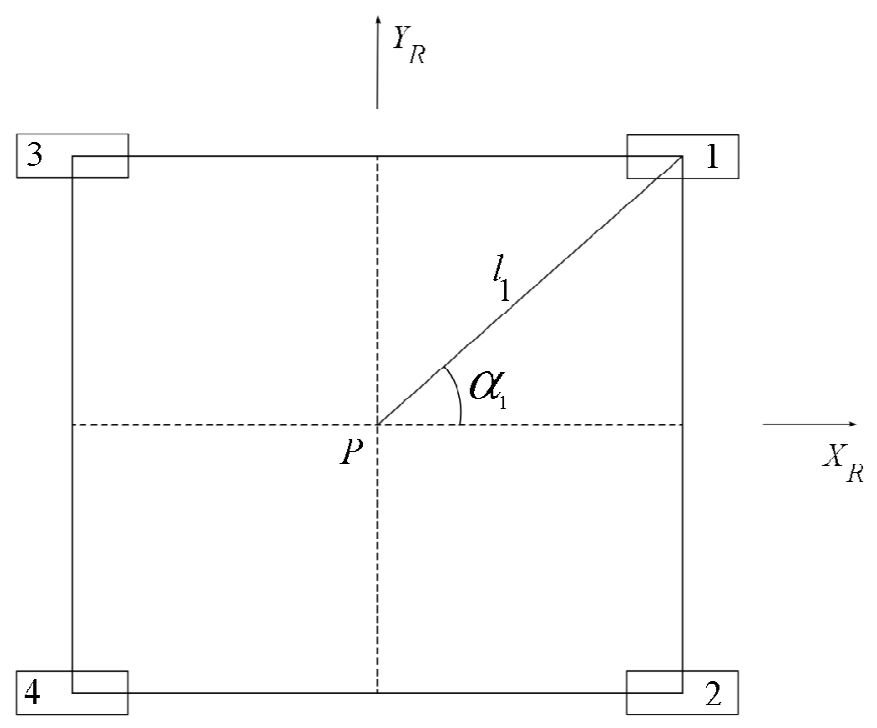

Figura 18 - Descrição da Geometria do VAA.

A Tabela 3 fornece os parâmetros da geometria do robô. O ponto $P$ está localizado no centro geométrico da figura. Como o robô é redimensionável em relação a distância entre as suas rodas, esta variação de parâmetros influencia nas características cinemáticas do robô.

Tabela 3 - Características Geométricas do VAA com abertura máxima e mínima.

\begin{tabular}{|c|c|c|}
\hline & Abertura Máxima $(2,2 \mathrm{~m})$ & Abertura Mínima (1,4 m) \\
\hline Distância $l$ & $1,5 \mathrm{~m}$ & $1,2 \mathrm{~m}$ \\
\hline Número de rodas fixas $\left(N_{f}\right)$ & 2 & 2 \\
\hline Número de rodas móveis $\left(N_{s}\right)$ & 2 & 2 \\
\hline Ângulo entre roda 1 e centro $\mathrm{P}\left(\alpha_{1}\right)$ & $46,95^{\circ}$ & $34,27^{\circ}$ \\
\hline Ângulo entre roda 2 e centro $\mathrm{P}\left(\alpha_{2}\right)$ & 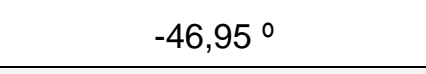 & $-34,27^{\circ}$ \\
\hline Ângulo entre roda 3 e centro $\mathrm{P}\left(\alpha_{3}\right)$ & $133,03 \stackrel{\circ}{\circ}$ & $145,72^{\circ}$ \\
\hline Ângulo entre roda 4 e centro $\mathrm{P}\left(\alpha_{4}\right)$ & $-133,03 \stackrel{0}{0}$ & $-145,72 \stackrel{\circ}{\circ}$ \\
\hline
\end{tabular}

As rodas 1 e 2 são rodas padrões esterçáveis e possuem ângulos de direção variáveis $\beta_{1 s}$ e $\beta_{2 s}$ respectivamente. As rodas 3 e 4 são rodas padrões fixas e possuem ângulos de direção fixos $\beta_{3}$ e $\beta_{4}$ respectivamente. As rodas possuem raio externo de $660 \mathrm{~mm}$. 


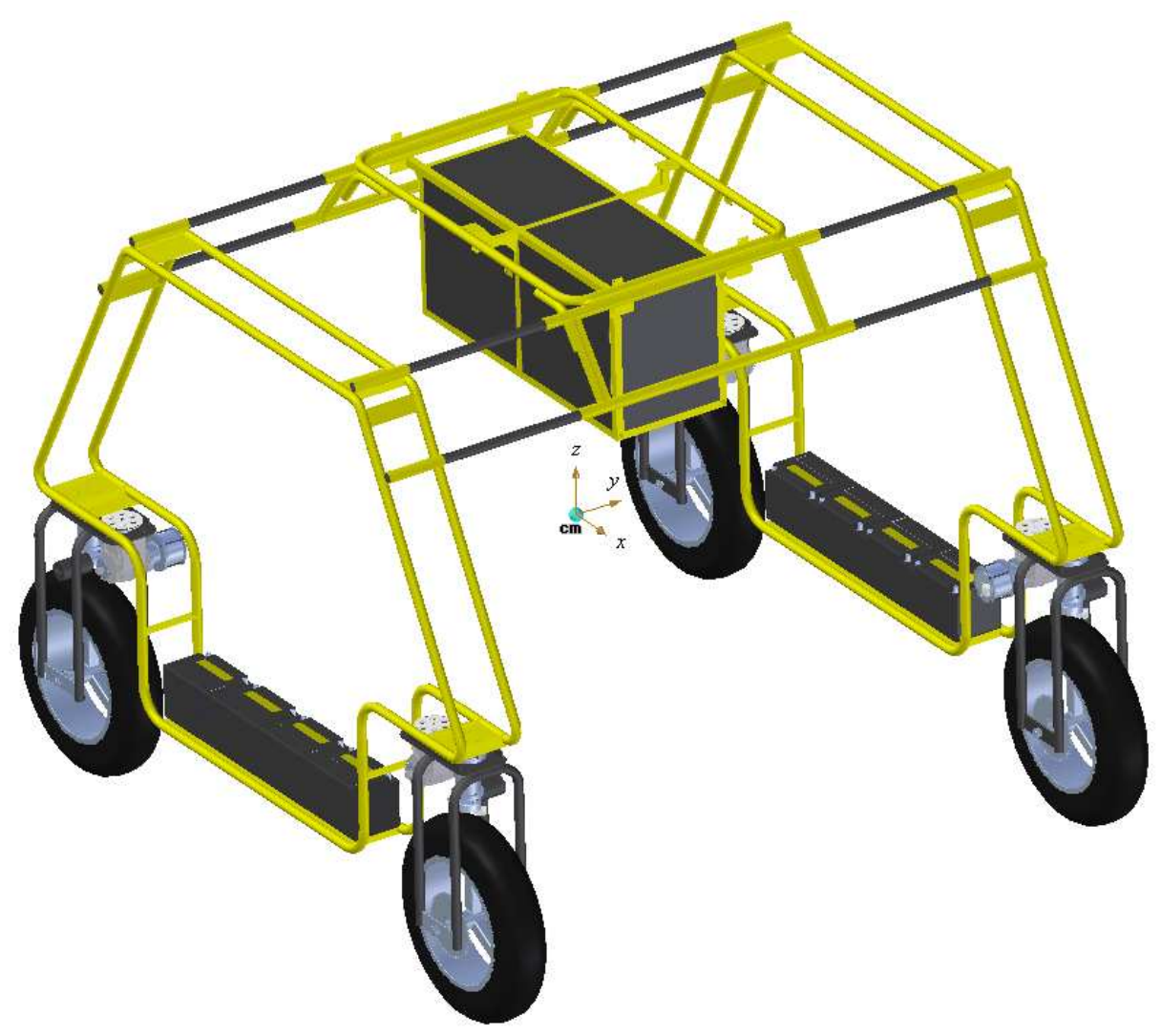

Figura 19 - Posição do Centro de Massa do VAA.

A partir da Figura 19 pode-se verificar a posição relativa do Centro de Massa (CM) do VAA. O CM foi calculado a partir do programa Solid Edge. A posição do $\mathrm{CM}_{\mathrm{z}}$ (vertical em relação ao plano formado pelos pontos de contato dos pneus com o chão) é de $0,89 \mathrm{~m}$, as demais componentes de CM não são significativas e podem ser consideradas que estão no centro geométrico do veículo.

A matriz (3.16) define as equações de movimento das quatro rodas em relação ao plano da roda (condição de rolagem pura de todas as quatro rodas). A matriz (3.17) define as equações de restrição de movimento em relação ao plano perpendicular da roda (condição de não escorregamento), conforme descrito no item 3.3. 


$$
J_{1}(\beta)_{S}=\left[\begin{array}{c}
J_{1} f_{4} \\
J_{1} f_{3} \\
J_{1}\left(\beta_{S_{2}}(t)\right) \\
J_{1}\left(\beta_{S_{1}}(t)\right)
\end{array}\right]=\left[\begin{array}{ccc}
\operatorname{sen}\left(\alpha_{4}+\beta_{4}\right) & -\cos \left(\alpha_{4}+\beta_{4}\right) & (-l) \cos \left(\beta_{4}\right) \\
\operatorname{sen}\left(\alpha_{3}+\beta_{3}\right) & -\cos \left(\alpha_{3}+\beta_{3}\right) & (-l) \cos \left(\beta_{3}\right) \\
\operatorname{sen}\left(\alpha_{2}+\beta_{S_{2}}(t)\right) & -\cos \left(\alpha_{2}+\beta_{S_{2}}(t)\right) & (-l) \cos \left(\beta_{S_{2}}(t)\right) \\
\operatorname{sen}\left(\alpha_{1}+\beta_{S_{1}}(t)\right) & -\cos \left(\alpha_{1}+\beta_{S_{1}}(t)\right) & (-l) \cos \left(\beta_{S_{1}}(t)\right)
\end{array}\right]
$$

$$
C_{1}(\beta)_{S}=\left[\begin{array}{c}
C_{1 f 4} \\
C_{1 f 3} \\
C_{1}\left(\beta_{S_{2}}(t)\right) \\
C_{1}\left(\beta_{S_{1}(t)}\right)
\end{array}\right]=\left[\begin{array}{ccc}
\cos \left(\alpha_{4}+\beta_{4}\right) & \operatorname{sen}\left(\alpha_{4}+\beta_{4}\right) & l \cdot \operatorname{sen}\left(\beta_{4}\right) \\
\cos \left(\alpha_{3}+\beta_{3}\right) & \operatorname{sen}\left(\alpha_{3}+\beta_{3}\right) & l \cdot \operatorname{sen}\left(\beta_{3}\right) \\
\cos \left(\alpha_{2}+\beta_{S_{2}}(t)\right) & \operatorname{sen}\left(\alpha_{2}+\beta_{S_{2}}(t)\right) & l \cdot \operatorname{sen}\left(\beta_{S_{2}}(t)\right) \\
\cos \left(\alpha_{1}+\beta_{S_{1}}(t)\right) & \operatorname{sen}\left(\alpha_{1}+\beta_{S_{1}}(t)\right) & l \cdot \operatorname{sen}\left(\beta_{S_{1}}(t)\right)
\end{array}\right]
$$

A matriz de transformação é dada pelo item 3.1.

$$
R(\theta)=\left[\begin{array}{ccc}
\cos \theta & \operatorname{sen} \theta & 0 \\
-\operatorname{sen} \theta & \cos \theta & 0 \\
0 & 0 & 1
\end{array}\right]
$$

A partir do item 3.3 e considerando rotação igual nas rodas traseiras, temos:

$$
J_{2} \phi=\left[\begin{array}{c}
r \phi_{4} \\
r \phi_{3} \\
r \phi_{2} \\
r \phi_{1}
\end{array}\right]=\left[\begin{array}{c}
r \phi_{5} \\
r \phi_{5} \\
r \phi_{2} \\
r \phi_{1}
\end{array}\right]
$$

Onde r é o raio externo de todas as rodas. Da equação (3.16), verifica-se que $J_{1 f 4}$ e $J_{1 f 3}$ são linearmente dependentes para qualquer configuração do chassi e, portanto fornece apenas uma equação para (3.16).Isto acontece porque ambas as 
rodas fixas, 3 e 4, compartilham o mesmo eixo de rotação horizontal igual as rodas traseiras de um veículo Ackerman como pode ser visto pela Figura 17.

A partir da equação (3.7) e considerando a condição da equação (3.19), escolhendo as equações da roda 3 em (3.16) de modo arbitrário (condição de independência linear), temos:

$$
\left[\begin{array}{ccc}
\operatorname{sen}\left(\alpha_{3}+\beta_{3}\right) & -\cos \left(\alpha_{3}+\beta_{3}\right) & (-l) \cos \left(\beta_{3}\right) \\
\operatorname{sen}\left(\alpha_{2}+\beta_{S_{2}}(t)\right) & -\cos \left(\alpha_{2}+\beta_{S_{2}}(t)\right) & (-l) \cos \left(\beta_{S_{2}}(t)\right) \\
\operatorname{sen}\left(\alpha_{1}+\beta_{S_{1}}(t)\right) & -\cos \left(\alpha_{1}+\beta_{S_{1}}(t)\right) & (-l) \cos \left(\beta_{S_{1}}(t)\right)
\end{array}\right] R(\theta) \xi_{I}^{*}=\left[\begin{array}{c}
r \notin \alpha \\
r \& \& \\
r \phi k
\end{array}\right](3 .
$$

Multiplicando ambos os lados de (3.20) pela matriz $J_{1}(\beta)_{S}{ }^{-1}$ resultante das condições descritas no parágrafo acima e depois multiplicando o restante em ambos os lados por $R(\theta)^{-1}$, temos:

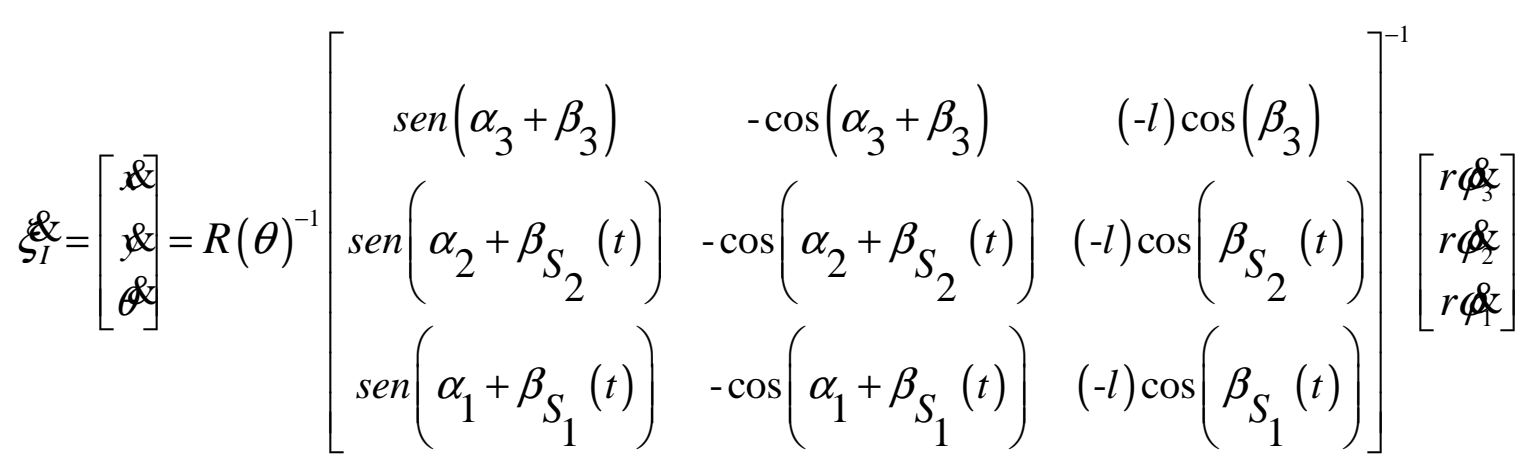

A partir da leitura dos sensores de posição (encoders) das rodas 1 e 2 (ângulo de direção), velocidade angular das rodas e posição relativa (GPS) é possível descrever o comportamento cinemático do modelo utilizando a equação (3.21) a cada instante desejado. 
Trabalhos que utilizam modelagem cinemática em veículos com sistema de mobilidade melhorada.

Existem diferentes tipos e configurações de robôs móveis. Neste trabalho procurou-se revisar a abordagem de modelagem Cinemática de robôs móveis destinados ao uso em ambientes agrícolas e também robôs móveis que foram desenvolvidos para atuar em ambientes fora de estrada, incluindo operações planetárias no quais todos estes apresentam a característica de trabalho em ambientes abertos, dinâmicos, pouco estruturados e com terrenos irregulares. As configurações das rodas desses robôs foram projetadas para operar adequadamente em tais ambientes. Neste contexto o robô foi projetado inicialmente sob a óptica relativamente simples no que se refere a sua modelagem Cinemática pelos fatores apresentados no item 3.6. Entretanto ele foi projetado como uma plataforma modular como descrito no item 2.2 , sendo possível a inserção de novos dispositivos e mecanismos que incorporem maior mobilidade ao seu chassi. Isto pode resultar em mobilidade melhorada sendo então possível a adoção de metodologias mais complexas para o estudo de seu comportamento Cinemático. Os trabalhos apresentados a seguir resultam o estado da arte em modelagem Cinemática de veículos autônomos projetados para atuar em ambientes relativamente irregulares.

Estes robôs pertencem a uma classe de robôs móveis chamados All terrain Rovers (ATR) ou Rovers para todo terreno, eles possuem sistema de mobilidade sofisticada para permitir sua travessia sobre terrenos irregulares. Segundo Lamon e Siegwart (2007), estes robôs estão sendo cada vez mais utilizados em diversas aplicações como explorações planetárias, operações de resgate, detecção de minas e remoção de minas, exploração de minas abandonadas, agricultura, missões 
militares, inspeção e operações de limpeza de sítios de despejos perigosos, entre outros.

Tarokh e McDermott (2005) descrevem uma análise cinemática de um rover desenvolvido pela NASA no qual foi enviado ao planeta Marte. O veículo apresenta um sistema complexo de mobilidade. Nele é apresentado um modelo cinemático abrangente de um ATR que pode tratar alguns dos desafios e problemas associados a estes rovers. É proposta a metodologia para o desenvolvimento de um modelo cinemático razoavelmente completo para um ATR genérico e sua interação com o terreno e também aplicar esta metodologia para um ATR particular, o rover Rocky Mar 7 que tem um sistema de mobilidade complexo.

Destaca-se que este modelo pode fornecer informações sobre vários escorregamentos, tais como: lateral, de rolamento e escorregamento de virada. Estas informações podem ser úteis para atuação e controle para reduzir movimentos indesejáveis tais como deslizamento, derrapagens e outros. Um modelo cinemático completo é útil também para controle de movimento e navegação do rover.

Primeiramente é definida uma abordagem genérica para a modelagem cinemática de um ATR, são derivadas as componentes das equações de movimento do rover relativo a um quadro de referência do rover. ATR é definido como sendo um robô móvel com rodas constituído de um corpo principal conectados com as rodas por meio de um conjunto de ligações e juntas. Ele possui capacidade de locomoção sobre terrenos irregulares por meio do rolamento de suas rodas e ajustes de suas juntas, e o único contato com o terreno é com a superfície de suas rodas. O rover possui um quadro de referência instantâneo $\mathrm{R}$ junto ao seu corpo que move com o rover e é definido relativo a um quadro global de coordenadas fixo como mostra a Figura 20 (a). O vetor de configuração do rover $U=\left[\begin{array}{llllll}X & Y & Z & \Phi_{x} & \Phi_{y} & \Phi_{z}\end{array}\right]^{T}$ é 
definido relativo ao quadro de coordenadas global W, onde $\left(\begin{array}{llll}X & Y & Z\end{array}\right)$ é a posição e $\left(\begin{array}{lll}\Phi_{x} & \Phi_{y} & \Phi_{z}\end{array}\right)$ é a orientação, com heading (rotação em torno do eixo x) $\Phi_{x}$, pitch (rotação em torno do eixo y) $\Phi_{y}$, e roll (rotação em torno do eixo z), $\Phi_{z}$. Cada roda também possui um quadro de coordenadas instantâneo $A i, i=1,2, \ldots, n$ preso ao eixo da sua roda e é definido relativo ao quadro de coordenadas do corpo do rover $\mathrm{R}$, onde $\mathrm{n}$ é o número de rodas. A transformação entre o quadro de coordenadas do corpo do rover $\mathrm{R}$ e cada quadro de coordenada de eixo de roda $\mathrm{Ai}$, denotada pela transformação homogênea $T_{R}$,Ai $(q)$ depende das ligações e juntas especificas do rover representada pelo vetor variável de junta q.

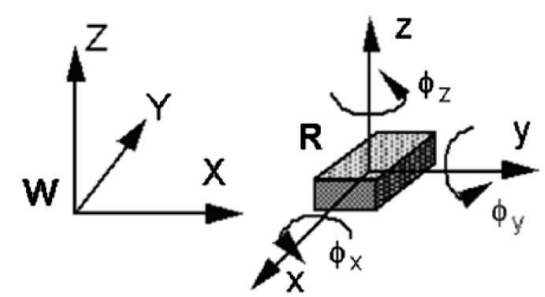

(a)

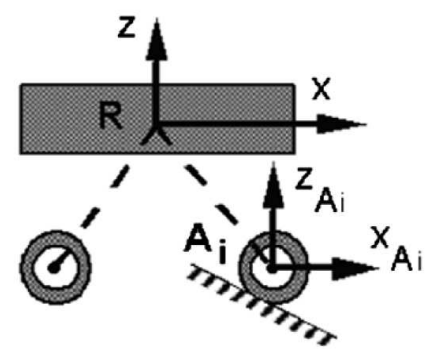

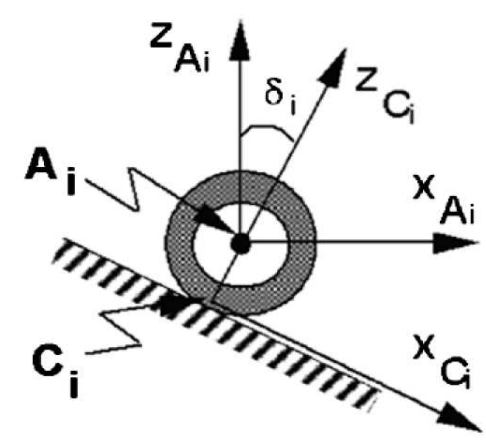

Figura 20 - (a) Quadro de referência do rover da NASA e (b) quadro de referência da Roda (TAROKH e McDERMOTT, 2005).

Nesta análise, cada roda é assumida pela representação por um disco rígido com um único ponto de contato com a superfície do terreno. Permitindo múltiplos ângulos de contatos para cada roda faz a análise cinemática extremamente complexa. $\mathrm{O}$ quadro de coordenada $\mathrm{C}_{\mathrm{i}}, \mathrm{i}=1,2, \ldots, \mathrm{n}$ é definido a cada ponto de contato da roda, como ilustrado na Figura 20(b), onde seu eixo x é tangente ao terreno no ponto de contato e seu eixo z é normal ao terreno. O ângulo de contato $\delta_{i}$ 
é o ângulo entre os eixos $z$ do i-ézimo eixo da roda e quadro de coordenada de contato, como ilustrado na Figura 20(b). Este ângulo de contato é a chave de distinção entre um OMR movendo superfícies planas e um ATR atravessando terrenos irregulares. No primeiro caso, o eixo $\mathrm{z}$ do quadro de contato está alinhado com o eixo $z$ do eixo da roda e o ângulo de contato é sempre zero, enquanto no segundo caso, $\delta_{\mathrm{i}}$ é variável. Estes ângulos de contatos tem papel muito importante na cinemática de ATRs.

O quadro de coordenadas do contato $C_{i}$ é obtido do quadro de coordenadas do eixo da roda $A_{i}$ por meio da rotação de $\delta_{i}$, sobre o eixo, e translação pelo raio $r$ da roda na direção negativa de $z$. A matriz de transformação do eixo $A_{i}$ para o contato $\mathrm{C}_{\mathrm{i}}$, denotado por $\mathrm{T}_{\mathrm{Ai}, \mathrm{Ci}}$ é dado por:

$$
T_{A i, C i}\left(\delta_{i}\right)=\left[\begin{array}{cccc}
\cos \delta_{i} & 0 & \operatorname{sen} \delta_{i} & -r \operatorname{sen} \delta_{i} \\
0 & 1 & 0 & 0 \\
-\operatorname{sen} \delta_{i} & 0 & \cos \delta_{i} & -r \cos \delta_{i} \\
0 & 0 & 0 & 0
\end{array}\right]
$$

A transformação do quadro de referência do rover para o quadro de contato $C_{i}$ é então $T_{R, C i}\left(q, \delta_{i}\right)=T_{R, A i}(q) T_{A i, C i}\left(\delta_{i}\right)$. Entretanto, esta transformação não inclui rolagem ou escorregamento e então não reflete movimento. A fim de incluir movimento, consideramos os quadros de contatos instantâneos $C i(t-\Delta t)$ e $C i(t)$, onde $\Delta t$ é o incremento de tempo, como mostrado na Figura 21.

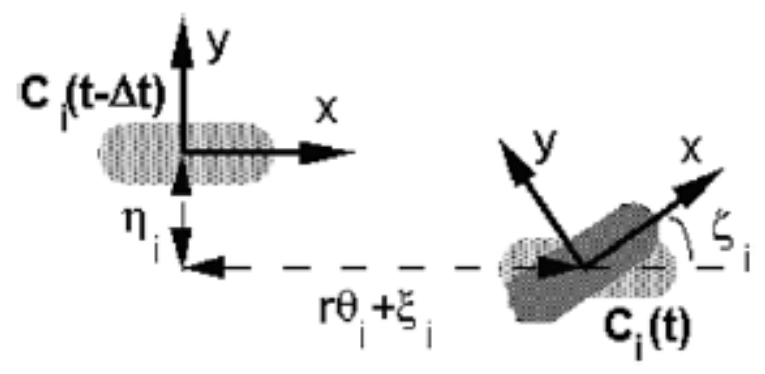

Figura 21 - Movimento Incremental por rolagem e escorregamento. (TAROKH e McDERMOTT, 2005). 
O movimento da roda de $C i(t-\Delta t) \equiv \bar{C}_{i}$ para $C i(t) \equiv C_{i}$ é definido pela transformação da coordenada correspondente a translação de rolagem da roda $\left(r \theta_{i}+\xi_{i}\right)$ ao longo do eixo $\mathrm{x}$, onde $\theta_{i}$ é a rotação angular, e $\xi_{i}$ é o escorregamento de rolagem, uma translação de escorregamento lateral da roda $\eta_{i}$ ao longo do eixo y e uma rotação de escorregamento de virada $\varsigma_{i}$ em relação ao eixo z. Então:

$$
T_{\bar{C}, C i}=\left[\begin{array}{cccc}
\cos \varsigma_{i} & \operatorname{sen} \varsigma_{i} & 0 & r \theta_{i}+\xi_{i} \\
\operatorname{sen} \varsigma_{i} & \cos \varsigma_{i} & 0 & \eta_{i} \\
0 & 0 & 1 & 0 \\
0 & 0 & 0 & 1
\end{array}\right]
$$

Note que a componente do movimento de translação $z$ é zero, desde que não seja permitido movimento ao longo do eixo z, devido ao fato que é assumido que a roda não salte para fora ou penetre no terreno.

A transformação do quadro de contato de uma roda no momento $(t-\Delta t)$ denotado por $\bar{C}_{i}$ para o quadro do rover $\mathrm{R}$ é:

$$
T_{\bar{C}_{i}, R}=T_{\bar{C}_{i}, C_{i}}\left(\theta_{i}, \varepsilon_{i}\right) T_{C_{i}, A_{i}}\left(\delta_{i}\right) T_{A_{i}, R}(q)
$$

Para quantificar o movimento, devemos relacionar mudanças no vetor de taxa

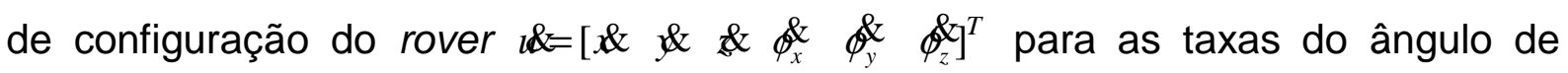
junta $\&$, taxas de rolagem da roda $\oint_{i}^{\&}$ e vetor de taxa de escorregamento da roda \& $\&$. Para fazer isso, consideramos a matriz de transformação $T_{\bar{R}, R}$ que descreve a transformação do quadro do rover no tempo $(t-\Delta t)$ para o quadro do rover no tempo t, que pode ser escrito como $T_{\bar{R}, R}=T_{\bar{R}, \bar{C}_{i}} T_{\bar{C}_{i}, R}$. Desde que $T_{\bar{R}, \bar{C}_{i}}$ é independente do tempo, a derivada de $T_{\bar{R}, R}$ : 


$$
T_{\bar{R}, R}^{\&}=T_{\bar{R}, \bar{C}_{i}} T_{\bar{C}_{i}, R}^{\stackrel{\&}{k}}
$$

A derivada da transformação $T_{\bar{C}_{i}, R}^{\&}$ define o movimento do quadro de referencia do rover $\mathrm{R}$, relativo ao quadro de referência $\bar{C}_{i}$ da roda i. Para um rover específico, $T_{\bar{C}_{i}, R}$ existe como dado em (3.24), e sua derivada pode ser computada como:

$$
\mathcal{T}_{\bar{C}, R}^{\&}=\frac{\partial T_{\bar{C}, R}}{\partial q} \& 4 \frac{\partial T_{\bar{c}, R}}{\partial \theta_{i}} \&_{i}^{\&}+\frac{\partial T_{\overline{C_{i}, R}}}{\partial \varepsilon_{i}} \&+\frac{\partial T_{\bar{C}_{i}, R}}{\partial \delta_{i}} \&_{i}^{\&}
$$

Avaliamos as derivadas parciais em (3.26) nas condições de referência. Agora, $\underset{R_{i}, R}{\&}$ pode também ser encontrado para um corpo genérico em movimento usando as taxas de posição e orientação.

$$
T_{R, R}^{\&}=\left[\begin{array}{cccc}
0 & -\phi_{z}^{\&} & \phi_{y}^{\&} & \& \\
\phi_{z}^{\&} & 0 & -\phi_{x}^{\&} & \& \\
-\phi_{y}^{\&} & \phi_{x}^{\&} & 0 & \& \\
0 & 0 & 0 & 1
\end{array}\right]
$$

Note que $T_{R, R}^{\&}$ é uma matriz anti-simétrica, e a matriz de transformação de produto do lado da mão direita de (3.25) também tem a estrutura de (3.27). Substituindo (3.26) e (3.27) em (3.25) a matriz de produto pode ser validada, e equalizando os elementos semelhantes da matriz em ambos os lados da equação resultante, podemos determinar o vetor de taxa de configuração do rover $\iota \&$ em termos do vetor de taxas angulares das juntas $\&$, taxa de ângulo de contato $\delta_{i}^{k}$, taxa de rolagem da roda $\oint_{i}^{\&}$, e vetor de escorregamento da roda \& \& Além disso, estas 
equações são lineares nas derivadas em relação ao tempo \&, \& $\delta_{i}^{\&}, \phi_{i}^{\&}, \underset{i}{\&}$, como visto de (3.26). Isto leva para uma equação na forma de:

$$
\left[\begin{array}{llllll}
\& & \& & \& & \phi_{x}^{\&} & \phi_{y}^{\&} & \phi_{z}^{\&}
\end{array}\right]^{T}=J i\left[\begin{array}{llll}
\& & \phi_{i}^{\&} & \& & \delta_{i}
\end{array}\right]^{T}
$$

$J_{i}$ é a matriz Jacobiana da roda. Equação (3.28) descreve a contribuição do movimento de cada roda e as juntas conectoras para o movimento do corpo do rover. O movimento da rede do corpo é o efeito composto de todas as rodas e pode ser obtido combinando (3.28) em uma simples matriz de equação como:

$$
[I]\left[\begin{array}{l}
\& \\
\& \\
\& \\
\& \\
\phi_{x} \\
\phi_{y}^{k} \\
\phi_{z}^{k}
\end{array}\right]=J\left[\begin{array}{l}
\& \\
\phi_{i} \\
\& \\
d_{z} \\
\delta_{i}
\end{array}\right]
$$

A matriz também pode ser escrita como $E_{l} \&=J_{F} \&$, onde $E$ é uma matriz obtida empilhando matrizes identidades, \& é vetor de ângulos de juntas do rover, \& é o vetor de taxa de rolagem da roda, \& é o vetor constituído das taxas de escorregamento de: rolagem $\&$, virada \& e lateral $\not \&$ e são os vetores de taxas de ângulo de contato. A Matriz Jacobiana do rover $J$ é uma matriz formada pelas matrizes Jacobianas individuais das rodas $J_{i}, \mathrm{i}=1, \ldots, \mathrm{n}$ e \&\& é o vetor composto de taxas angulares. Observe que da equação (3.28) e (3.29) que J é uma matriz esparsa.

Como descrito no item 2.1, outro rover desenvolvido para exploração planetária é o veículo denominado SOLERO apresentado por Siegwart e Pierre (2007). É tratado o desafio de desenvolver um veículo no qual mecanismos de 
sensoriamento absoluto não estão disponíveis por longos períodos e onde o tipo de solo não é conhecido em um primeiro momento. A maioria das aplicações lida com o problema de localização de veículos em solos planos e suaves. Em tais condições modelos de veículos relativamente acurados podem ser desenvolvidos, no qual levase a uma boa estimativa de estado.

A intenção é combinar diferentes métodos para reduzir tanto quanto possível os erros de dead reckoning (processo matemático utilizado para determinar a localização do veículo a partir do conhecimento de informações de curso e velocidade em um determinado período). Em particular, é mostrado como o rastreamento de posição 3D pode ser melhorada considerando locomoção do rover em ambientes desafiadores como um problema holístico. A maioria dos trabalhos anteriores tem focado em um aspecto de rastreamento de posição e/ou está limitado a terrenos relativamente planos e suaves. Este trabalho propõe estender 0 rastreamento dos ambientes constituindo por arestas cortantes tais como degraus e considerar não apenas sensoriamento, mas também aspectos mecânicos (configuração de chassis) e de controle (minimização de erros). Em terrenos irregulares, é crucial selecionar apropriadamente sensores e usar suas complementaridades para produzir estimativas de movimentos confiáveis. Cada sensor tem suas próprias vantagens e desvantagens dependendo da situação e então confiar em somente um sensor pode levar em resultados catastróficos. Embora a escolha de sensores é importante, não é o único aspecto a ser considerado. $\mathrm{Na}$ verdade, as características específicas de locomoção do rover e o modo como é dirigido também tem impacto forte na estimativa de posição. O sinal do sensor pode ser não usável se não adaptáveis chassi e controladores forem utilizados em terrenos irregulares. Por exemplo, o sinal de taxa de ruído é pobre 
para uma unidade de medição inercial montada em um rover de quadro rodas com suspensão dura. Igualmente, odometria fornece estimativas ruins se o controlador da roda não inclui minimização de escorregamento ou se a cinemática do rover não é levado em conta nos algoritmos. O alvo principal deste trabalho de pesquisa é reduzir crescimento de erros de posição considerando todos estes aspectos juntos.

\subsection{Considerações Finais}

Neste Capítulo foi desenvolvido o modelo cinemático do VAA de acordo com as suas condições de geometria e adoção de simplificações em seu modelo. Porém, foi destacado que existem outros modelos cinemáticos desenvolvidos para sistemas mais complexos que atuam em ambientes altamente irregulares e que possuem sistemas de mobilidade com geometria complexa. Tais modelagens podem ser introduzidas em projeto de VAA's juntamente com o aprimoramento de seus sistemas de mobilidade de acordo com as condições de topologia de terreno ou outros parâmetros como, por exemplo, redução de erros de odometria, redução de níveis de ruídos em sensores, e outros. Porém a introdução dessas metodologias atualmente é desafiadora, pois exigem altas capacidades computacionais e desenvolvimento de sistema de mobilidade mais avançados, como exemplo os que são utilizados em veículos desenvolvidos para atuação em ambientes extra-planetários. 


\section{ESTRUTURAS EM PÓRTICOS}

Os veículos utilizados para operar em ambientes agrícolas no qual possuem alta densidade de planta, tais como: café, milho e cana de açúcar possuem um grande espaço livre entre o seu chassi e as suas rodas, ou seja, o chassi destes veículos possui um formato em pórtico. Este formato é utilizado para evitar ou minimizar o contato entre a máquina (veículo) e a cultura em que este esteja operando. Deste modo estes veículos são projetados para operar em tais ambientes com a finalidade de minimizar as perdas por eventuais danos mecânicos às plantas provocadas pela máquina.

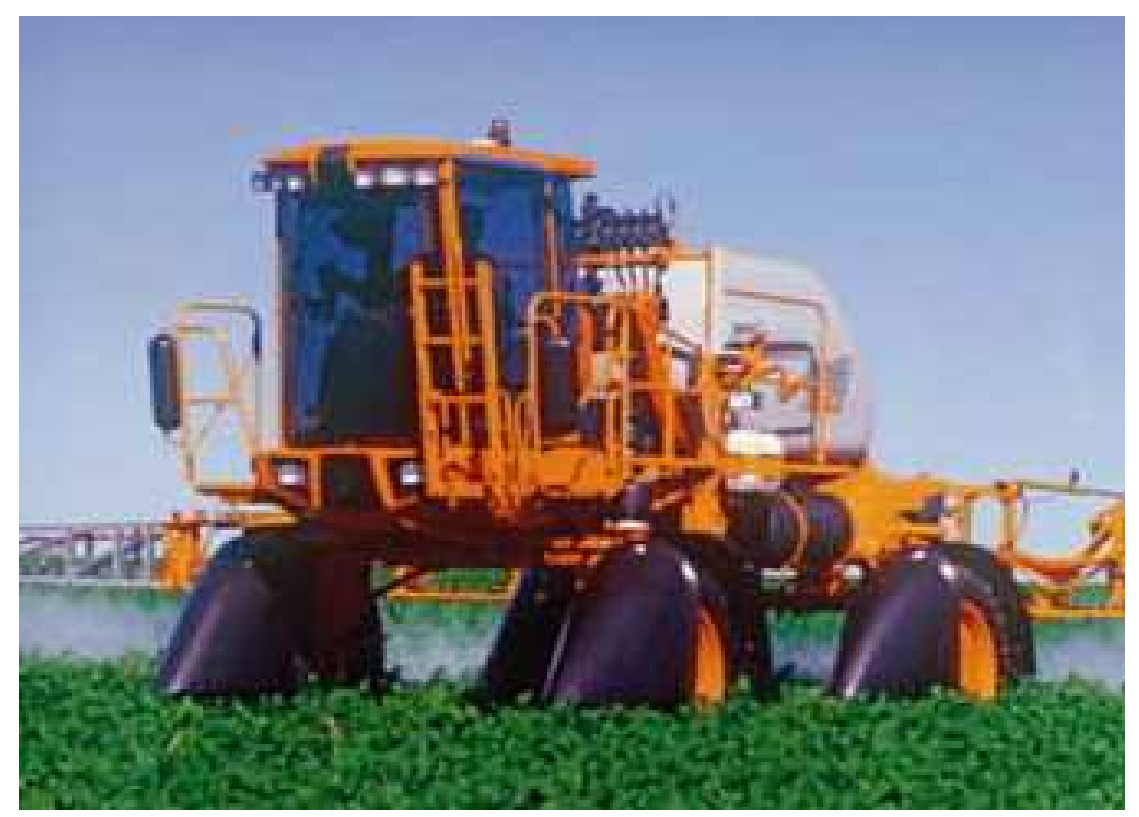

Figura 22 - Pulverizador com formato da estrutura em pórtico.

No Brasil, os veículos com estrutura em formato em pórtico são utilizados para a aplicação de insumos líquidos, sólidos e também utilizados para colheita de café. Eles são caracterizados por elevado peso e potência, dados das colhedoras de café e pulverizadores são descritos nas tabelas 3 e 4 respectivamente. 
Tabela 4 - Dados de Colhedoras de Café

\begin{tabular}{llcccl}
\hline \multicolumn{5}{c}{ Colhedoras de Café } \\
\hline Marca & Modelo & Largura(m) & Altura(m) Comprimento(m) & $\begin{array}{l}\text { Massa } \\
(\mathrm{kg})\end{array}$ \\
\hline TDI & Electron & 3,2 & 4,02 & 4,7 & $4.900 \mathrm{~kg}$ \\
\hline TDI & Mini & 2,1 & 3 & 4,0 & $3.000 \mathrm{~kg}$ \\
\hline Case & TCX 2100 & 3,55 & 3,5 & 4,6 & $4.050 \mathrm{~kg}$ \\
\hline Case & A2000 & 3,5 & 3,27 & 5,22 & $4.100 \mathrm{~kg}$ \\
\hline Jacto & k-34x4 & 3,2 & 4,95 & 5,0 & $3.000 \mathrm{~kg}$ \\
\hline Jacto & Advance & 3 & 5,32 & 5,0 & $6.700 \mathrm{~kg}$ \\
\hline
\end{tabular}

Tabela 5 - Dados de Pulverizadoras

\begin{tabular}{|c|c|c|c|c|c|c|}
\hline \multicolumn{7}{|c|}{ Pulverizadoras } \\
\hline Marca & Modelo & $\begin{array}{l}\text { Largura } \\
\qquad(\mathrm{m})\end{array}$ & Altura $(m)$ & $\begin{array}{l}\text { Comprimento } \\
(\mathrm{m})\end{array}$ & $\begin{array}{l}\text { Massa } \\
(\mathrm{kg})\end{array}$ & Bitola $(m)$ \\
\hline Montana & Parruda & 3,36 & 3,65 & 8,45 & 7600 & 2,6 a 3,0 \\
\hline Metalflor & Hidro 3000BR & 3,2 & 3,4 & 7,6 & 7000 & 2,7 a 3,2 \\
\hline $\begin{array}{l}\text { John } \\
\text { Deere }\end{array}$ & 4720 & 4,0 & 3,8 & 7,3 & 9707 & $\begin{array}{c}3,048 \mathrm{a} \\
3,861\end{array}$ \\
\hline Jacto & Uniport 3000 Canavieiro & 3,18 & 3,9 & 7,5 & 9450 & 2,69 a 3,26 \\
\hline Jacto & $\begin{array}{l}\text { Uniport 3000/28 } \\
4 \times 4 \text { Hidro }\end{array}$ & 3,2 & 3,6 & 7,3 & 9700 & 2,56 a 3,13 \\
\hline Jacto & $\begin{array}{l}\text { Uniport } 3000 / 28 \\
4 \times 4 \text { Vortex }\end{array}$ & 3,4 & 3,8 & 8 & 9800 & 2,56 a 3,13 \\
\hline Jacto & Uniport 250024 Star & 3,2 & 3,7 & 6,6 & 6500 & 2,1 a 2,7 \\
\hline Case & Patriot 350 & 4,0 & 3,78 & 8,2 & 9500 & 3,5 a 3,99 \\
\hline
\end{tabular}

Tais configurações de formato, peso e potência são necessários para poder desempenhar as suas funções com sucesso. No caso de aplicação de insumos líquidos, é necessário o transporte de grande quantidade de líquido, portanto 0 veículo necessita transportar seu elevado peso próprio mais o peso do insumo de aplicação resultando em veículos com alta potência, na ordem de 150 kW (200 HP). Já em colhedoras de café o veículo se desloca por cima de uma linha de planta por vez, sendo o vão livre do pórtico o lugar onde o veículo se desloca sobre a planta a fim de efetuar a operação da colheita dos grãos de café. 


\subsection{Fundamentos da estrutura em pórtico}

Existem poucos trabalhos publicados em relação aos projetos de estruturas de veículos agrícolas autônomos ou robôs agrícolas móveis. Não foram encontrados trabalhos publicados especificamente em relação a estes veículos e que justificam seus formatos e suas adaptações aos ambientes de trabalho.

Entretanto, características em relação a robôs agrícolas móveis tais como configurações de rodas, manobrabilidade e quantidade de sensores e atuadores montados no mesmo são tendências e requisitos descritos por Blackmore, Have e Fountas (2002).

Os robôs agrícolas encontrados na literatura científica, conforme descrito no item 2.1, foram: a plataforma desenvolvida em Hague, Marchant e Tillet (2000) e em SRI (2005), ela é apropriada para o trabalho em horticultura e conforme a Figura 5 verifica-se que ele possui o chassi configurado para atuar em plantações com altura de planta o que é justificável para a atuação em hortaliça de folha. O veículo desenvolvido por Bak e Jakobsen (2004), Figura 6, apresenta uma configuração de chassi em pórtico, mas também apresenta altura pequena, pois foi projetado para atuar em linhas de plantio baixas. O veículo Aurora (Figura 8) possui uma configuração bem restrita em seu chassi, pois sua configuração foi idealizada para atuar somente nos corredores de estufas.

O veículo SAVAGE (SAVAGE, 2007) possui formato em pórtico semelhante a esse projeto de VAA. Possui característica de movimentos independentes em suas rodas, tanto na direção quanto na guiagem. Não foi feita nenhuma publicação científica em relação ao seu projeto estrutural, pois o projeto está em desenvolvimento, sua configuração está ilustrada na Figura 23. 


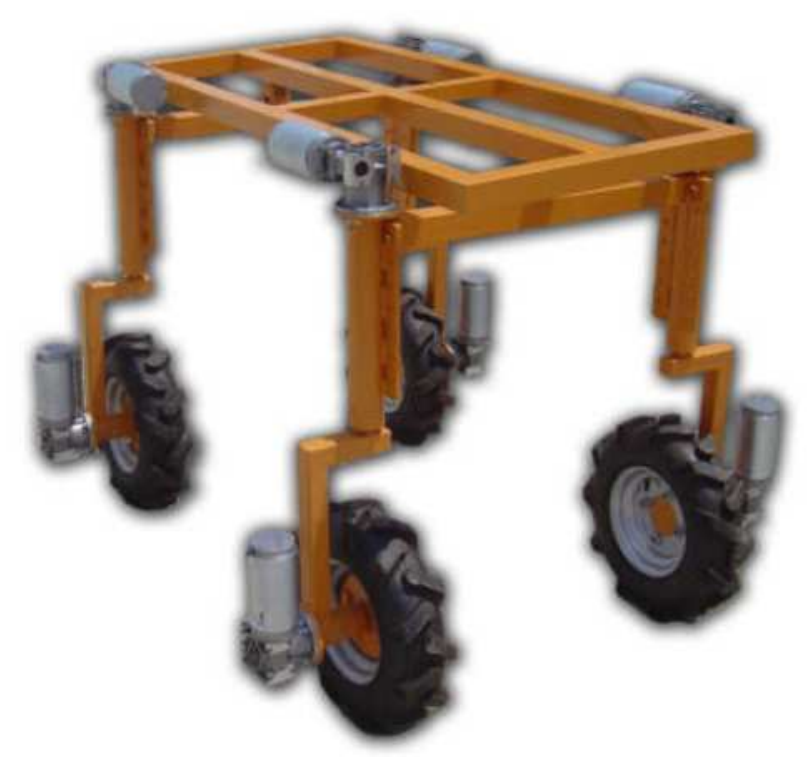

Figura 23 - Estrutura do SAVAGE (SAVAGE, 2007).

Nota-se que na literatura internacional foram desenvolvidos VAA's com 0 papel de desempenhar funções tais como: preparação de solo (UIUC AGRICULTURAL ENGINEERING, 2007), plantio (NAGASAKA et al., 2004), controle de plantas invasoras (ÅSTRAND E BAERVELDT, 2002), pulverização e operações em estufa (GÓMEZ-DE-GABRIEL et al., 1996) e também com o intuito de suprir a escassez de mão-de-obra.

A proposta desenvolvida no Brasil (SOUSA et al., 2004) é a utilização de VAA's com foco principal o sensoriamento ou coleta de dados de variáveis agronômicas em diferentes culturas brasileiras com o objetivo de detectar ou medir a variabilidade ou localização dos parâmetros de interesses agronômicos tais como infestações de pragas, doença, estresse nutricional da planta, variação edafoclimática, entre outros.

Sua estrutura foi desenvolvida de modo a minimizar os efeitos do veículo sobre as plantas em que ele estiver operando. O formato em pórtico foi utilizado para o veículo deslocar no campo sobre plantações com altura até de $2 \mathrm{~m}$. Além disso, a distância entre cada lateral do veículo é ajustável, variável entre 1,4 m a 2,0 
$\mathrm{m}$, conforme mostrado pela Figura 24. O objetivo é a adaptação ao ambiente para poder operar em culturas com diferentes espaçamentos entre as linhas de plantio.

\subsection{Desenvolvimento da Estrutura em Pórtico}

Em VAA's no qual seu papel principal é monitorar variáveis agronômicas em determinada área e em determinadas culturas, configurações tais como peso e potência podem ser reduzidos consideravelmente se comparados ao veículos comerciais utilizados atualmente com configuração semelhante de estrutura. Isto acontece porque não existem tarefas que exigem o transporte de elevadas cargas (insumos) para aplicação ou transferência de quantidade de movimento às plantas, como no caso das colhedoras de café. Além disso, não há a necessidade de espaço destinado ao operador do veículo e todos os sistemas ou componentes necessários para o operador. Entretanto para VAA's poderem operar de forma eficiente nos mesmos ambientes que os veículos comerciais descritos anteriormente é necessário o formato em pórtico similar ao formato dos veículos encontrados comercialmente, como descrito anteriormente. Isto se deve ao mesmo fator que os dos veículos desenvolvidos para aplicação em pulverização ou colheita. O formato é concebido devido às restrições físicas das plantações e dos caminhos (linhas de plantios) que o veículo percorre durante o seu trabalho. Portanto é necessário que o contato não prejudique o desenvolvimento de planta na qual esteja sendo efetuada determinada operação.

A estrutura mecânica foi projetada por meio do estudo da condição de trabalho prevista em campo. Levaram-se em conta as características almejadas ao projeto como descrito no item 1.1 e repetidas aqui: 
- Estrutura leve e flexível enquanto comparado com os veículos comercias que foram projetados para operar em ambiente agrícola no qual possam ser inseridos novos sensores e atuadores.

- Estrutura em formato em pórtico capaz de operar em culturas com altura de plantas até $2 m$ de altura.

- Estrutura com a bitola redimensionável com o objetivo de atuar em diferentes culturas com diferentes espaçamentos entre plantas (Figura 24).

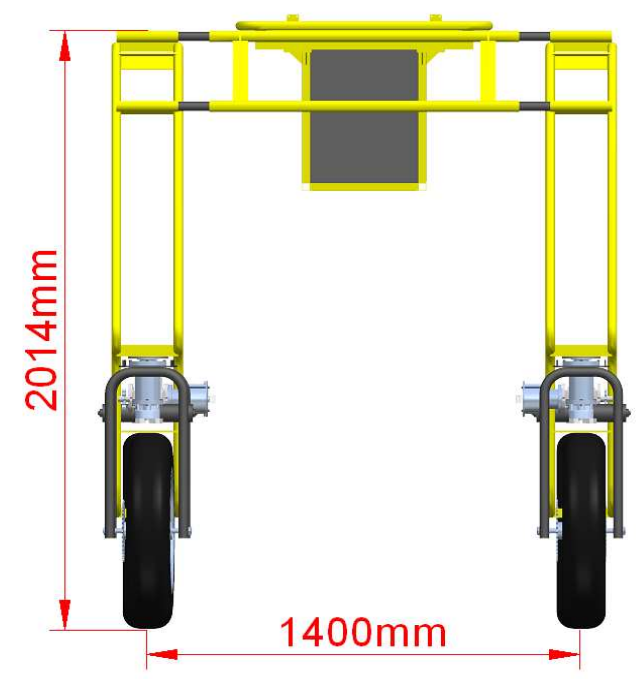

(a)

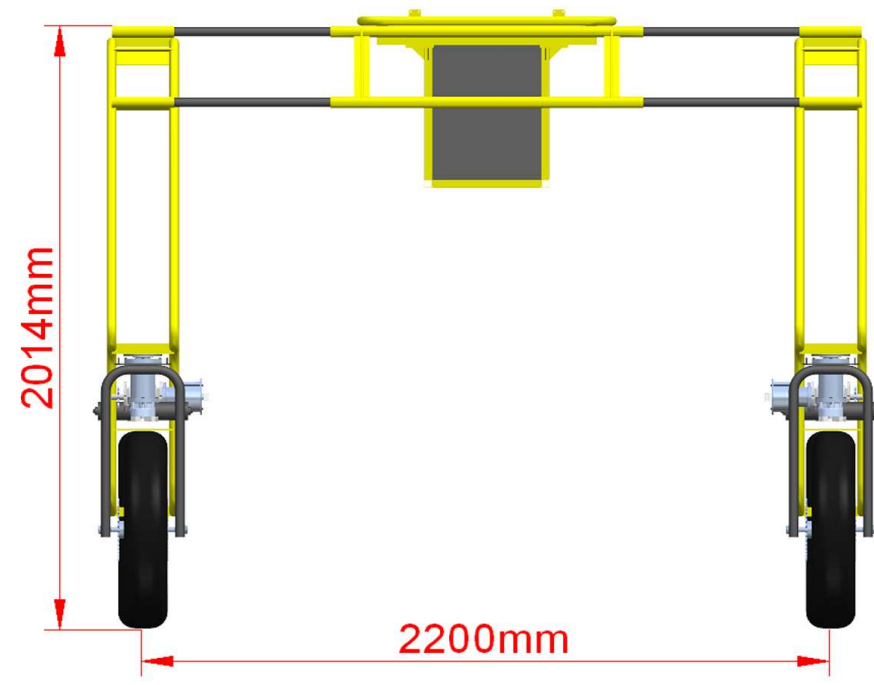

(b)

Figura 24 - Vista Frontal do VAA, (a) Abertura Mínima e (b) Abertura Máxima.

Além disso, a estrutura foi desenhada através de metodologia de prototipagem virtual baseada no programa computacional Solid Edge (SIEMENS, 2007). Parâmetros de tensão e deformação mecânica foram calculados e obtidos com a utilização de outro programa computacional de cálculo estrutural ANSYS (ANSYS, 2007.). Destaca-se que o programa ANSYS possui a capacidade de importação dos arquivos gerados pelo programa Solid Edge, facilitando o processo de prototipagem descrito abaixo. 
Os passos do processo de prototipagem e simulação foram: cálculo de potência e levantamento inicial de parâmetros (materiais para a estrutura, dimensões e massas), modelagem tridimensional e desenho mecânico e simulação para a validação e refinamento de parâmetros. O fluxograma da Figura 25 explica o processo de prototipagem.

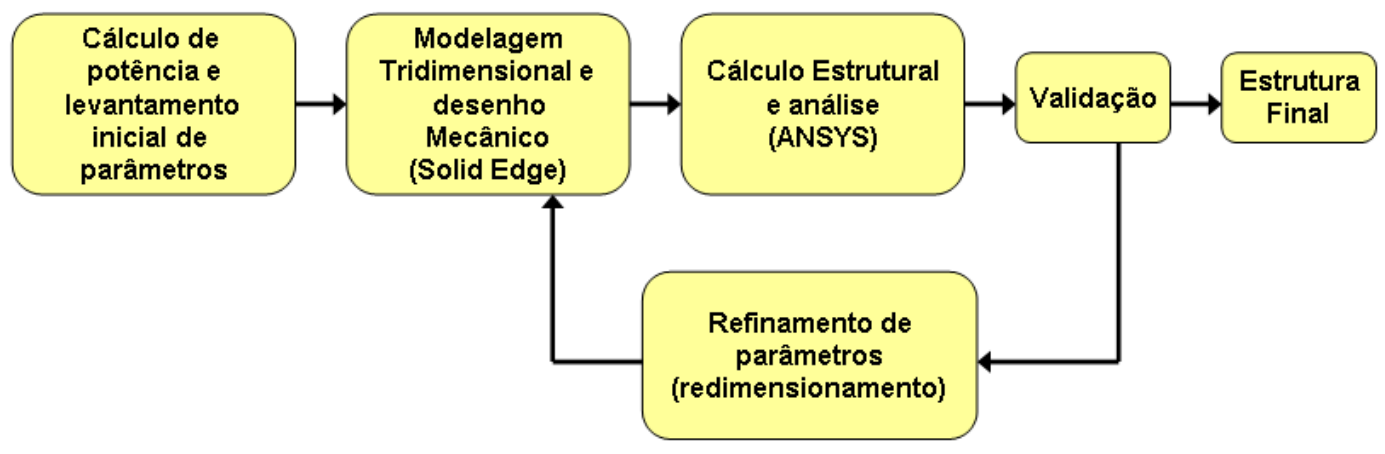

Figura 25 - Processo de prototipagem virtual da estrutura mecânica do RAM.

O Chassi Inferior, Chassi Superior, e o MPG são compostos basicamente por estrutura tubular, com material SAE1020 (aço carbono), com diâmetro externo 1 1/4" e espessura de 1/8".

Tabela 6 - Massa dos Principais Conjuntos do VAA.

\begin{tabular}{llr}
\hline & Principais Componentes & Massa (kg) \\
\hline Conjunto Superior & & \\
\hline & Chassi Superior (CHS) & 33,2 \\
\hline & Gabinete & 18,4 \\
\hline Conjunto Lateral & Total & $\mathbf{5 1 , 6}$ \\
\hline & Barras 1, 2,3 e 4 & 7,1 \\
\hline & Chassi Inferior (CHI) & 44,9 \\
\hline MGP & Total & $\mathbf{5 2 , 0}$ \\
\hline Total Conjunto Lateral & 1 Conjunto Lateral+2MGPs & $\mathbf{3 4 , 1}$ \\
\hline & & $\mathbf{1 2 0 , 2}$ \\
\hline Laterais & 2 & \\
\hline Baterias & & $\mathbf{2 4 0 , 4}$ \\
\hline TOTAL VAA & Laterais + Conjunto & $\mathbf{9 6 , 0}$ \\
\hline
\end{tabular}

Os valores de massa dos componentes do VAA foram obtidos utilizando o programa Solid Edge, foram inseridos os valores de densidades dos respectivos 
matérias. Valores de massa de outros componentes como motores, redutores, rodas, pneus, correntes, e outros foram obtidos por meio de catálogo de fabricantes ou medidos em balanças.

Utilizando o programa computacional ANSYS a estrutura foi sendo desenvolvida segundo os passos do processo. A simulação foi realizada considerando o veículo em posição estática. Este fato está relacionado à condição inicial de operação nominal adotada de aproximadamente $3 \mathrm{~m} / \mathrm{s}$.

Foram analisadas as deformações e tensões para diferentes tipos de esforços nos módulos $\mathrm{CHI}$ e o $\mathrm{CHS}$ (descrito no item 2.2). A Tabela 7 mostra os principais resultados de simulação para a estrutura final obtida.

Tabela 7 - Resultados finais da simulação estática das estruturas CHI e CHS.

\begin{tabular}{|c|c|c|}
\hline $\begin{array}{l}\text { Deformação e } \\
\text { Tensão no CHI }\end{array}$ & $\begin{array}{l}\text { Suporte na interface módulo roda. Forças: } \\
\text { gravidade, peso das baterias, peso do gabinete } \\
\text { e força remota nos mancais (posição do } \\
\text { gabinete, } 100 \mathrm{~N} \text { em cada gabinete). }\end{array}$ & $\begin{array}{l}\text { Deformação máxima: } \\
\text { 0,756 mm. } \\
\text { Tensão Máxima } \\
\text { Equivalente: } 111 \mathrm{Mpa} \text {. }\end{array}$ \\
\hline $\begin{array}{l}\text { Torção } \\
\text { horizontal no } \\
\text { CHI }\end{array}$ & $\begin{array}{l}\text { Torção na Direção X, fixando mancais do } \\
\text { suporte do pórtico e colocando força lateral } \\
\text { (sentido Y) na interface com módulo roda. } \\
\text { Forças: gravidade e peso das baterias e força } \\
\text { lateral de } 400 \mathrm{~N} \text { na interface módulo roda } \\
\text { dianteira }\end{array}$ & $\begin{array}{l}\text { Tensão bem } \\
\text { distribuída, com pico } \\
\text { de } 180 \text { Mpa na } \\
\text { interface com módulo } \\
\text { roda. }\end{array}$ \\
\hline $\begin{array}{c}\text { Torção vertical } \\
\text { no } \mathrm{CHI}\end{array}$ & $\begin{array}{l}\text { Torção na direção } \mathrm{Z} \text {, fixando mancais traseiros } \\
\text { do suporte do pórtico e roda traseira. Forças: } \\
\text { gravidade, peso das baterias, peso do gabinete } \\
\text { e força lateral de } 400 \mathrm{~N} \text { na interface módulo } \\
\text { roda dianteira. }\end{array}$ & $\begin{array}{l}\text { Pico de tensão na } \\
\text { interface com nódulo } \\
\text { roda de } 205 \mathrm{Mpa} \text {. }\end{array}$ \\
\hline Torção no CHS & $\begin{array}{l}\text { Tração no eixo Y como força de tração nas } \\
\text { seções finais do tubo, puxando para fora, } 300 \mathrm{~N} \\
\text { cada. }\end{array}$ & $\begin{array}{c}\text { Tensão bem } \\
\text { distribuída com pico de } \\
13 \mathrm{MPa} \text {. }\end{array}$ \\
\hline
\end{tabular}

A Figura 26a ilustra o ambiente de simulação de tensão e deformação para cargas verticais. Os resultados de deformação apresentados na Figura 26b mostram 
que o ponto maior de deformação está no centro da parte superior da estrutura, com valor de deformação máxima de $0,756 \mathrm{~mm}$ levando em conta o material adotado para a construção da estrutura (aço SAE 1020).

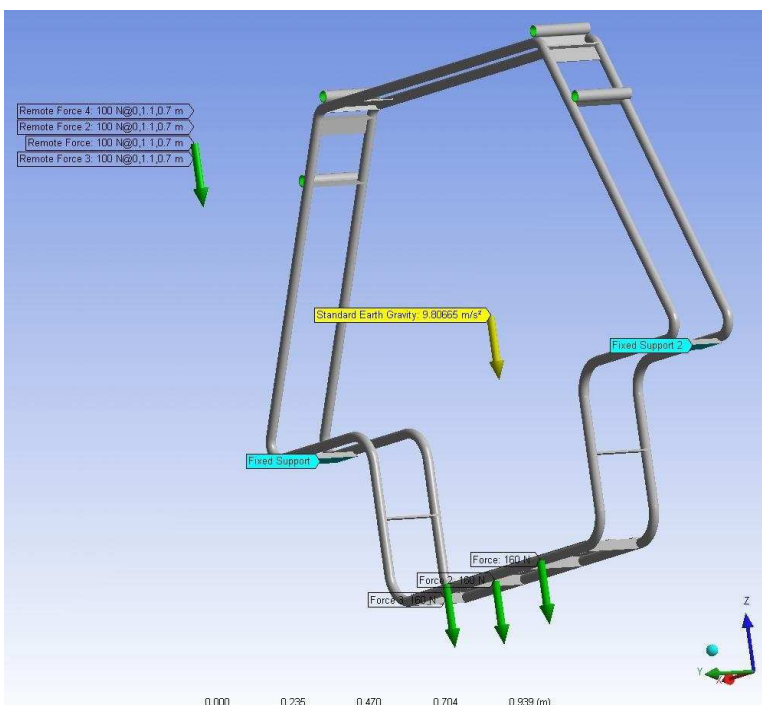

(a)

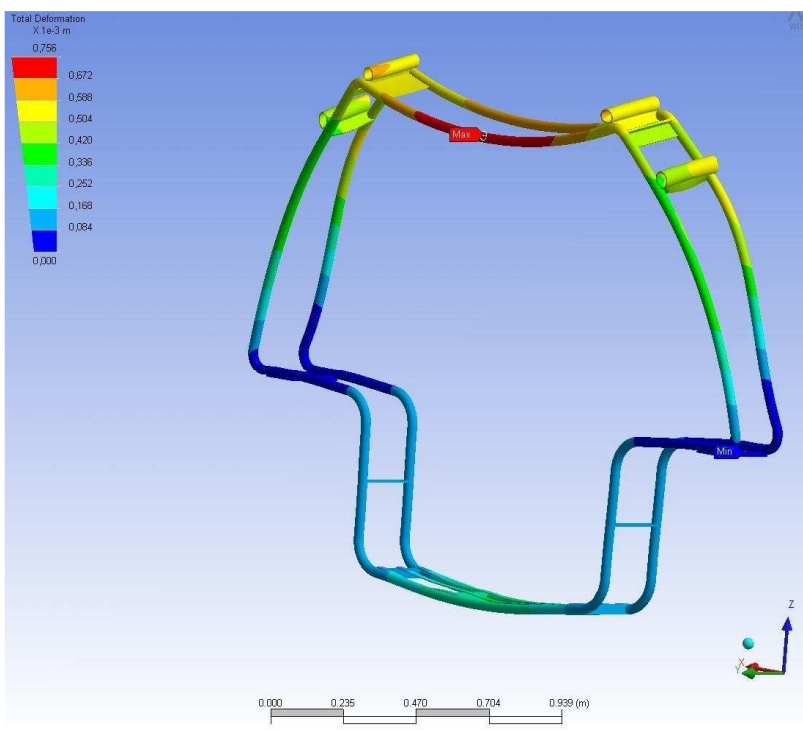

(b)

Figura 26 - (a) Ambiente simulação de tensão e deformação e (b) resultado da simulação de deformação (deformação visual ampliada).

A Figura 27 ilustra o resultado final da simulação de torção no $\mathrm{CHS}$ mostrando que a distribuição é bastante uniforme das tensões para tração de $300 \mathrm{~N}$ nas seções finais do tubo (para fora).

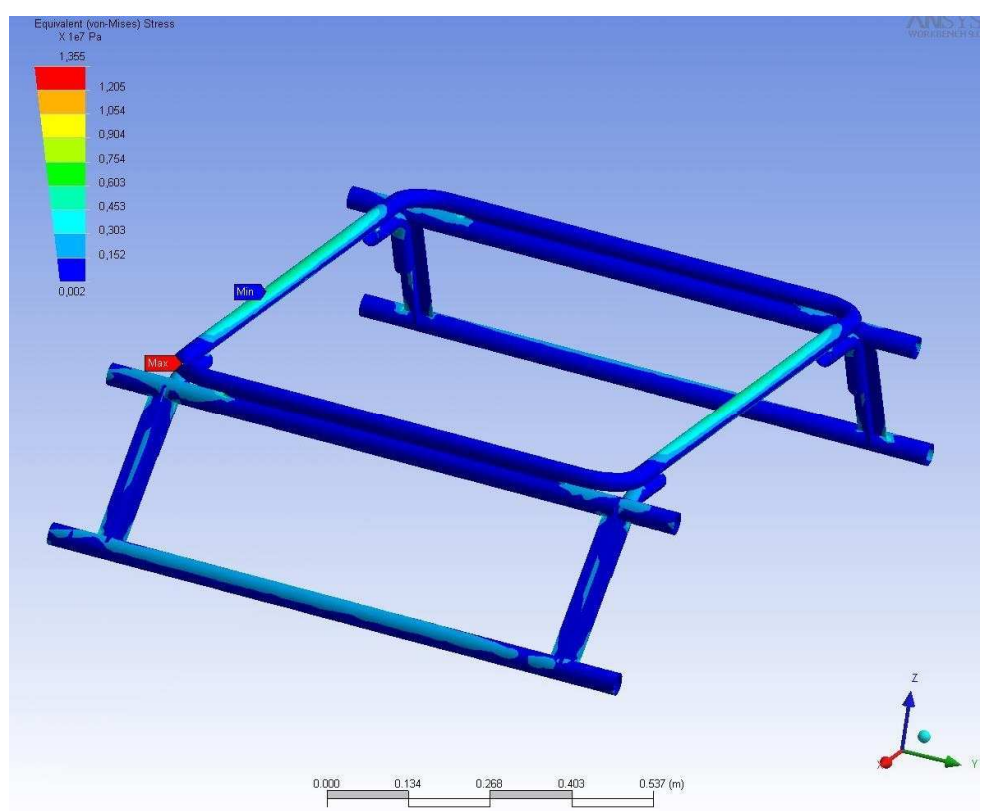

Figura 27 - Resultado da simulação do CHS para torção por forças horizontais. 


\section{CONCLUSÕES}

Apesar de existir no mercado um número razoável de máquinas agrícolas com arquitetura em pórtico (cerca de 14 modelos), verifica-se que existem poucos trabalhos na Literatura que buscam dimensionar a estrutura em formato pórtico de veículos agrícolas, incluindo as plataformas que formam os veículos autônomos ou robôs destinados para o uso em tais ambientes. De um modo geral a altura é baseada nas plantas em que a máquina irá atuar e a largura adaptável ao espaçamento de plantio adotado, porém pode-se considerar que os valores são empíricos e há situações como na cultura de café que houve a necessidade da lavoura adaptar à máquina. No ponto de vista da dinâmica e estabilidade da estrutura, aparentemente os valores adotados por fabricantes são baseados em variáveis de um veículo como centro de massa, estabilidade e mobilidade.

Além disso, verifica-se que apesar deste formato ser altamente desejável para cumprir os requisitos de forma eficiente a sua missão, tais veículos apresentam mobilidade reduzida se comparada a rovers devido as suas dimensões ditadas pelas plantas.

Conclui-se que apesar da existência de máquinas agrícolas em formato pórtico e de rovers autônomos, ao unir os conceitos, surgem questões importantes a serem estudados. A plataforma em questão possui grande potencial para aplicação em veículos autônomos ou semi-autônomos, cuja função principal é a de monitoramento de variáveis agrícolas, nas condições pré-estabelecidas e que teve como parâmetros as características de ambientes agrícolas Brasileiras. Os 
parâmetros levantados nesse projeto, portanto, muito provavelmente poderá auxiliar nos futuros projetos.

\section{SUGESTÃO DE TRABALHOS FUTUROS}

Veículos Agrícolas Autônomos é um assunto abrangente e multidisciplinar. Ao integrar tecnologias, surgem novos desafios. O controle antes realizado por homens ou mesmo a resolução aceita pela agricultura tradicional trazia uma menor exigência quanto ao equacionamento e acurácia. O comportamento do solo modificado pelo estado e pela dinâmica do ambiente agrícola, exige uma maior adaptabilidade dos elementos e atuadores mecânicos. Sendo autônomo por sua vez, traz possibilidade de arquiteturas que antes não seria possível por exigir um posicionamento privilegiado do operador para visualizar e dirigir a máquina.

Trabalhos futuros devem seguir na direção de refinar os dados de projeto como mobilidade da estrutura; diferentes graus de liberdade nas rodas; estudo de lay-out e distribuição de carga dinâmica nas rodas; sistemas de potência como célula de combustível, bateria, geradores entre alternativas; implementação de motores trifásicos; suspensão ativa e atuadores verticais nas rodas para vencer obstáculos. Atualmente existem pilotos automáticos, porém para uma guiagem autônoma há grandes desafios. 


\section{REFERÊNCIAS*}

AUERNHAMMER, H. (2001). Precision farming - the environmental challenge. Computer and Electronics in Agriculture, v. 30, n1-3, p.31-43.

ANSYS (2007). Site do desenvolvedor do programa computacional ANSYS. Disponível em: <http://www.ansys.com>. Acesso em: nov. 2007.

ÅSTRAND, B.; BAERVELDT, A. (2002). An Agricultural Mobile Robot with VisionBased Perception for Mechanical Weed Control. Autonomous Robots, v.13, n.1, July, p.21-35.

BAK, T.; JAKOBSEN, H. (2004). Agricultural Robotic Platform with Four Wheel Steering for Weed Control. Biosystems Engineering, v. 87, Issue 2, February, p. 125-136.

BALASTREIRE, L. A. (1990). Máquinas Agrícolas. 1Edição. São Paulo: Manole, 307p.

BLACKMORE, S.; HAVE, H.; FOUNTAS, S. (2002). Specification of Behavioral Requirements for an Autonomous Tractor. In: AUTOMATION TECHNOLOGY FOR OFF-ROAD EQUIPMENT, 2002 ASAE International Conference, 2002, Chicago, Illinois, USA, ASAE Publication 701P0502 - July 26, pp 033-042.

BOSCH (2004). Site de fabricante de motores elétricos. Disponível em: <www.bosh.com.br>.Acesso em: out. 2004.

CANALE, A. C. (1989). Automobilística: Dinâmica e Desempenho. 1ª Edição. São Paulo: Érica, 125p.

EARL, R.; THOMAS, G.; BLACKMORE, B.S. (2000). The potential role of GIS in autonomous field operations. Computers and Electronics in Agriculture. v.25, p.107-120.

GE, S. S.; LEWIS, F. L. (2006). Autonomous Mobile Robots: Sensing, Control, Decision Making and Applications. $1^{\text {ST }}$ Edition. CRC Press, 709p.

GÓMEZ-DE-GABRIEL, J. M.; MARTíNEZ, J. L.; OLLERO, A.; MANDOW, A.; MUNÕZ, V. F. (1996). Autonomous and Teleoperated Control of the Aurora Mobile Robot.

\footnotetext{
" De Acordo com: ASSOCIAÇÃO BRASILEIRA DE NORMAS TÉCNICAS. NBR 6023: informação e documentação: referências: elaboração. Rio de Janeiro, 2002.
} 
SRI (Silsoe Research Institute) Grupo de Robótica e Automação do Instituto de Pesquisa de Silsoe - Reino Unido (2005). Disponível em: <www.sri.bbsrc.ac.uk>. Acesso em: abril 2005.

HAGUE, T.; MARCHANT, J.A. TILLETT, N.D. (2000). Ground based sensing systems for autonomous agricultural vehicles. Computer and Electronics in Agriculture, Amsterdam, v.25, n. 1-2, p. 11-28.

HOLLAND SCIENTIFIC (2007). Fabricante de sensor óptico Crop Circle. Disponível em: <http://www.hollandscientific.com>. Acesso em: 20 out.2007.

INAMASU, R. Y.; SOUSA, R. V.; PORTO, A. J. V.; FORTES, C.; LUCHIARI JR, A; SCHEPERS, J. S.; SHANAHAN, J. F; FRANCIS, D. D. (2006). Active sensor readings for assessing sugarcane crop canopy chlorophyll status. In: INTERNATIONAL CONFERENCE ON PRECISION AGRICULTURE, 8, 2006, Minneapolis. Conference Abstracts, 2006. p. 156-156.

ISO 11783 (2007). Standard: Tractors and machinery for agriculture and forestry Serial control and communications data network. Composed by 14 parts. Disponível em: <www.iso.org $>$. Acesso em: out. 2007

KEICHER, R.; SEUFERT, H. (2000). Automatic guidance for agricultural vehicles in Europe. Computers and Electronics in Agriculture. v.25, n.1-2, p.169-194.

LAMON, P.; SIEGWART, R. (2007). 3D Position Tracking in Challenging Terrain. The International Journal of Robotic Research, v.26, n.2, p.167-168.

LINDGREN, D. R.; HAGUE, T.; PROBERT SMITH, P. J.; MARCHANT, J. A.; (2002). Relating Torque and Slip in an Odometric Model for an Autonomous Agricultural Vehicle. Autonomous Robots, v13, 73-86.

MACOPEMA (2004). Fabricante de Redutores. Disponível em: $<$ http://www.macopema.com.br>. Acesso em: out. 2004.

MOLIN, J. P., INAMASU, R. I., SARAIVA, A. M., SOUZA R. V. (2005). Rumo ao Isobus. Cultivar Máquinas, p. 34-36, 2005.

MOORE, K. L.; FLANN N. S. (2000). A Six-Wheeled Omnidirectional Autonomous Mobile Robot. IEEE Control Systems Magazine, v.20, n.6, v.20, p. 53-66.

NAGASAKA, Y.; UMEDA, N.; KANETAI, Y.; TANIWAKI, K; SASAKI, Y. (2004). Autonomous Guidance for rice transplanting using global positioning and gyroscopes. Computers and Electronics in Agriculture, v.43, n.3, p.223-234.

NIELSEN, K. M.; ANDERSEN, P.; PEDERSEN, T. S.; BAK, T.; NIELSEN, J. D. (2002). Control of an Autonomous Vehicle for Registration of Weed and Crop in Precision Agriculture. In: Proceedings IEEE Conference on Control Applications CCA/CACSD, v.2, p. 909-914, Glasgow, Scotland, UK. 
NWOKAH, O. D. I.; HURMUZLU, Y. (2002). The Mechanical Systems Design Handbook: Modeling, Measurement, and Control. $2^{\text {nd }}$ Edition. CRC Press. 819p.

PC/104. (2007). Site com informações sobre o padrão PC/104. Disponível em: $<$ http://www.pc104.org >. Acesso em: dez. 2007.

PORTO, A. J. V.; SOUSA, R. V.; INAMASU, R. Y. (2003). Robô Agrícola Móvel (RAM): uma revisão das pesquisas sobre sistemas de navegação autônoma de robôs e veículos agrícolas: In: CONGRESSO BRASILEIRO DA SOCIEDADE BRASILEIRA DE INFORMATICA APLICADA À AGROPECUÁRIA E AGROINDUSTRIA - SBIAGRO, 4, 2003, Porto Seguro. Anais. SBIAGRO. 1 CDROM.

REID, J. F. (2004). Mobile Intelligent Equipment for off-road Environments. Automation Technology for Off-Road Equipment, In: Proceedings of 7-89 October 2004 Conference (Kyoto, Japan).

REID, J.F.; ZHANG, Q; NOGUCHI, N.; DICKSON, M. (2000). Agricultural automatic guidance research in North America. Computers and Electronics in Agriculture. v.25, n.1-2, p.155-167.

SAVAGE - SUPPORTIVE AUTONOMOUS VEHICLE FOR AGRICULTURE (2007). University of Thessaly. Department of Agriculture, Crop Production, and Agricultural Environment. Greece. Disponível em: $<$ http://users.forthnet.gr/ath/startrek/index.html>. Acesso em: nov. 2007.

SIEGWART, R.; NOURBAKHSH, I.R. (2004). Introduction to Autonomous Mobile Robots. Massachusetts London, England: The Massachusetts Institute of Technology Press Cambridge, 2004.

SIEMENS (2007). Site do desenvolvedor do programa computacional Solid Edge. Disponível em:

http://www.plm.automation.siemens.com/en us/products/velocity/solidedge/index.sht ml> . Acesso em: nov. 2007.

SOUSA, R.V. (2002) CAN (Controller Area Network): uma abordagem para automação e controle na área agrícola. 2002, 84p. Dissertação (Mestrado em Engenharia Mecânica) - Escola de Engenharia de São Carlos, Universidade de São Paulo, São Carlos, 2002.

SOUSA, R.V. (2007). Robô Agrícola Móvel (RAM): uma arquitetura baseada em comportamentos hierárquicos e difusos para sistemas autônomos de guiagem e navegação. 195p. Tese (Doutorado em Engenharia Mecânica) - Escola de Engenharia de São Carlos, Universidade de São Paulo, São Carlos, 2007.

SOUSA, R. V.; BRAZ, D. C.; BORGES-JUNIOR, S. R.; SILVA, A. R. Y.; PORTO, A. J. V.; INAMASU, R. Y. (2004). Uma Plataforma Autônoma para Aquisição de Variabilidade Espacial. In: Congresso Brasileiro de Agricultura de Precisão - 
CONBAP, 2004, São Pedro, Anais. São Pedro: ESALQ-USP, 17-19 Maio. 1CDROM.

SOUSA, R. V.; FREITAS, R. R.; SAKAI, R. M. R.; INAMASU, R. Y.; PORTO, A. J. V. (2006). Mechanical Design and Implementation of a Modular Robotic Agricultural Platform. In: INTERNATIONAL CONFERENCE ON PRECISION AGRICULTURE, 8, 2006. Minneapolis. Conference Abstracts, 2006. p. 136-136.

SOUTHALL, B.; HAGUE, T.; MARCHANT, J. A.; BUXTON, B. F.; (2002). An Autonomous Crop Treatment Robot: Part I. A Kalman Filter Model for Localization and Crop/Weed Classification. The International Journal of Robotics Research, v.21, n.1, p.61-74.

TAROKH, M.; McDERMOTT, G. J. (2005). Kinematics Modeling and Analyses of Articulated Rovers. IEEE Transaction on Robotics, v.21, n.24, august, p.539-553.

THRUN, B.; THAYER, S.; WHITTAKER, W.; BAKER, C., BURGARD, W.; FERGUSON, D; HAHNEL, D.; MONTEMERLO, M.; MORRIS, A.; OMOHUNDRO, Z.; REVERTE, C.; WHITTAKER, W. (2004). Autonomous Exploration and Mapping of Abandoned Mines. IEEE Robotics \& Automation Magazine, v.11, n.1, p. 79-91.

TORII, T. (2000). Research in autonomous agriculture vehicles in Japan. Computers and Electronics in Agriculture. v.25, n.1-2, p.133-153.

UIUC AGRICULTURAL ENGINEERING. (2007). Disponível em: $<$ http://www.age.uiuc.edu/oree>. Acessado em: nov. 2007. 


\section{APÊNDICE}

São apresentados a seguir desenhos em conjunto dos cinco módulos editados por

SolidEdge. As dimensões foram omitidas para simplificar a visão qualitativa dos elementos.

$$
\begin{aligned}
& \text { A - Módulo de Guiagem e Propulsão } \\
& \text { B - Sistema de Guiagem } \\
& \text { C - Sistema de Propulsão } \\
& \text { D - Conjunto Superior } \\
& \text { E - Conjunto Lateral } \\
& \text { F - VAA }
\end{aligned}
$$




\section{APÊNDICE A - Módulo de Guiagem e Propulsão}

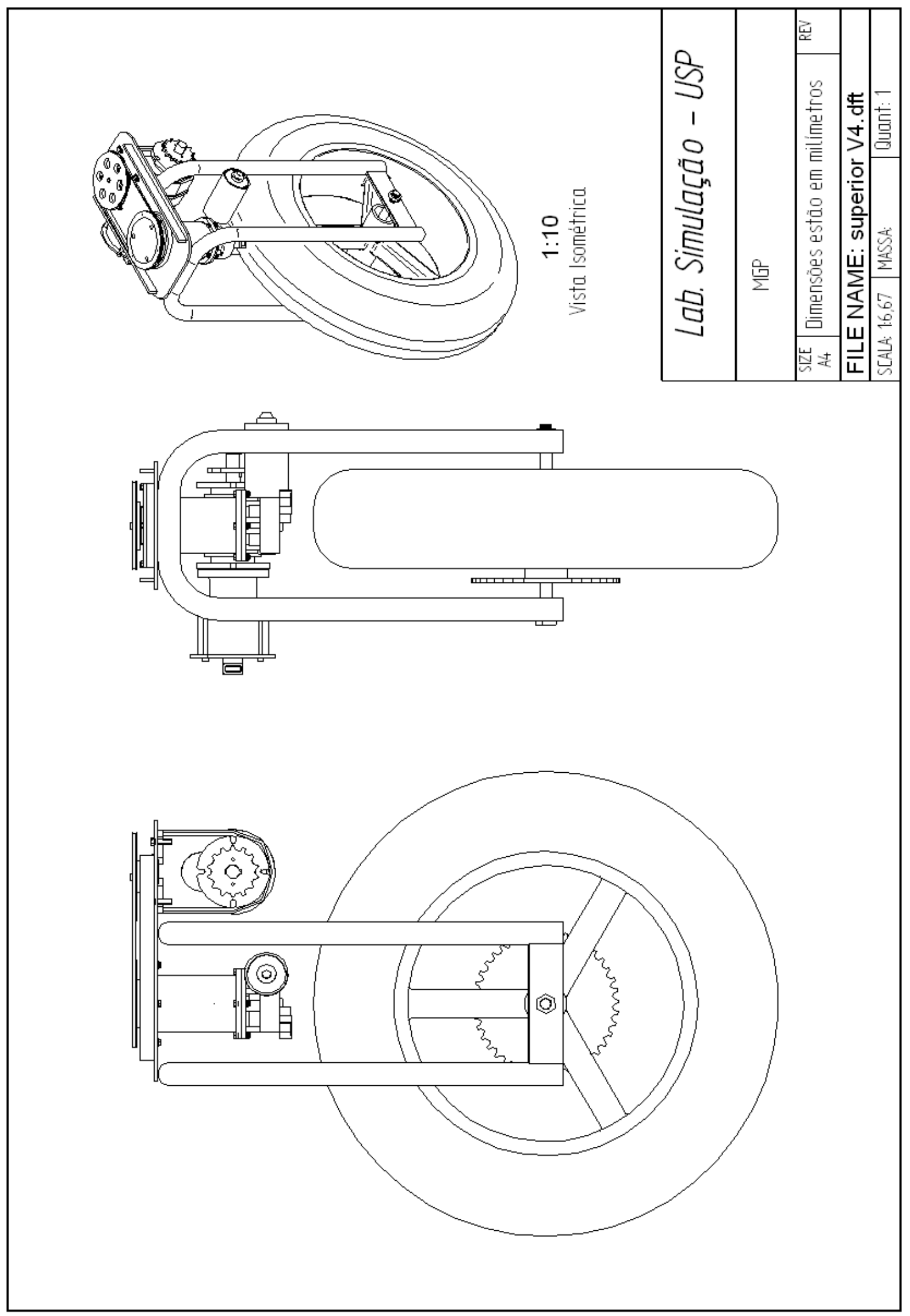




\section{APÊNDICE B - Sistema de Guiagem}

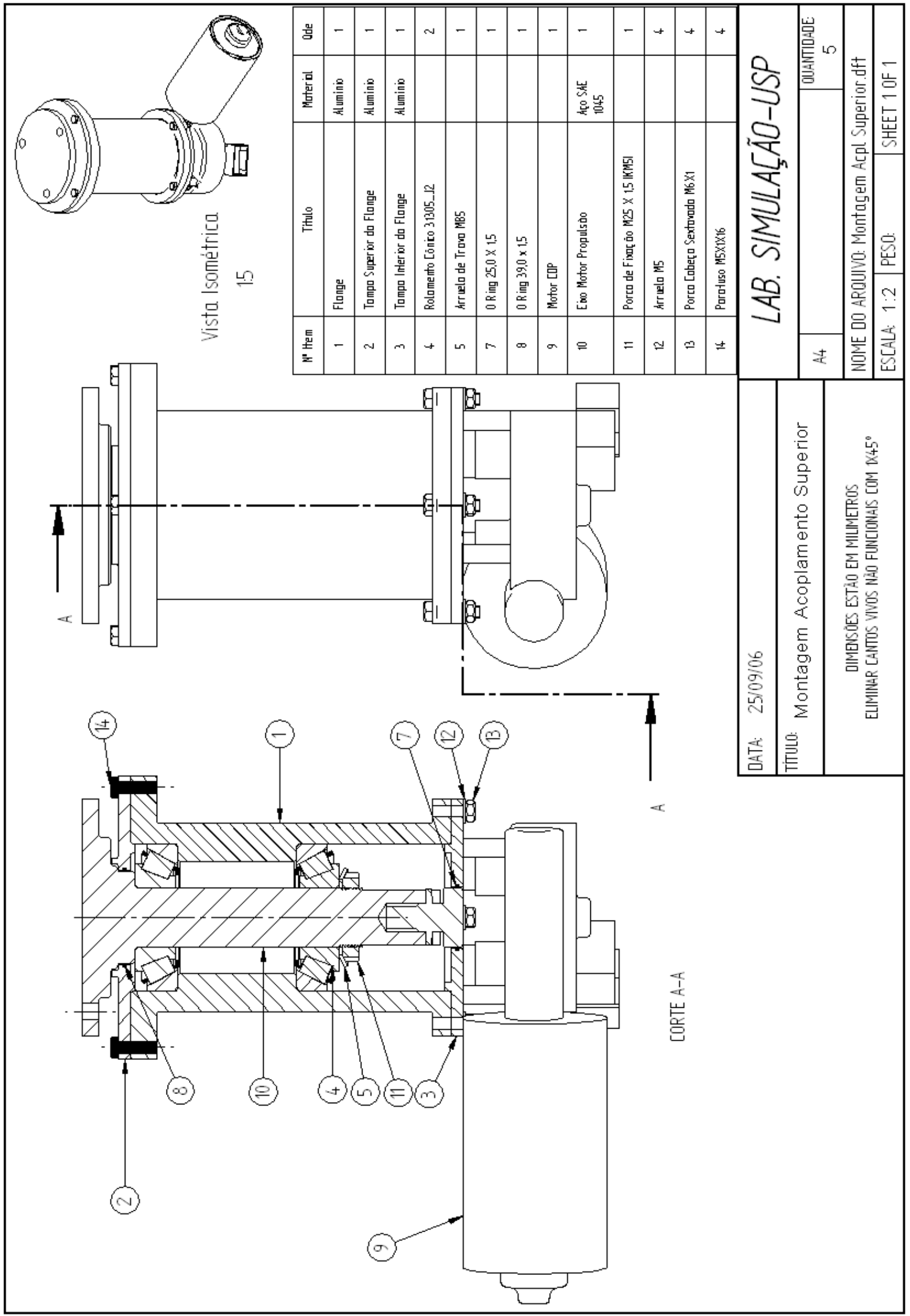




\section{APÊNDICE C - Sistema de Propulsão}

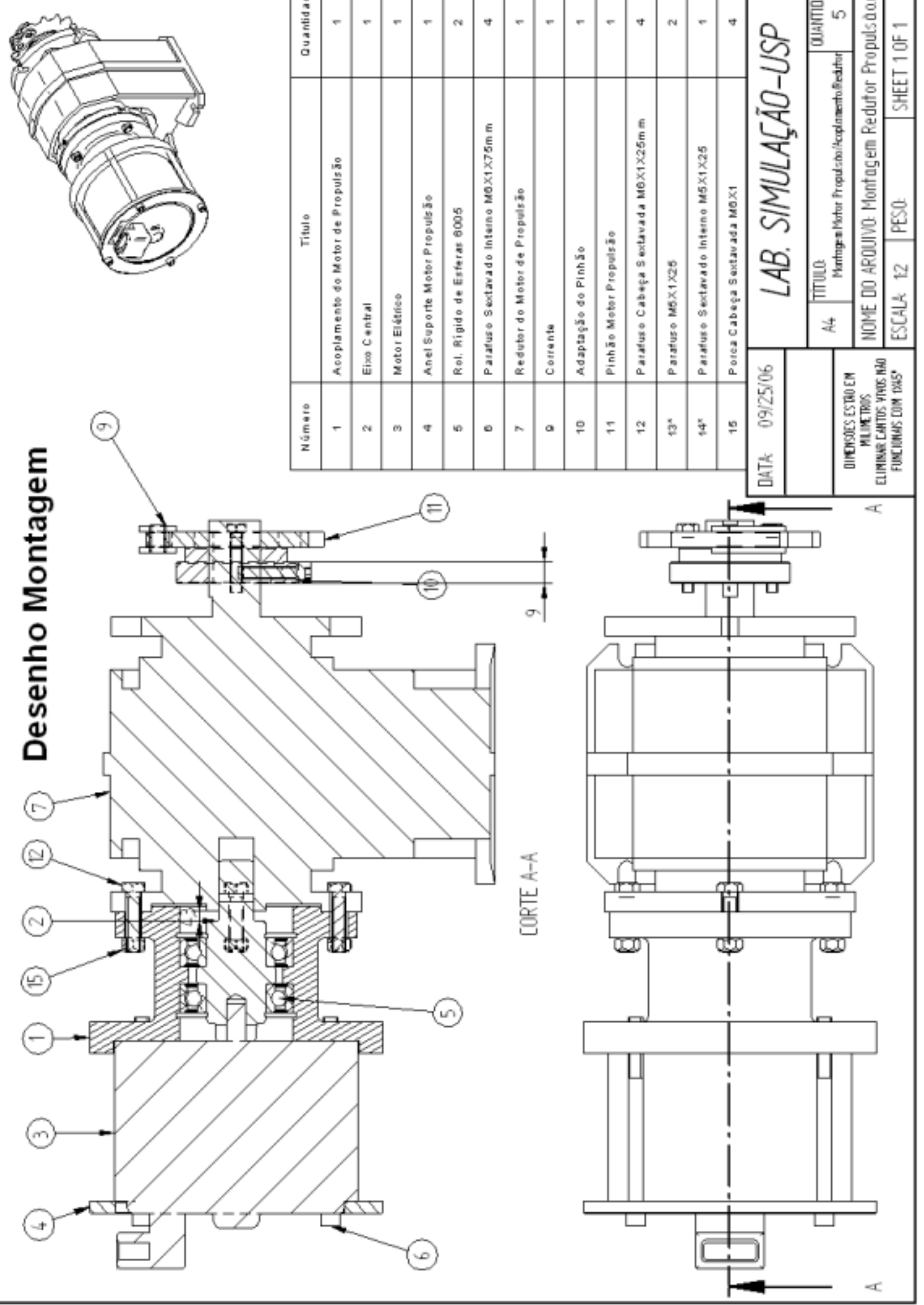


APÊNDICE D - Conjunto Superior

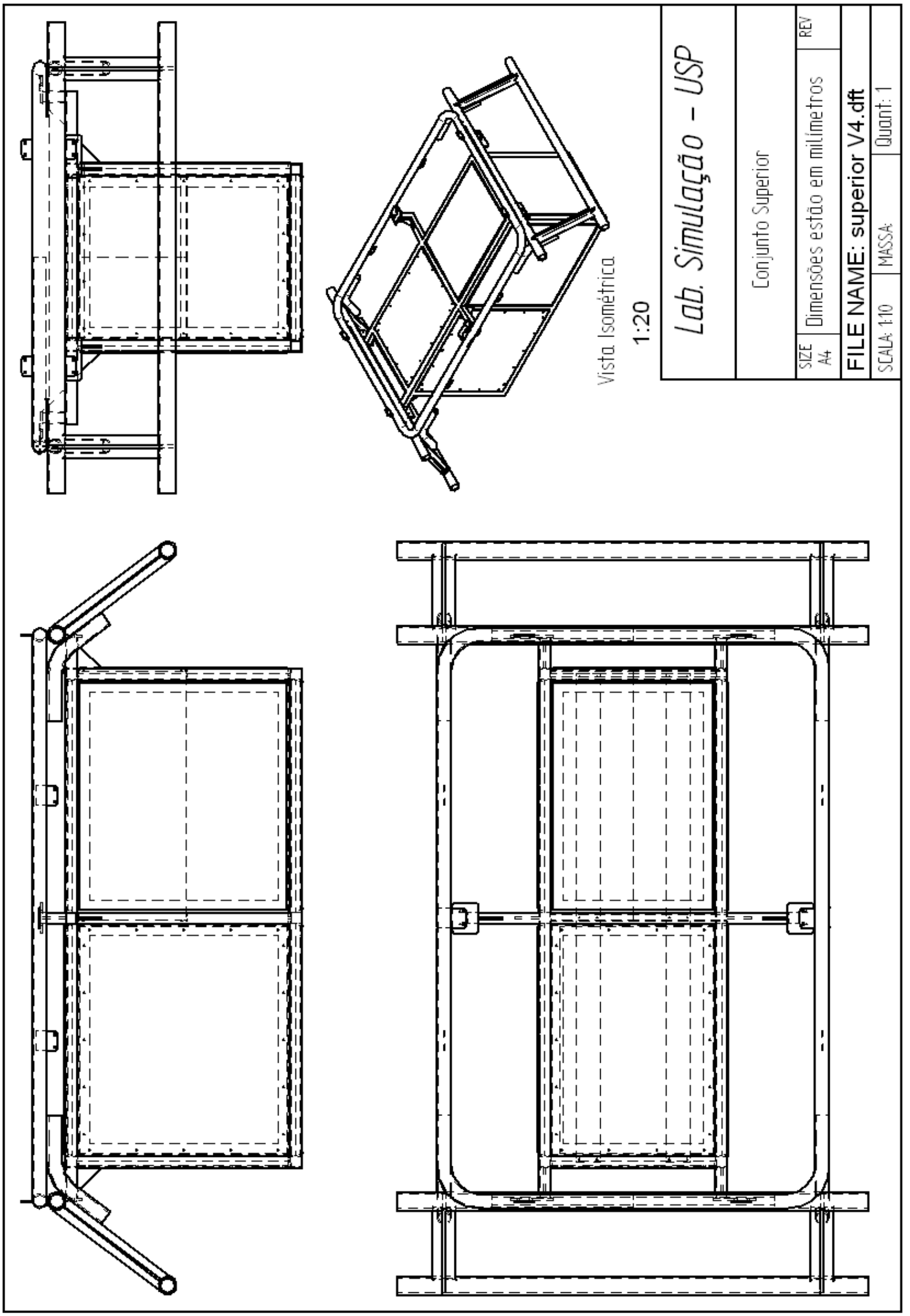




\section{APÊNDICE E - Conjunto Lateral}

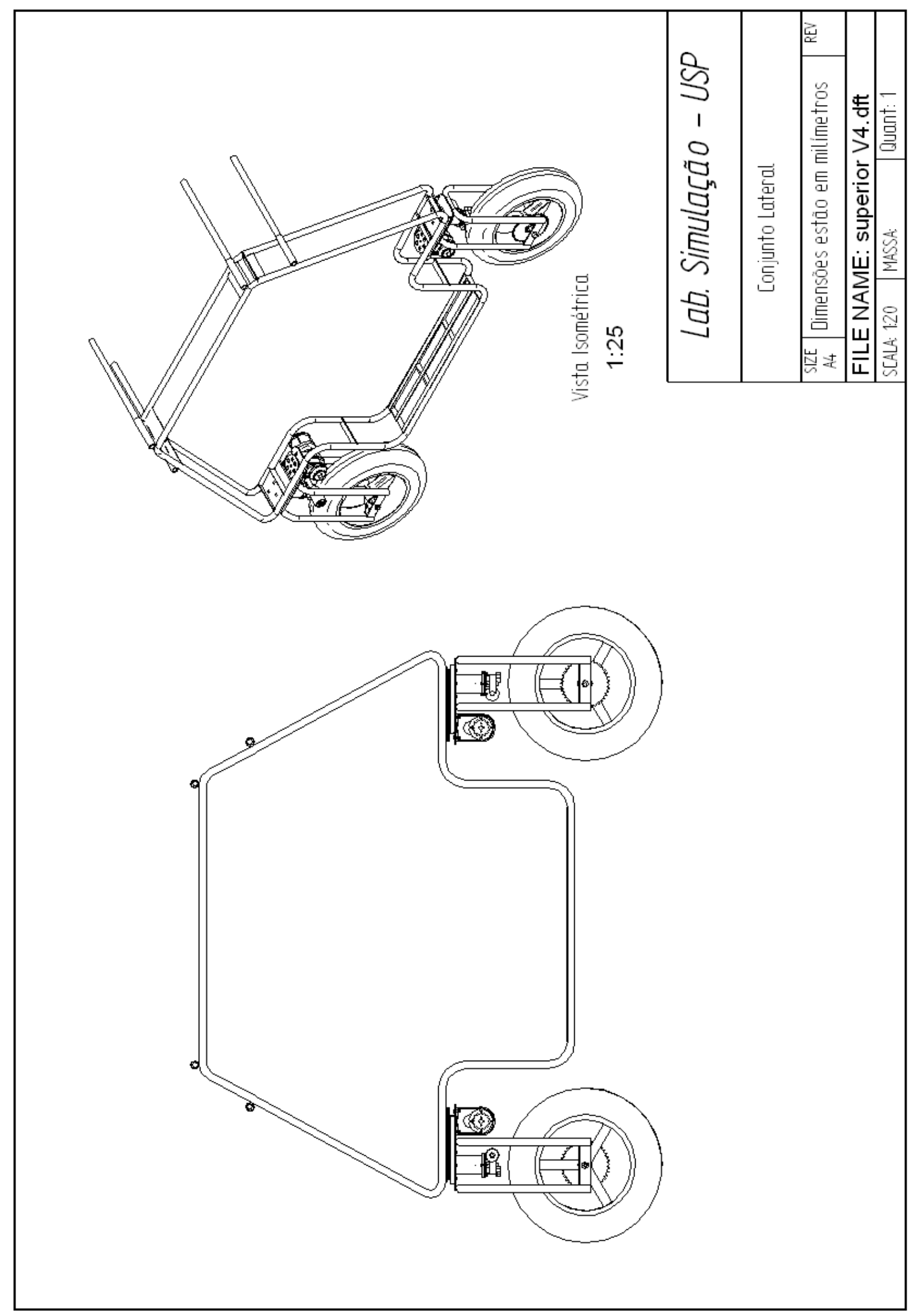


APÊNDICE F - VAA

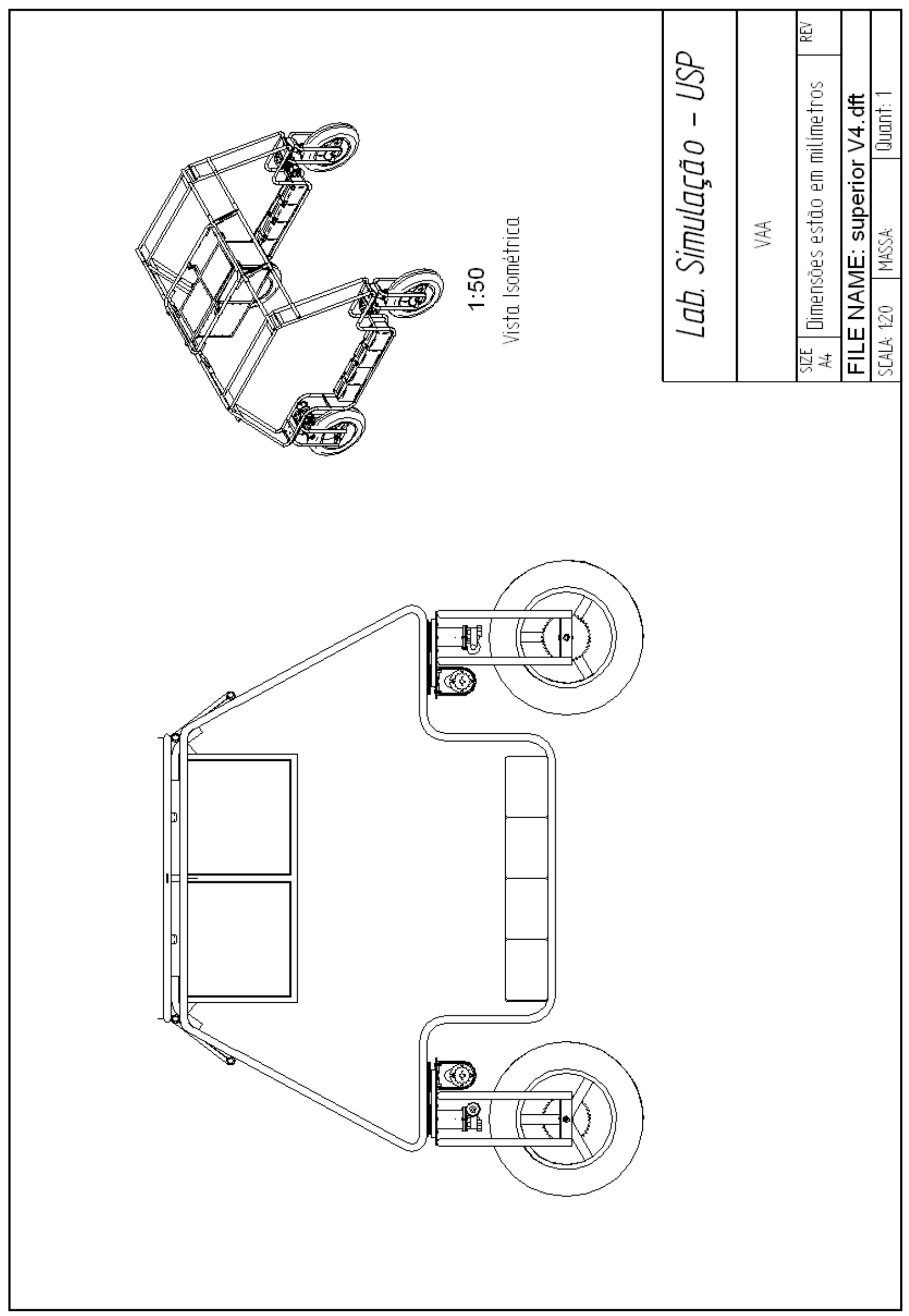

